\title{
BLUE COD, PARAPERCIS COLIAS: MATURITY, FECUNDITY, SEX CHANGE, AND POTENTIAL DRIVERS OF SEX RATIO IN THE MARLBOROUGH SOUNDS
}

Kasper Kjeldager Brandt

A thesis submitted in partial fulfilment of the requirements for the degree of Master of Science in Marine Biology

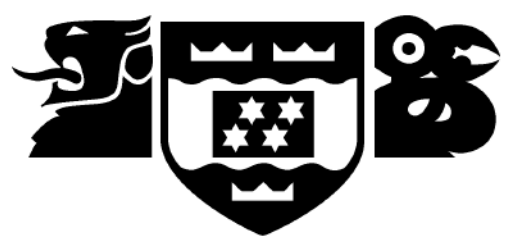

Victoria University of Wellington

Te Whare Wānanga o te Ūpoko o te Ika Māui

March 2016 



\begin{abstract}
Blue cod, Parapercis colias (Pinguipedidae), are widely considered to be the most important recreational finfish species in the South Island. However, blue cod have been declining in abundance in the Marlborough Sounds for many years, and currently, sex ratios are highly malebiased. Blue cod are believed to be a socially structured hermaphroditic species whose populations are prone to local depletion. A potting survey in the Marlborough Sounds was carried out by NIWA in 2013, and along with environmental measurements, 3247 blue cod were measured, weighed, sexed, and stage of sexual maturity was classified macroscopically at sea. Gonads from a subsample of these fish were removed and preserved. In Chapter Two, the preserved gonads were processed histologically and a species-specific histological maturity key was developed. Histological and macroscopic maturity classifications and length-at-maturity estimates were compared. Additionally, estimates of spawning frequency and batch fecundity were made using histological and gravimetric methods. In Chapter Three, possible drivers of sex ratio were investigated using the survey data. Density, large male influence, and environmental factors were considered. In Chapter Four, the feasibility of using digital imaging software to age blue cod otoliths was investigated using the OtolithM application in ImagePro Premier.
\end{abstract}

There was poor agreement between macroscopic and histological maturity classifications (20\%, overall). Macroscopic methods overestimated the proportion of mature fish at length in the larger sample, which led to biased length-at-50\% maturity $\left(\mathrm{L}_{50}\right)$ estimates. Macroscopic $\mathrm{L}_{50}$ estimates differed markedly from histology estimates. Using histological data, male $\mathrm{L}_{50}$ was 26 $\mathrm{cm}$ TL. Histology indicated that there was no length at which $100 \%$ of females were mature. Therefore, a three-parameter capped logistic model was used. Histologically, female $\mathrm{L}_{50}$ was $23.6 \mathrm{~cm}$ TL, and the Cap was 0.78 , indicating the proportion of mature females reached an asymptote at 0.78 . Spawning frequency was 4.6 days, and mean relative batch fecundity was 6.5 hydrated oocytes per gram body weight $(\mathrm{SD}=3.3$ ). Hermaphroditism was confirmed for blue cod and was macroscopically identifiable. The analyses in Chapter Three indicated that density had some effect on sex ratio, and large males influenced local sex ratios. Finally, the imaging software could not accurately estimate age compared to an expert reader, and it produced highly variable age estimates.

This research found that the macroscopic maturity classifications for blue cod were inaccurate, and revision of the macroscopic key is suggested. The biased estimates of $L_{50}$ from macroscopic data could lead to biased estimates of spawning stock biomass (SSB). Batch fecundity was markedly lower than the previously reported estimates. The finding of a macroscopically identifiable hermaphroditic stage suggested that 'hermaphrodite' should be added as a sex class 
in the macroscopic key. From the GLM in Chapter Three, in more dense populations, the proportion of males increased. This may have been from changes to male mating strategies, or density may influence the occurrence of primary and secondary males. Finally, areas with males $>45 \mathrm{~cm}$ TL had a higher proportion of females, suggesting that large males should be protected in order to help balance sex ratios. 


\section{TABLE OF CONTENTS}

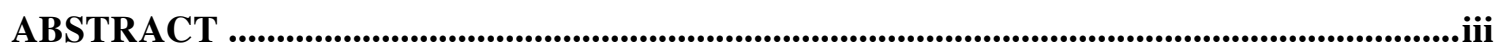

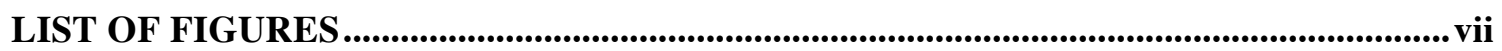

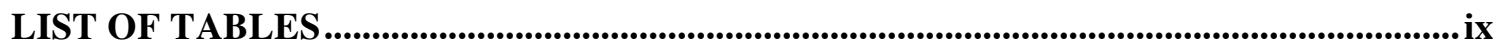

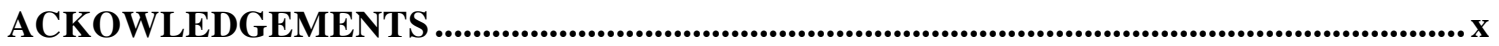

\section{CHAPTER I}

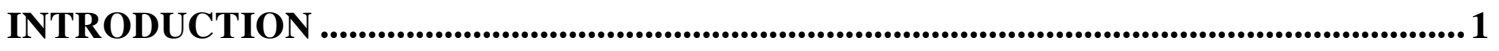

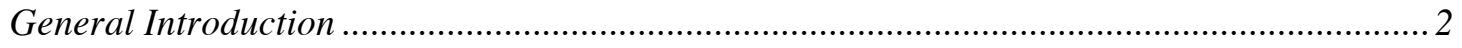

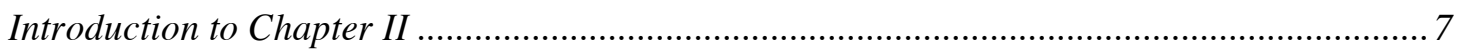

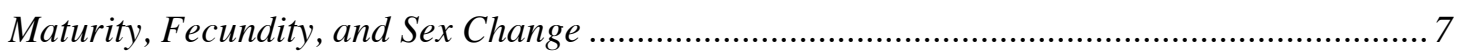

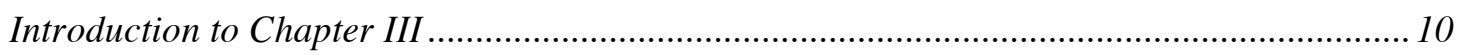

Potential Drivers of Blue Cod Sex Ratio in the Marlborough Sounds ...................................... 10

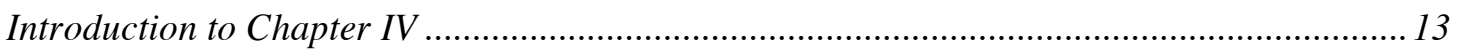

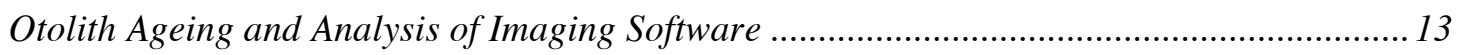

\section{CHAPTER II}

BLUE COD MATURITY, FECUNDITY, AND SEX CHANGE .....................................16

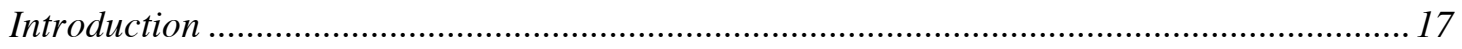

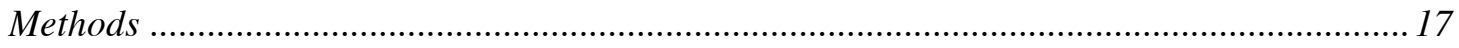

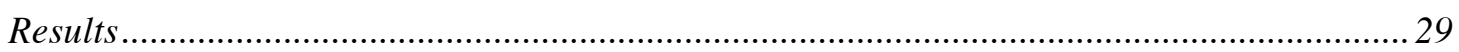

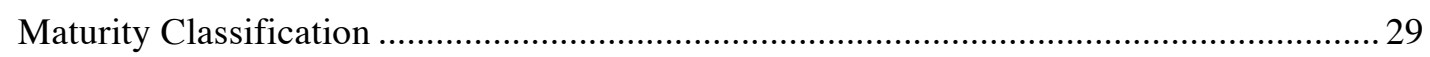

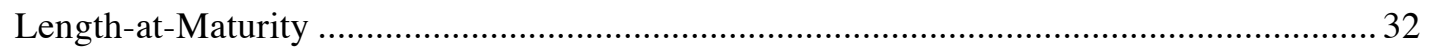

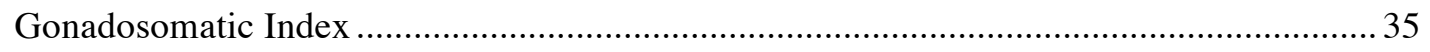

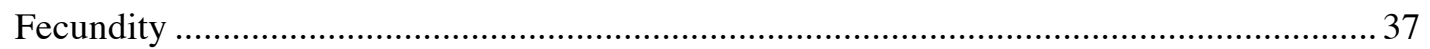

CHAPTER III

POTENTIAL DRIVERS OF BLUE COD SEX RATIO IN THE MARLBOROUGH

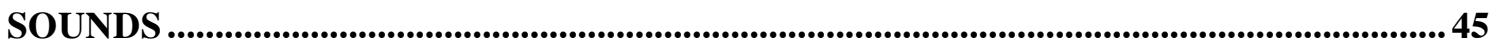

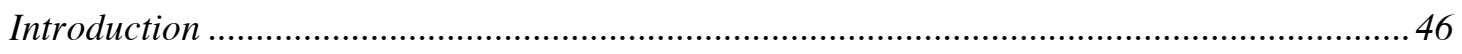

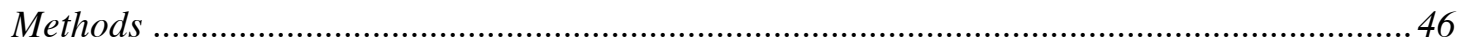

Hypothesis 1: Environmental Influences on Sex Ratio ..................................................... 49

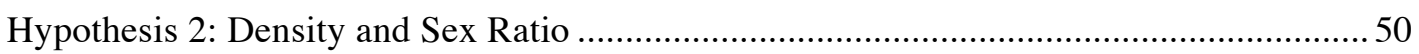

Hypothesis 3: Influence of Large Males on Sex Ratio ........................................................ 51

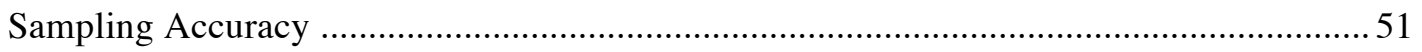

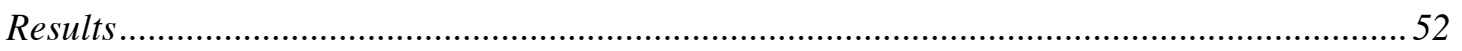

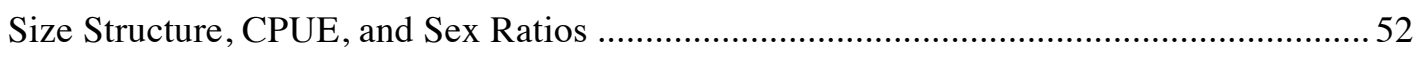

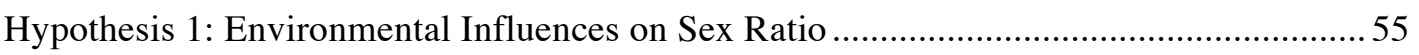

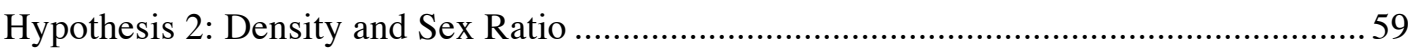

Hypothesis 3: Influence of Large Males on Sex Ratio ......................................................... 61

\section{CHAPTER IV}

ANALYSIS OF OTOLITH READING SOFTWARE WITH BLUE COD OTOLITHS ... 65

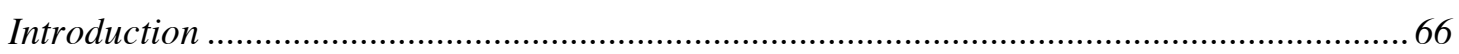




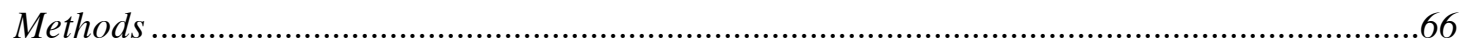

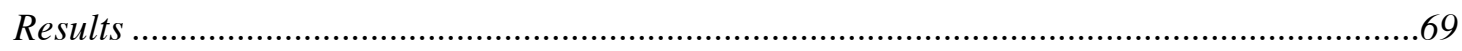

Accuracy of Software: Age Estimates Between Transect Lines...............................................

Accuracy of Software: Equivalent Settings Between Otoliths ............................................76

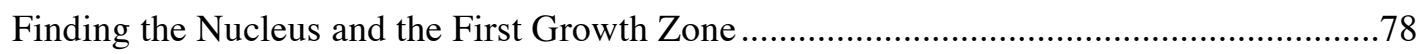

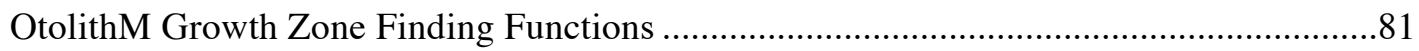

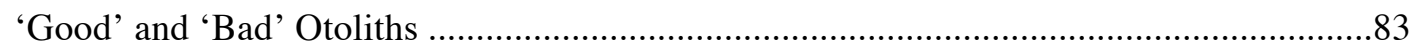

\section{CHAPTER V}

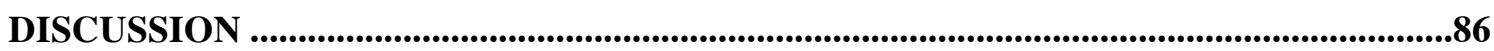

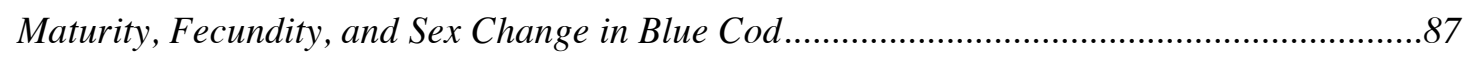

Potential Drivers of Blue Cod Sex Ratio in the Marlborough Sounds .....................................93

Analysis of Otolith Imaging Software With Blue Cod Otoliths ................................................97

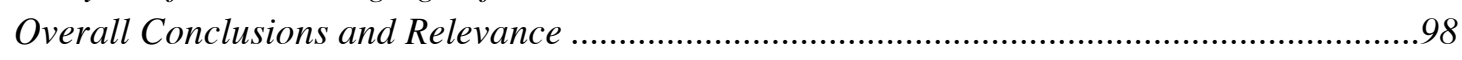

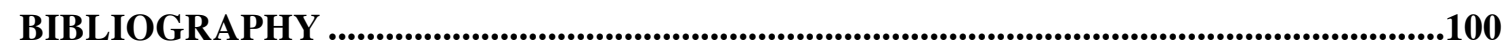

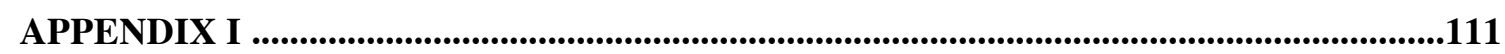




\section{LIST OF FIGURES}

Page

Chapter 1

1.1 Blue cod management areas of New Zealand .5

Chapter 2

2.1 Map of the Marlborough Sounds showing the sampling stations used in the survey ....18

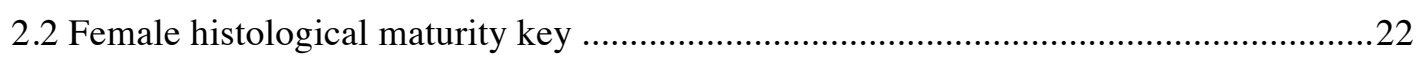

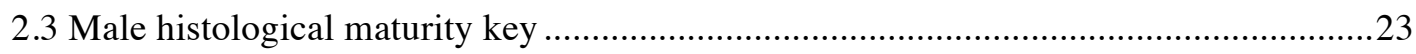

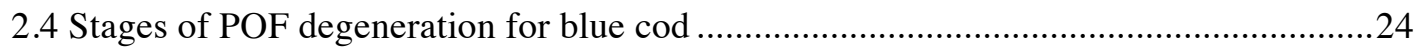

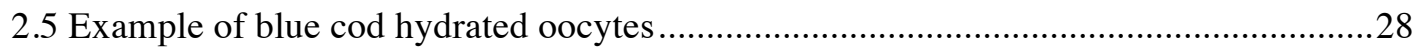

2.6 Proportion of histologically classified maturity stages at length ..................................31

2.7 Proportion of macroscopically classified maturity stages at length ...............................31

2.8 Macroscopic and histologically determined maturity ogives from the subsample .........34

2.9 Histologically determined maturity ogives from the subsample and macroscopically

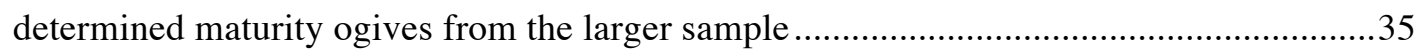

2.10 Mean male and female GSI values for histologically determined histology stages ......36

2.11 Batch fecundity relationships by length and weight.....................................................

2.12 Batch fecundity frequency distributions with and without POFs................................39

2.13 Fish length and batch fecundity relationship with and without POFs ..........................40

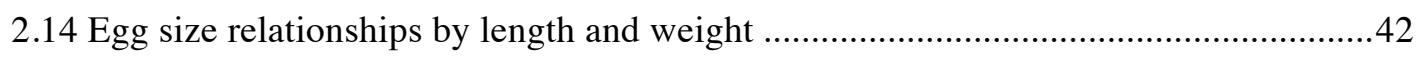

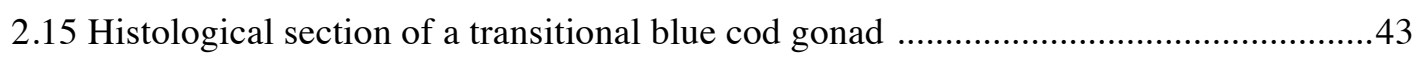

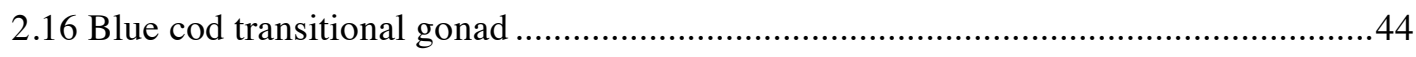

2.17 Histological section of a ripe/running male blue cod gonad containing oocytes .........45

Chapter 3

3.1 Map of the Marlborough Sounds showing the sampling stations used in the survey ....47

3.2 Map of sampling stations colour-coded by stratum with an example of how groups were defined

3.3 Proportion of sex at length, and size-frequency distribution of all blue cod caught in the 2013 Marlborough Sounds Survey.

3.4 Size-frequency distributions of blue cod by stratum from the 2013 Marlborough Sounds

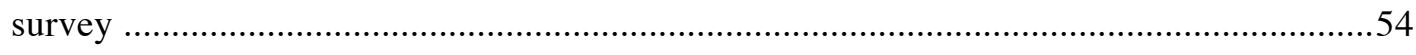

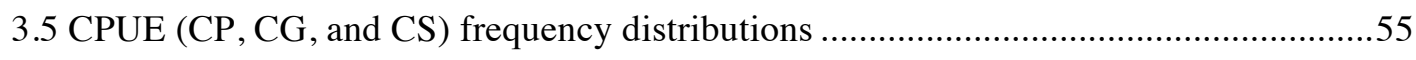

3.6 Correlation matrix of the environmental variables measured in the survey ....................56 
3.7 Predicted effects graphs for each model predictor in the GLM and model diagnostics 58

3.8 Relationships between CPUE (CP, CG, and CS) and proportion male

3.9 Box plots of the proportion male for groups and pots with differing largest male size. 61

3.10 (A) Frequency distributions of number of females per pot; (B) relationship between number of fish and proportion male; (C) cumulative proportion male graph

3.11 Cumulative proportion male and CV with increasing sample (number of pots) size .. 63

3.12 Box plots of the proportion male for groups and pots with differing largest male size. These analyses were done with pots with more than 9 fish and groups with more than 4 pots

Chapter 4

4.1 Light intensity graph from OtolithM application in ImagePro Premier 67

4.2 Examples of transect lines on the same otolith with growth zones counted in OtolithM in ImagePro Premier. 68

4.3 Relationship between expert age estimates and imaging software age estimates for blue cod otoliths

4.4 Accuracy of age estimates between transect lines on the same otoliths

4.5-4.16 Blue cod otoliths analysed using the OtolithM application. These images compare age estimates between transect lines of the same otolith 70-76

4.17-4.19 Blue cod otoliths analysed in the OtolithM application. These images compare age estimates using otolith-specific settings between otoliths.

4.20-4.21 Blue cod otoliths analysed in the OtolithM application. Imaging software's interpretation of the nucleus $79-80$

4.22-4.25 Blue cod otoliths analysed in the OtolithM application. Examples of different growth zone finding functions in the OtolithM application .81-83

4.26-4.27 Blue cod otoliths analysed in the OtolithM application. Examples of otoliths that the software read well and otoliths that the software read poorly 84-85 


\section{LIST OF TABLES}

Page

Chapter 2

2.1 Length and sex summary of the blue cod histology subsample .19

2.2 Haematoxylin and Eosin staining schedule for blue cod gonad slides .20

2.3 Comparisons of histological and macroscopic maturity classifications for the subsample of blue cod gonads .30

2.4 Maturity ogive model parameters and AIC values for histological subsample .32

2.5 Maturity ogive model parameters and AIC values for larger sample .33

2.6 Maturity ogive model parameters and AIC values for larger sample with model sensitivities . .34

2.7 Spawning fraction and spawning frequency by sample day 41

2.8 Spawning fraction and spawning frequency by length on sample day 5 .41

Chapter 3

3.1 Summary of catch data from the 2013 Marlborough Sounds survey .53

3.2 Model predictors, AIC, and deviance explained for the GLM predicting sex ratio ........57

3.3 Description of sea condition codes .59

3.4 Linear regression analyses results for CPUE and sex ratio .59

3.5 Pairwise non-parametric Dunn's test results for the difference in proportion male between pots and groups with differing largest male size. .62 


\section{ACKOWLEDGEMENTS}

I wish to express sincere appreciation to Dr. Matthew Dunn for guidance and supervision throughout this thesis, and Dr. Stephen Brouwer for the initial proposal of the thesis project, technical assistance, and ongoing support. Thanks to colleagues of Steve in the fisheries division at SPC, New Caledonia for input during discussions. Special thanks to MPI and NIWA for supplying survey data, blue cod otoliths, and gonads. Very special thanks to Deepwater Group and Fisheries Inshore New Zealand for scholarship funding. Thanks to Dorothy Leigh for moral support, Janet Pitman for the use of her histology lab, Alan Hoverd for histology help and advice, Angela Jones for histological help, Daniel McNaughtan and John Van der Sman for lab assistance at VUCEL, and thanks to Dr. Peter Horn for providing expert age estimates of blue cod otoliths. Og tusin tak til min mor og far for at føder mig og for et hjælp mig over de sidste måneder. 
CHAPTER I

INTRODUCTION 


\section{General Introduction}

Blue cod, Parapercis colias, are not a true cod but a member of the Pinguipedidae family, and are endemic to New Zealand (Nelson 2006). The Pinguipedidae (Sandperches and Weevers) are widely distributed and are found from the Atlantic coasts of South America and Africa, to the Pacific, including Chile, New Zealand, and Hawaii (Nelson 2006). Pinguipedids are benthic carnivores that feed on small invertebrates and fishes. Many, but not all, Pinguipedids are protogynous hermaphrodites (Nelson 2006; Venerus et al. 2014), pelagic spawners, and exhibit territorial and haremic behaviour (Nelson 2006). There are three species of the Pinguipedidae family in New Zealand waters: yellow cod ( $P$. gilliesii), the banded weever ( $P$. binivirgatai), and blue cod (P. colias) (Andrew \& Francis 2003; Carbines 2004b).

Blue cod are a bottom-dwelling species that are most commonly found on sandy, shingle, and gravel substrates near to reef edges or rocky outcrops (Beentjes \& Carbines 2005). They are also associated with biogenic reefs, which are important juvenile habitat (Carbines et al. 2004). Blue cod can inhabit depths to approximately $150 \mathrm{~m}$, but are most plentiful in shallower waters closer to shore (Beentjes \& Carbines 2005). They are found from the shore to the edge of the continental shelf throughout New Zealand's coastal area and are most abundant in the temperate coastal areas south of the Cook Strait (Beentjes \& Carbines 2005; Cole et al. 2012).

Jiang and Carbines (2002) reviewed the diet of blue cod. In southeast New Zealand they primarily feed on crustaceans, small fish, and molluscs. In central New Zealand blue cod feed on pelagic fish, predominantly pilchards, and sprats (Clupeidae). On the northern coast of the Chatham Islands they predominantly eat octopus and fish. Whereas, in northern New Zealand their diet has been found to be size-dependent, where juveniles feed on amphipod and isopod crustaceans, and adults feed on crabs and ophiuroids. In the Foveaux Strait (southeast New Zealand), their diet consists of crustaceans, molluscs, and polychaetes.

Blue cod have a large-scale isolation-by-distance genetic pattern across mainland New Zealand, and there is a significant genetic differentiation between mainland New Zealand and the Chatham Islands (Smith 2012). Tagging studies within the Marlborough Sounds indicate that most blue cod usually move less than $1 \mathrm{~km}$ over a few years (Mace \& Johnston 1983; Cole et al. 2000). However, some have travelled over $41 \mathrm{~km}$, and up to $30 \%$ of the tagged individuals in one study moved $7.4 \mathrm{~km}$ on average (Mace \& Johnston 1983). Similar movement patterns have been observed in Southland and in Dusky Sound (Carbines \& Beentjes 2003). Southland blue cod populations have a source-sink structure (BCO5) (Carbines \& McKenzie 2001). Moreover, limited mixing over small spatial scales has been observed in populations of blue cod in 
Fiordland (Beer \& Wing 2013). Long distance dispersal is limited for blue cod, and by and large, they have local breeding populations with little mixing between them. Therefore, small-scale population structure is expected.

Tagging studies in the Marlborough Sounds found that smaller blue cod $(<30 \mathrm{~cm})$ moved greater distances than larger blue cod, which were frequently recaptured near to the release site (Mace \& Johnston 1983). However, only one fish below $21 \mathrm{~cm}$ was recaptured in that study. In the Mace and Johnston (1983) study, the mean number of days at liberty for small fish was more than twice that of large fish, allowing more time for movement. They concluded that most blue cod stayed within the same headland or reef where tagged, although some did move great distances. The Mace and Johnston (1983) recapture rate was low (3.5\%) and the majority of tags were returned by fishers unlikely to be using GPS (because of the year of the study), and therefore, capture locations may be inaccurate. Further, Mace and Johnston (1983) used baited hooks to catch blue cod, which may have resulted in high rates of post-release mortality (Carbines 1999a). Despite the possible errors in tagging studies, blue cod most likely have small scale breeding populations with limited mixing between populations, making them prone to local depletion.

Blue cod are social, territorial, and sedentary (Mace \& Johnston 1983; Cole et al. 2000), often approaching SCUBA and free divers fearlessly (pers. obs.). Mutch (1983) observed large male blue cod defending temporary territories often containing three to five smaller females, and within these territories females defended small patches of terrain. The dominant male would defend the larger area encompassing the female sub-territories, and breed with the females within his territory.

Blue cod are batch spawners (Carbines 2004b). They spawn multiple times from early June to late January, and peak spawning occurs in late winter and spring (Pankhurst \& Conroy 1987; Beer et al. 2013). Spawning times occur later in the year in populations farther south (Beer et al. 2013). Time and length of the spawning period can differ markedly between populations at similar latitudes, for example, blue cod from the Cook Strait spawn in September and October, whereas the Marlborough Sounds population spawns from early June until late November (Beer et al. 2013). Late afternoon and evening spawning is estimated from observed spermiation of male blue cod, and an unpublished observation that ovulation is only seen in the afternoon (Pankhurst \& Kime 1991). Following fertilisation, eggs are free floating for $c$. five days, and thereafter exist as planktonic larvae for a further $c$. five days (Robertson 1973). Larval settlement is not well documented, although juveniles are most commonly seen in shallow $(<15$ m) sandy areas and open reefs (Carbines 2004b). An observation of a single juvenile blue cod 
inhabiting an artificial reef was made near Goat Island in the Leigh marine reserve (Russell 1975).

Blue cod are a relatively slow growing and long-lived species where the oldest recorded blue cod was 32 years old (MPI 2014, 2015a). Growth rate can be influenced by habitat quality (Carbines et al. 2004). Male blue cod grow larger on average and at a faster rate than females (Carbines 2004a). Previous size-at-50\% maturity and age-at-50\% maturity estimates for blue cod in the Marlborough Sounds are between 21-26 cm (Total Length, TL) and three to six years old (MPI 2014).

Historically, Maori targeted blue cod in Northland, the Chatham Islands, Southland, the Cook Strait, and the Marlborough Sounds, however, they were not a major target species and fishing methods were not size selective (Leach et al. 1999). Blue cod are reported as one of the most commonly landed species by recreational fishers in the Akaroa harbour (Källqvist et al. 2015) and the west coast of the South Island (Davey et al. 2006), and are described as the most important recreational fish in the South Island (MPI 2015a). Recreational fishing methods are most commonly hook and line fishing, however, spearfishing, set netting, and cod potting are also used (MPI 2014). There is an allowed annual recreational take of $556 \mathrm{t}$ and in 2012 the estimated recreational take was 302 t (MPI 2014). Charter vessels contribute to a large proportion of recreational catch in the Marlborough Sounds; a 1997-98 survey indicated that the charter vessel catch in $\mathrm{BCO} 7$ exceeded the total allowable commercial catch (TACC) in that year (MPI 2015b).

The historical blue cod commercial catch is summarised by MPI (2014). Total national harvest was about $3000 \mathrm{t}$ in the 1930s and remained high (c. $2500 \mathrm{t}$ ) through to the late 1960s, although, landings were lower during World War II. Landings have been negatively correlated with the success of the rock lobster fishery, whose operators have turned to blue cod fishing in years of low rock lobster catch. Blue cod were introduced into the QMS in 1986, and since then total commercial take has steadily increased and is currently 2174 t (MPI 2015b). Commercial fisheries are predominantly inshore aside from some reported by-catch from deep-water fisheries (MPI 2015b). Southland (BCO5) and the Chatham Islands (BCO4) support the major commercial catch, although smaller commercial fisheries exist off Otago, Wanganui, Canterbury, and the Marlborough Sounds (MPI 2014). Commercial blue cod fishers use cod pots and line fishing. Commercial and recreational catches are regulated by the quota management system (QMS), managed as eight stocks (Figure 1.1) (MPI 2015b). Based on the blue cod movement and connectivity studies mentioned above, smaller populations within the management stocks are expected. 


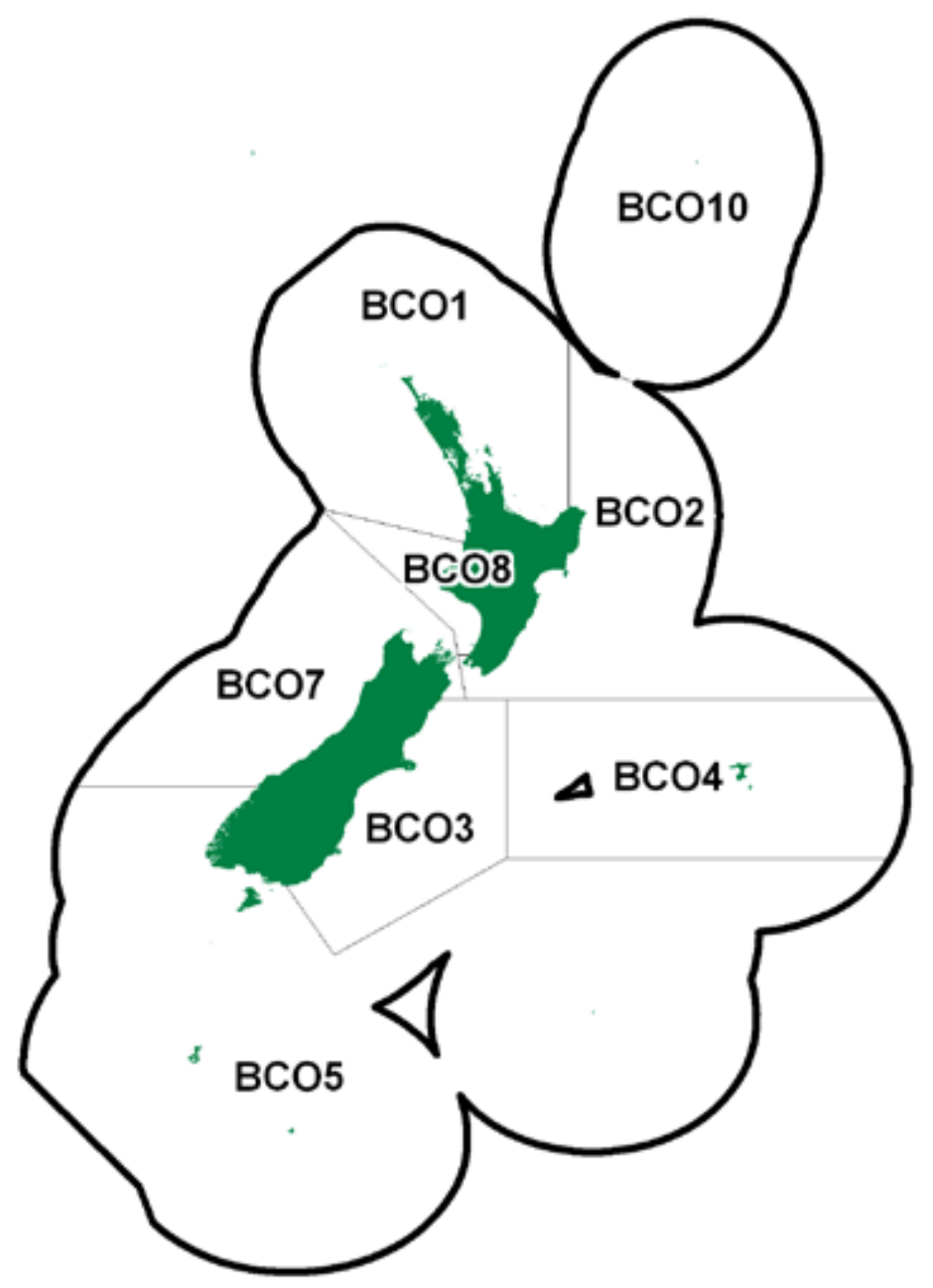

Figure 1.1

Blue cod management areas of New Zealand from MPI (2014).

The Marlborough Sounds recreational blue cod fishery is iconic to New Zealand, however, over the past two decades there have been a number of changes to the local fishing regulations (MPI 2015b), some of which were contested by fishers (MPI 2015a). The initial blue cod minimum landing size (MLS) was $30 \mathrm{~cm}$ TL with a maximum daily limit of 12 fish per person. This was raised to $33 \mathrm{~cm}$ TL and the maximum daily limit was reduced to 10 per person in 1993 (MPI 
2014). This was later changed to $28 \mathrm{~cm}$ TL with a limit of six per person in 1994 in response to reports of frequent mortality of returned undersized fish (Carbines 1999b; MPI 2014). In response to the decline in blue cod biomass within the Marlborough Sounds, MPI closed the fishery from 2008 to 2011 and thereafter implemented (1) the slot size rule where only fish over $30 \mathrm{~cm}$ TL and under $35 \mathrm{~cm}$ TL could be landed; (2) the blue cod bag limit was reduced to two blue cod per person per day; (3) a transit rule was implemented which restricted the transport of blue cod through the Marlborough Sounds to two per person, regardless of where they were caught, and; (4) filleting of blue cod was not allowed at sea (MPI 2014). The slot-size rule and transit rule were protested by local fishers, who claimed that the slot-size rule was damaging fish stocks because of high return rates of fish with high post-release mortality, and the slot size and transit rule were regarded as unfair and impractical by local fishers (MPI 2015a). In December 2015 the rules changed yet again; the slot and transit rules were removed and a minimum landing size of $33 \mathrm{~cm}$ was implemented (MPI 2015a). The maximum daily limit remains at two blue cod per person in 2016 and the rules apply to the entire Challenger East area, including the Marlborough Sounds.

Within the Marlborough Sounds there has been a marked decline in blue cod size and abundance since the late 1930s (Beentjes \& Carbines 2011). The largest decline was between 1997 and 2007 , where blue cod abundance decreased by $c .60 \%$, and localised depletion of blue cod and shifts to male-biased sex ratios were observed (Beentjes \& Carbines 2011). An analysis of survey data before and during the fishery closure indicated that blue cod abundance and size increased substantially within the closed areas (Beentjes \& Carbines 2011). However, a different survey indicated that the Marlborough Sounds' stock had already increased in abundance by 2007, before the fishery closure (MPI 2014). Surveys indicated that recreational harvest in the BCO7 area, which included the Marlborough Sounds, had decreased from $288 \mathrm{t}$ in 2000 to $75 \mathrm{t}$ in 2012 (MPI 2015b). It is not clear whether the fishery closure directly facilitated the increase in blue cod biomass.

In areas where fishing pressure was high, specifically, inshore areas close to Banks Peninsula and in the Marlborough Sounds, blue cod populations commonly had male-biased sex ratios, lower abundance, and were smaller on average (Beentjes \& Carbines 2005). Whereas, in comparatively less fished areas, for example, offshore areas near Banks Peninsula and Dusky Sound, blue cod were larger and commonly had a sex ratio skewed towards females (Beentjes \& Carbines 2005). 


\section{Introduction to Chapter II}

\section{Maturity, Fecundity, and Sex Change}

Sustainable management and assessment of fish stocks is dependent upon accurate knowledge of stock-specific biological information such as size and age at maturity, fecundity, and reproductive mode (Morgan 2008; Klibansky \& Scharf 2015). Size at maturity estimates are obtained from either macroscopic or histological evaluation of gonads, and can be used in concert with stock biomass, catch, growth, longevity, and length composition data to estimate the spawning-stock biomass (SSB) (Klibansky \& Scharf 2015). Fecundity estimates at size and age are important for assessing population growth potential, and evaluating the reproductive input of females at different sizes or ages (Birkeland \& Dayton 2005; Beer et al. 2013). Female fecundity is correlated with fish size and body condition in some species (Alheit, 1993; Kurita, Meier, \& Kjesbu, 2003). Larger females can produce larger and higher quality eggs with greater larval success (Kamler 2005). Therefore, as the size-structure and sex ratio change in a population, so may the overall fecundity of the population, even when SSB remains constant. Finally, population response to fishing pressure can depend upon the reproductive mode of the species, particularly for sex changing species, where fishing pressure can cause changes to population sex ratios and influence rates of sex change (Hawkins \& Roberts 2004; Alonzo et al. 2008).

Macroscopic maturity estimation is quick, cheap, and does not require many resources, however, it lacks accuracy (Vitale et al. 2006). Histological maturity estimation is most accurate, however, it is a costly, time consuming, and a resource-demanding process. Inaccuracy in macroscopic maturity assessment is a common feature of fisheries research. Klibansky and Scharf (2015) presented an overview of research exposing the inaccuracy of macroscopic methods in estimating maturity in fishes. Of 18 species studied, only two had maturity stages that were estimated with less than $10 \%$ error when using macroscopic techniques compared with microscopic techniques; agreement between techniques was as low as $31 \%$. Inaccuracy in maturity assessment will likely give rise to incorrect estimates of size and age at maturity, which can lead to inaccurate estimation of the proportion of biomass that is mature (SSB). For example, Vitale et al. (2006) found that when macroscopic maturity data were used to estimate age at maturity, SSB was overestimated by up to $35 \%$ when compared with histological maturity estimates.

In a multiple (batch) spawner like blue cod (Carbines 2004b; Beer et al. 2013), there are many oogenic stages within mature ovaries, and the spawning season is extended (Pankhurst \& 
Conroy 1987). Oocytes in many stages of development within mature ovaries indicate multiple spawning fish with asynchronous oocyte development (Wallace \& Selman 1981). To estimate annual fecundity, knowledge of the spawning season duration, the number of eggs females release per spawning episode (batch fecundity), and how often females spawn (spawning frequency) is needed (Murua et al. 2003). Spawning season length, batch fecundity, and spawning frequency may differ between size and age classes of females.

Batch fecundity can be estimated by quantifying the number of hydrated oocytes (HOs) within the ovaries of ripe/running females. HOs are encompassed by a follicle layer made up of the inner epithelial layer of granulosa cells, and an outer connective tissue layer of thecal cells and blood capillaries (McMillan 2007). After ovulation, this follicle layer, known as the postovulatory follicle (POF), remains in the ovary (Hunter \& Macewicz 1985). POFs deteriorate over time and can be aged (Hunter \& Macewicz 1985). Preceding spawning, ripe females can be identified by the absence of early stage POFs, and the presence of hydrated oocytes (Murua et al. 2003). These females can be used for batch fecundity estimation. The daily proportion of mature females with early stage POFs (indicating recent spawning) are used to estimate the spawning fraction, and the spawning fraction is inverted to produce an estimate of spawning frequency (Wilson \& Nieland 1994).

Beer et al. (2013) made the first estimate of batch fecundity for blue cod and investigated the relationship between female size and egg quality. The mean blue cod batch fecundity was 6529 HO g ${ }^{-1}$ body weight in October 2008 and $4786 \mathrm{HO} \mathrm{g}^{-1}$ body weight in December 2009. However, that research did not use histological methods to identify and age POFs. Therefore, the results may be inaccurate as females who had recently spawned, and therefore had fewer HOs than at the time of spawning, may have been included in the fecundity counts. If HOs were identified correctly in Beer et al. (2013), these estimates of batch fecundity may have been underestimated.

There has been some doubt concerning the occurrence of hermaphroditism in blue cod (MPI, pers. comm.). However, they are believed to be diandric protogynous hermaphrodites, where individuals initially develop as either male or female, and some females change sex later in life (Mutch 1983; Carbines 2004b). Mutch (1983) reported a single transitional gonad from a $37 \mathrm{~cm}$ TL blue cod caught at Leigh, New Zealand. The gonad had resting stage oocytes, defined by Mutch (1983), and all stages of spermatogenesis. Within the transitional gonad, breakdown of oocytes was seen in the distal portion of each gonadal lobe, and small crypts of spermatogonia, primary spermatocytes, secondary spermatocytes, and spermatids were observed in the proximal regions. Carbines (2004) found transitional gonads in 28 individuals from a sample of 306 blue cod from Stewart Island. As was the case for Mutch (1983), transitional gonads were primarily functional testes containing previtellogenic and/or vitellogenic oocytes. Oocytes were located in 
the distal spermatic tissue, between lobes of gonad epithelial lining, in crypts of spermatozoa, or in the vas deferens. Transitional individuals ranged from 280-455 mm TL and were aged from 6 to 11 years. The condition of diandry in blue cod was inferred from the presence of small sexually immature males in blue cod populations which were said to be unlikely to have previously matured as female (Carbines 2004b).

The macroscopic maturity-staging key used for blue cod maturity assessment does not appear to have been validated and therefore the accuracy of size and age at maturity estimates is unknown. Other histological maturity keys have been used by Mutch (1983) and (Carbines 2004b) to stage blue cod, however, these keys were undesirable as the stages were based on relative proportions of tissues and used subjective language.

The aims of Chapter Two were: (1) develop a simpler objective histological key; (2) evaluate the accuracy of the macroscopic maturity key; (3) use histological and gravimetric methods to estimate batch fecundity and spawning frequency; and (4) investigate hermaphroditism in blue cod. 


\section{Introduction to Chapter III}

\section{Potential Drivers of Blue Cod Sex Ratio in the Marlborough Sounds}

Hermaphroditism is widespread throughout the animal kingdom and is particularly prominent among socially structured species (Munday et al. 2006a). The modes of hermaphroditism are adapted to local conditions, spawning type, and the relative fecundity at size of each sex (Erisman et al. 2013). Protogyny is one of the most common forms of hermaphroditism in fishes, where individuals initially develop as females and later transition to males (Alonzo et al. 2008). The onset of sex change may be genetically determined, environmentally educed, or be influenced by social factors (Sadovy \& Shapiro 1987; Devlin \& Nagahama 2002).

Sex allocation theory explains the relative fitness benefits of sex change in sequential hermaphrodites. The Size Advantage Model (SAM) predicts that when the expected number of progeny for each sex varies with size, there is a fitness advantage for individuals who change sex at a particular size (Ghiselin 1969). The size at which sex change becomes advantageous is dependent upon population or social group size, sex ratio, population mortality, population growth, and sex-specific size advantages of the species (Munday et al. 2006a). In blue cod, territorial males are thought to monopolise mating with a number of females (Mutch 1983). Under SAM it is predicted that the largest males are most likely to monopolise mating, therefore, it is most beneficial for an individual to remain female until a size is reached where it can challenge the largest male. Under these conditions, sex ratios in blue cod populations are expected to be female-biased.

In protogynous hermaphrodites, dominant males in social groups can suppress female to male sex change. This has been demonstrated where large dominant males have been removed from populations, and subsequently, subordinate females undergo sex change (Ross et al. 1983; Liu \& Sadovy 2004; Walker \& McCormick 2009). Other studies have shown that female to male sex change is influenced by the abundance and size of females within social groups, and the size of the largest male (Cole \& Shapiro 1995).

In a number of reef-dwelling sequential hermaphroditic species, visual sex change cues and social interactions from conspecifics are needed to trigger sex change (Ross et al. 1983; Shapiro 1983; Nakamura et al. 2005). Frequency of interactions amongst conspecifics is related to group 
size, where in populations with very low densities of fish, social interactions are minimised and sex change cues are not exchanged (Lutnesky 1994). The density of populations can therefore influence rates of sex change and overall sex ratio.

Initial sexual determination (male or female) can also be influenced by population density (Liu $\&$ Sadovy 2004). In diandric protogyny, male development has two pathways: (1) primary males initially develop male gonads and retain the male state; and (2) secondary males initially mature as female and later transition to male (Reinboth 1983). In some species, individual male developmental pathways are influenced by population size. For example, in the bluehead wrasse Thalassoma bifasciatum, the proportion of primary males is strongly correlated with population size; smaller populations have fewer primary males than larger populations (Warner \& Hoffman 1980). This phenomenon was theorised to occur because mating in smaller populations was monopolised by larger (usually secondary) males. On the contrary, large populations became difficult to control by large males, and small male reproductive success was increased in large populations (Warner 1984). From a manipulative experiment, Munday et al. (2006) showed that the sexual pathway of males was related to the population size and was unlikely to be genetically determined. Larger populations had significantly higher proportions of primary males, and therefore had a higher overall proportion of males than smaller populations.

A range of environmental factors may also influence sex ratios; temperature has been shown to influence sex determination of fish (Devlin \& Nagahama 2002); the sex ratio of offspring may be related to maternal condition, where females in better condition may produce more male than female young (Trivers \& Willard 1973), and maternal condition may be influenced by availability of food (Donelson et al. 2010) and habitat type (Lloret et al. 2002). Finally, environmental composition may favour certain social mating systems (i.e. availability of certain habitat types), as shown in butterflyfishes (Chaetodontidae) (Hourigan 1989), and may therefore influence local sex ratios.

A feature of the Marlborough Sounds blue cod stock is the heavily male-biased sex ratio (MPI 2015b). A sex ratio bias towards males is expected to decrease overall population fecundity as eggs become limited (Parker 1980), and may also decrease genetic diversity (Amos \& Harwood 1998). Coupled with diminishing abundance from fishing, sex-ratio skewedness may therefore have detrimental effects to the viability of blue cod populations. Blue cod stocks in the Marlborough Sounds have become increasingly male-dominated over time, and recreational fishing pressure is the likely culprit (MPI 2014). One hypothesis is that the disproportionate removal of larger males from the population has increased the frequency of female to male sex change (Beentjes \& Carbines 2012; MPI 2014). Large, dominant males are thought to suppress sex change in females (Carbines 2004b). The disproportionate removal of large males is 
attributed to size-selective fishing promoted by minimum landing size regulations and fishers tendency to land larger fish and return smaller fish (i.e. high grading). On the other hand, sex ratio could be explained by density dependent sex-ratio adjustment, environmentally induced sexual selection, or may be attributed to unrepresentative sampling, or other sampling error.

In Chapter Three, the data from the 2013 Marlborough Sounds blue cod potting survey were used to test three hypotheses concerning sex ratio: (1) sex ratios are environmentally influenced; (2) sex ratios are density-dependent; and (3) large males suppress sex change in females. Further, the effect of sampling method on sex ratio estimates is explored. 


\section{Introduction to Chapter IV}

\section{Otolith Ageing and Analysis of Imaging Software}

Otoliths are ear bones, and are formed from the precipitation of aragonite of the endolymph fluid within the auditory vesicle (Green et al. 2009). Importantly, biological and environmental fluctuations associated with growth are reflected in the precipitation of either mineral-rich or mineral-deficient zones (Green et al. 2009). The difference in density between these zones is visually perceived as a series of light and dark growth bands, and are often associated with daily, seasonal, or annual fluctuations in growth and can be used to estimate age if the rate of band production is known (Green et al. 2009). Growth bands in the sagittal otoliths of blue cod are laid annually (Carbines 2004a). A combination of partial otolith increment analysis and the oxytetracyclene (OTC) capture-mark-recapture method was used to validate light and dark zones as regular annual markings (Carbines 2004a).

Variation in otolith growth-band width and changes in otolith density are associated with lifehistory events. For example, metamorphosis at larval settlement can produce significant growth band anomalies, or 'settlement marks' in otoliths of tropical reef fish (Wilson \& McCormick 1997). Further, the area of the otolith associated with the onset of sexual maturity in orange roughy Hoplostethus atlanticus shows narrowing of growth zone width and marked changes in the proportion of opaque and hyaline area within these zones compared to areas of normal growth (Francis \& Horn 1997). Further, sex change signatures, namely, changes in otolith growth zone width and primary growth axis of growth rings, have been observed in Parapercis cylyndrica, a closely related (to P. colias) reef-dwelling protogynous hermaphrodite (Walker \& McCormick 2009). The distance between growth rings of $P$. cylyndrica was significantly shorter throughout the sexual transition phase and distance between the male stage growth rings were significantly larger than that of the female stage. This allowed accurate estimation of age at sexual transition.

Age estimates are a vital biological measurement used in fisheries biology, and fish stock monitoring and modelling (Forrest et al. 2008; Martell et al. 2008). Typically, otoliths are used for ageing, although, scales, spines, and other bones can also be used (Morales-Nin 1992). Otoliths are manually aged under the microscope, where readers count the number of growth bands from the nucleus to the outer margin (Campana 2001). Otoliths can be read whole, broken and burnt, or sectioned (and potentially stained) and mounted on glass slides (Chilton \& Beamish 1982). Sectioned otoliths generally provide the clearest growth ring counts, but are more expensive and time consuming to prepare than other methods. Growth bands are 
commonly difficult to distinguish in some areas of the otolith, which can lead to variable age estimates between readers and between readings of the same otolith (Kimura \& Lyons 1991). Furthermore, growth bands in the regions that are difficult to read, and often the first growth band, are commonly counted by inference of the reader, which introduces subjectivity into the process. Growth zones can be especially difficult to distinguish in blue cod otoliths, for which the ageing protocol was being redeveloped during 2015 and 2016 (MPI, pers. comm.). Therefore, if imaging software can be used to age otoliths and accurately interpret growth zones, it would provide an objective, useful, repeatable, and accurate measure of age in fish.

Image-Pro Premier is imaging software that allows users to capture, process, measure, and analyse images (http://www.mediacy.com/index.aspx?page=IP_Premier). The Otolith $M$ application was developed to detect changes in light intensity along user-drawn transect lines on an otolith or similar structure. The user must identify the center (nucleus) or first year growth zone; the software cannot do this. The software can interpolate peaks, valleys, or other distinguishable changes in light intensity along a user-drawn transect line, provided these exist (i.e. there are growth zones). Further, the software can measure distances between these features and quickly output measurements. For use with this software, a clear high-definition photograph of the otolith must be taken, which requires a high-powered microscope with a camera. Generally, the otolith would be sectioned and mounted on a glass slide.

Imaging software is also used for otolith shape analysis (Ye et al. 2015), otolith increment measurements (Sardenne et al. 2015), and to assist readers with age estimates (Mercier et al. 2011). However, examples of image software used autonomously for age measurements could not be found in the literature.

Originally I had hoped to analyse the blue cod otoliths from the 2013 Marlborough Sounds survey that were associated with the gonad histology samples and to use an increment analysis to investigate changes in growth rate between male, female, and transitional blue cod. Specifically, to look for changes in growth zone widths associated with sex change in blue cod. Such growth anomalies in otoliths are commonly attributed to life-history events in other fish, and have been associated with sex change in a hermaphroditic reef fish of the same genus (Walker \& McCormick 2009). If such changes in growth rate were attributable to sex change, it would provide a useful and novel tool for measuring age at sex change in blue cod. Further, as blue cod otoliths have been collected by NIWA's scientific surveys over a number of years, sex change in blue cod could be investigated over the long-term or for different areas. However, the blue cod otoliths from the 2013 Marlborough Sounds survey could not be obtained because they were being used to develop the blue cod ageing protocol, which was not completed within the duration of this thesis. 
The aims were therefore revised to: (1) analyse the ability of imaging software to interpret yearly growth zones in blue cod otoliths; (2) determine how sensitive age estimation is to transect line angle; and (3) investigate the ability of imaging software in finding the nucleus and first yearly increment in the otolith. A historical otolith collection was obtained from NIWA and used for these analyses. 
Chapter II | Blue Cod Maturity, Fecundity, and Sex Change

CHAPTER II

BLUE COD MATURITY, FECUNDITY, AND SEX CHANGE 


\section{Introduction}

In this chapter, a new species-specific histological maturity classification key was developed for blue cod. The key was used to assess maturity in a sample of blue cod gonads that were collected from the Marlborough Sounds area. These stages were compared to macroscopic maturity stages of the same sample allocated at sea. Length-at-50\% maturity estimates from histological and macroscopic data were also compared. Histological and gravimetric methods were used to estimate fecundity in blue cod. Finally, evidence for hermaphroditism in blue cod was evaluated.

\section{Methods}

Blue cod samples were collected by the National Institute of Water and Atmospheric Research (NIWA) from Queen Charlotte Sound, Pelorus Sound, D'Urville Island, and the Cook Strait (Figure 2.1), from 26/09/13 to 09/11/13. Blue cod were caught with baited cod pots set for approximately 60 minutes. The fish were weighed, measured from the snout to the tip of the caudal fin (Total Length, TL), sexed, and maturity was staged by macroscopic inspection of the gonad. Gonads from 550 of the fish were removed, fixed in $10 \%$ neutrally buffered formalin, and thereafter stored in $70 \%$ ethanol. 
Chapter II | Blue Cod Maturity, Fecundity, and Sex Change

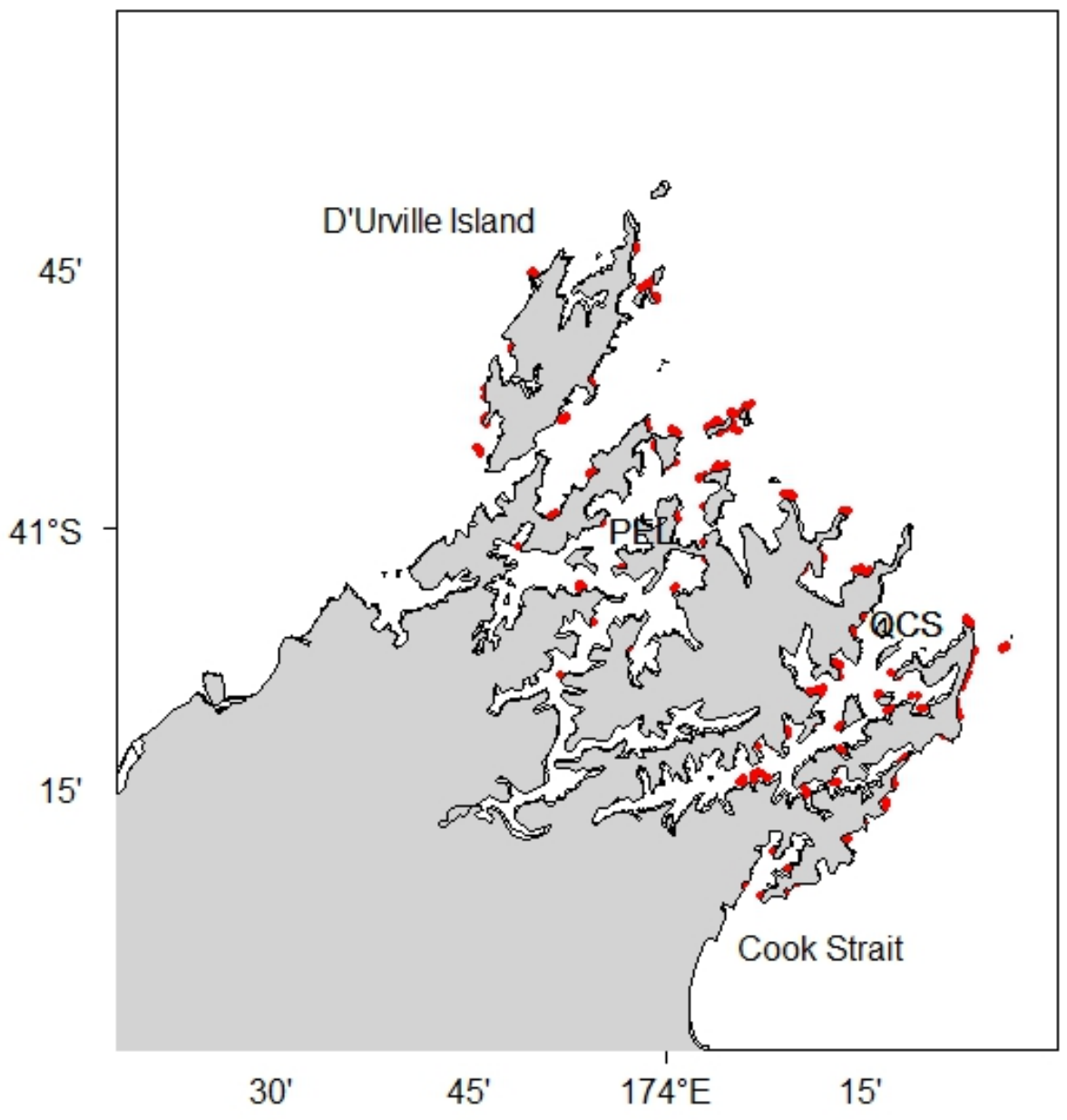

Figure 2.1

The Marlborough Sounds, Cook Strait, and D'Urville Island. The red dots represent blue cod sampling stations in the 2013 Marlborough Sounds survey carried out by NIWA. QCS = Queen Charlotte Sound, $\mathrm{PEL}=$ Pelorus Sound. 
The gonads were macroscopically staged fresh on the vessel using a 6-stage classification modified from the 5-stage Stock Monitoring (SM) method used on previous blue cod surveys. Gonads were staged as follows: (1) immature; (2) maturing (oocytes visible in females); (3) mature (hyaline oocytes in females, milt expressible in males); (4) running ripe (eggs and milt free flowing); (5) spent; (6) resting.

A subsample of 252 gonads from the preserved gonads was taken; all females and fish of unknown sex were included, and at least 5 males were chosen at random from each $1 \mathrm{~cm}$ length bin. In length bins with less than 5 male fish, all male fish were included in the subsample. Some of the gonads in the subsample were not preserved well enough for histological processing. The final subsample is summarised in Table 2.1. These gonads were removed from the alcohol, photographed, blotted dry, and weighed to the nearest $0.001 \mathrm{~g}$. Transverse sections of approximately $4 \mathrm{~mm}$ thickness were taken from the gonads for histological processing. Tissue dehydration and wax impregnation were performed using an automated tissue processor. Samples were then embedded in paraffin wax and $5 \mu \mathrm{m}$ sections were cut using a microtome and mounted on glass slides. Slides were left overnight to dry and then stained with haematoxylin and eosin (H\&E). The H\&E staining schedule is shown in Table 2.2. Finally, coverslips were attached with DPX mounting medium.

Table 2.1

The subsample of blue cod gonads by macroscopic sex and length class processed for histological analysis.

\begin{tabular}{|lccc|}
\hline Length $(\mathbf{c m})$ & Female & Male & Unknown sex \\
$15-19$ & 5 & 0 & 0 \\
$20-24$ & 14 & 9 & 3 \\
$25-29$ & 49 & 25 & 5 \\
$30-34$ & 51 & 44 & 1 \\
$35-39$ & 5 & 28 & 0 \\
$40-44$ & 0 & 13 & 0 \\
Total & $\mathbf{1 2 4}$ & $\mathbf{1 1 9}$ & $\mathbf{9}$ \\
\hline
\end{tabular}


Table 2.2

Haematoxylin and Eosin (H\&E) staining schedule for blue cod gonad sections. Two identical reagents in series means that slides were placed in a fresh batch of the reagent following the first exposure.

\begin{tabular}{|lcl|}
\hline Reagent & Exposure time (minutes) & Comments \\
Xvlol & 5 & \\
Xylol & 5 & \\
$100 \%$ Ethanol & 5 & \\
$100 \%$ Ethanol & 5 & \\
$70 \%$ Ethanol & 3 & Agitate every two minutes \\
Running tap water & 3 & Ouick rinse \\
Haematoxylin & 12 & 10 quick dips \\
Tap water & - & \\
$1 \%$ Acid ethanol & - & \\
Scott's blueing agent & 5 & \\
Running tap water & 5 & Agitate every 30 seconds \\
Eosin & 3 & Ouick rinse \\
Tap water & 5 & \\
$70 \%$ Ethanol & 5 & \\
$100 \%$ Ethanol & 5 & \\
$100 \%$ Ethanol & 5 & \\
Xylol & 5 & \\
Xylol & 5 & \\
& & \\
\hline
\end{tabular}


Developmental differences between left and right lobes, and along the length of the lobes of the gonad, were investigated by sectioning a random subsample of 27 gonads at the anterior, medial, and posterior regions of both lobes. Apart from a single transitional gonad, where left and right lobes were intertwined and were of testicular and ovarian tissue, histological sex identification and evaluation of histological maturity stage for this subsample revealed that there was no difference in histologically determined maturity between lobes, or along the length of the lobes. Thereafter, all samples were taken from the medial region of the right lobe, or a medial section containing both left and right lobes was taken where individual lobe dissection was not possible. More than 400 histological slides were produced and examined in this study.

Histological slides were examined at 80-400 $\times$ magnification through transmitted light. A new sex-specific histological maturity key was developed for blue cod. The key was developed by examining a variety of gonads at various stages of development and comparing them to the histological maturity stages for carpenter seabream Argyrozona argyrozona (Brouwer \& Griffiths 2005) and butterfish Odax pullus (Trip et al. 2011). Females were classified by the most advanced oogenic stage found within the gonad section (West 1990) and the presence of atretic oocytes. Oocyte development stage and atretic oocytes were identified using the criteria of McMillan (2007). Males were graded by the most advanced and most abundant stage of spermatogenesis (Grier 1981), the appearance of connective tissue and abundance of spermatozoa in the primary sperm duct.

The six female maturity stages were characterised as: (1) most advanced stage is the cortical alveolus stage, pre-vitellogenic oocytes predominate (Immature or Resting); (2) vitellogenic oocytes are the most advanced stage, no germinal vesicle migration or hydrating oocytes present (Developing); (2a) most advanced oocyte stage are vitellogenic oocytes, however some vitellogenic oocytes are atretic (Developing Atretic); (3) early stages of hydration and germinal vesicle migration are the most advanced stages (Mature); (4) hydrated oocytes are the most advanced stage (Ripe/Running); and (5) late stage vitellogenic oocytes and early hydrating oocytes (yolked oocytes) are atretic (Post spawning). The six-stage female maturity key is illustrated in Figure 2.2. 

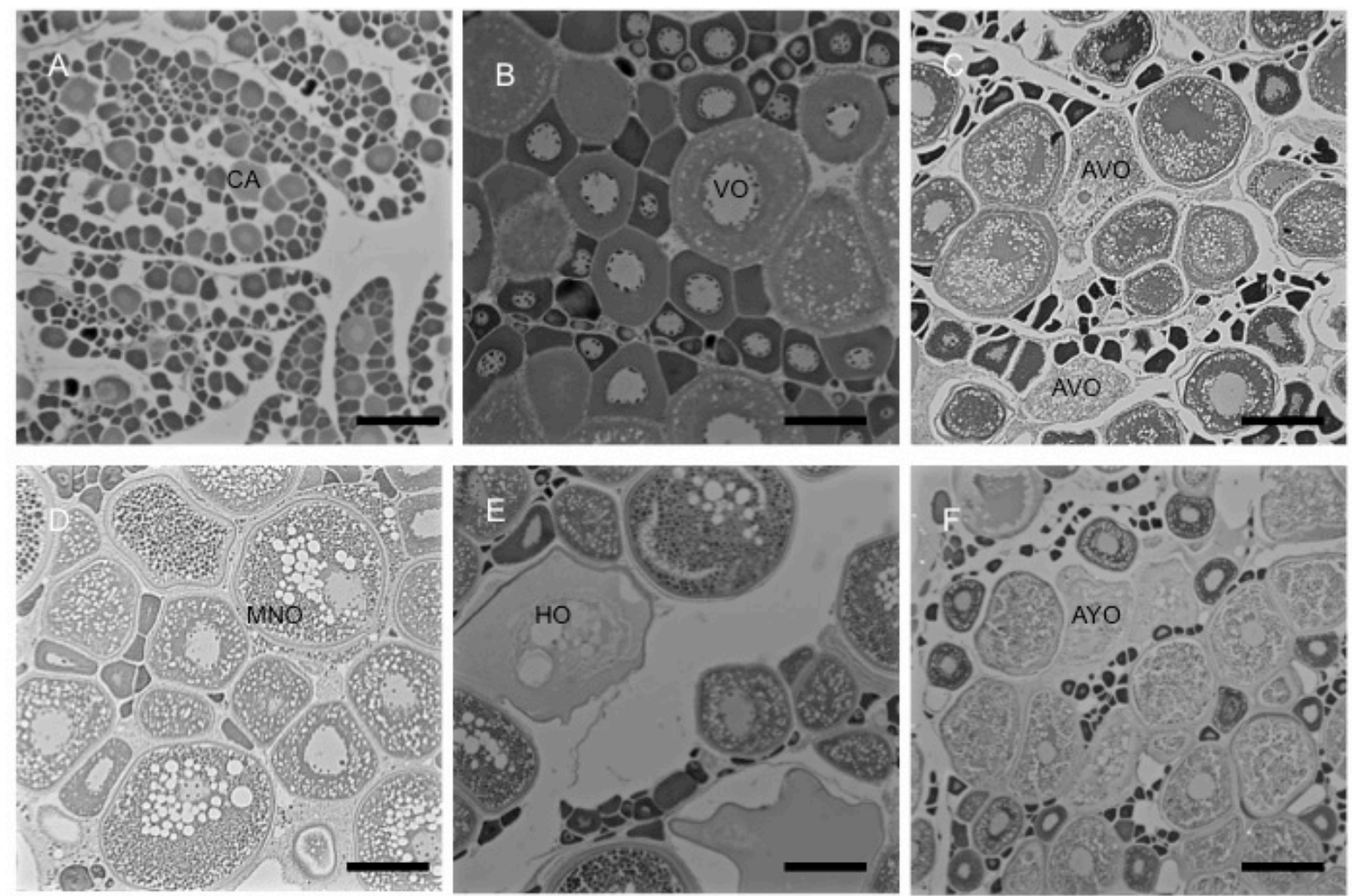

Figure 2.2

The six stages of histological maturity in female blue cod. (A) Immature/resting female with cortical alveolus (CA) stage oocytes as the most advanced stage (scale bar $=100 \mu \mathrm{m}$ ), (B) developing female with vitellogenic oocytes (VO) being the most advance stage (scale bar $=150 \mu \mathrm{m}),(\mathrm{C})$ developing atretic female with VO and atretic vitellogenic oocytes (AVO) (scale bar $=200 \mu \mathrm{m}$ ), (D) mature female with migratory nucleus oocytes $(\mathrm{MNO})$ as the most advanced stage (scale bar $=200 \mu \mathrm{m})$, (E) ripe/running female with hydrated oocytes (HO) as the most advanced stage (scale bar $=200 \mu \mathrm{m}$ ), and $(\mathrm{F})$ post spawning female with atretic yolked oocytes (AYO).

The male maturity stages were classified as: (1) connective tissue abundant, sperm sinuses undeveloped, spermatogonia dominate (Immature or Resting); (2) sperm sinuses begin to develop, spermatocytes dominate and spermatids are present (Developing); (3) sperm sinuses fill with spermatozoa, spermatozoa predominant throughout the testis, primary sperm duct begins to fill with spermatozoa (Mature); (4) primary sperm duct is packed with spermatozoa, major sperm ducts appear within the lobes of the testis and are filled with spermatozoa (Ripe/Running); (5) sperm sinuses begin to empty, outer margins of testis dominated by loose connective tissue, residual spermatozoa remains within the primary sperm duct (Spent). The new five-stage male maturity key is illustrated in Figure 2.3. 

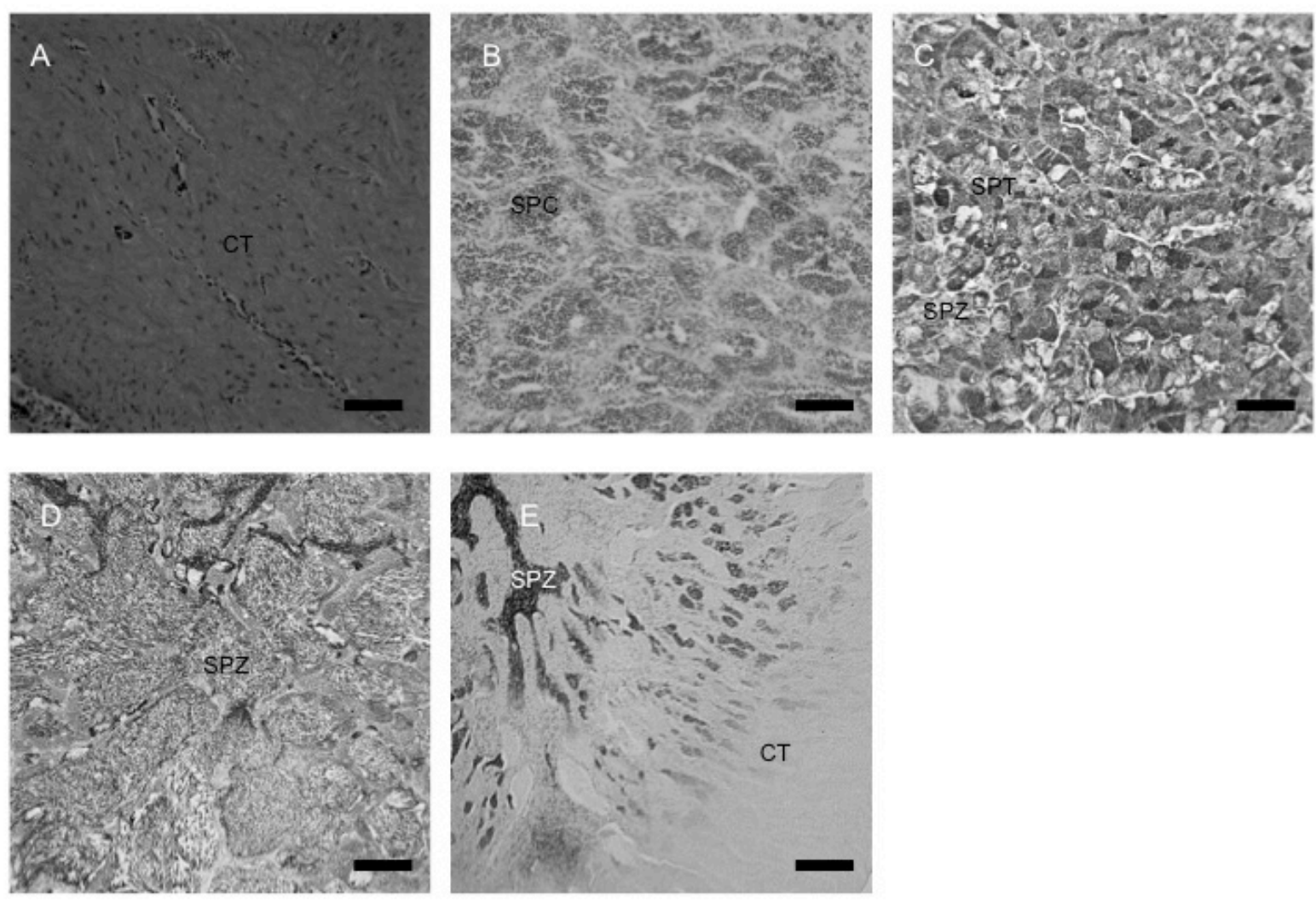

Figure 2.3

The five stages of histological maturity for male blue cod. (A) Immature/resting male is predominantly connective tissue $(\mathrm{CT})$ (scale bar $=50 \mu \mathrm{m})$, (B) developing male dominated by spermatocytes (SPC) in sperm sinuses (scale bar $=100 \mu \mathrm{m}),(\mathrm{C})$ mature male, sinuses contain spermatids (SPT) and spermatozoa $(\mathrm{SPZ})($ scale bar $=200 \mu \mathrm{m})$, (D) ripe/running male, sperm sinuses are packed with SPZ (scale bar $=200$ $\mu \mathrm{m})$, and (E) spent male with residual SPZ and abundant CT (scale bar $=400 \mu \mathrm{m})$.

All ovarian histological sections were examined for the presence of POFs and atretic oocytes. POFs were graded as stage 1, 2 or 3 (Figure 2.4) by comparing them to known age POFs of the carpenter seabream (Brouwer \& Griffiths 2005). Stage 1 POFs were determined from a loosely arranged string of follicle cells with conspicuous lumen. Stage 2 POFs were more densely packed and the lumen was still clearly visible. Stage 3 POFs were small, tightly packed clusters of follicle cells. 


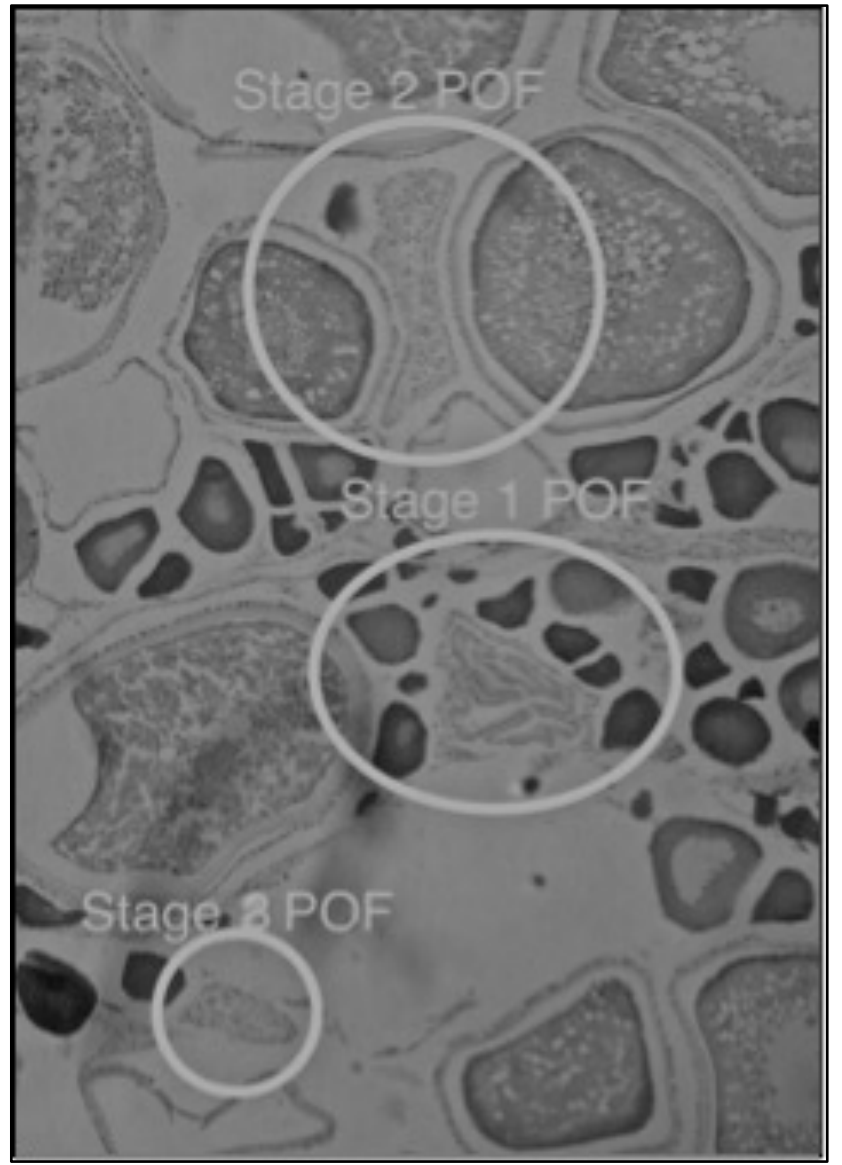

Figure 2.4

Stage 1, 2 and 3 postovulatory follicles (POFs) from a histological section of a blue cod ovary. Stage 1 POFs were determined defined as having more densely packed and the lumen was still clearly visible. Stage 3 POFs were small, tightly packed clusters of follicle cells.

Size-at-maturity was modelled for females and males separately using two-parameter and threeparameter logistic ogives and a GLM (Generalized Linear Model) with logit link and binomial response. A two-parameter logistic ogive is a sigmoidal model fitted to the proportion of mature fish at length using least-squares estimation. In the histological analyses, stages three and above were classified as mature, whereas in macroscopic analyses, stages 3, 4, and 5 were classified as mature, and all others as immature. Maturity ogives were fitted to macroscopic and histological data using the subsample $(\mathrm{n}=252)$ (Table 2.1), and macroscopic maturity ogives were also fitted using the larger survey sample $(n=3247)$. 
The two-parameter logistic ogives had the form:

$$
p_{i}=\frac{1}{1+19^{-\left(L_{i}-L_{50}\right) / L_{t o 95}}},
$$

Where $p_{i}=$ the proportion of mature fish in size class $i$;

$L_{i}=$ the length of size class $i$

$L_{50}=$ the length at which $50 \%$ of the fish are mature (stage $3+$ ); and

$L_{t 095}=$ the difference between the length at which $95 \%$ of the fish are mature and the $L_{50}$

Model parameters $\mathrm{L}_{50}$ and $\mathrm{L}_{\text {to95 }}$ were estimated by minimising the sum of the squared residuals, using the $n l s$ function in R.

A three-parameter capped-logistic ogive was used to model length-at-maturity for females and to estimate the proportion of females in the higher length classes that mature as females each spawning season. A capped-logistic ogive was used because there was no length at which $100 \%$ of females were mature in the histological sample.

The three-parameter capped logistic ogive had the form

$$
p_{i}=\frac{\operatorname{Cap}}{1+19^{-\left(L_{i}-L_{50}\right) / L_{t o 95}}}
$$

Where Cap $=$ asymptote of the logistic model (interpreted as the proportion of the population that become sexually mature);

$p_{i}=$ the proportion of mature fish in size class $i$;

$L_{i}=$ the length of size class $i$;

$L_{50}=$ the length at which $50 \%$ of the fish are mature (stage $3+$ ); and

$L_{t o 95}=$ the difference between the length at which $95 \%$ of the fish are mature and the $L_{50}$.

Model parameters $\mathrm{L}_{50} \mathrm{~L}_{\text {t095 }}$ and Cap were estimated by minimising the sum of the squared residuals, using the $n l s$ function in $\mathrm{R}$. 
When the same dataset was used, model fits were compared by their Akaike Information Criterion (AIC) values and their visual fits to the data. AIC is a measure of lack of fit of the model to the data, penalised for increasing the number of model parameters. Models with lower AIC values are considered better fits to the data.

Macroscopic and histological logistic maturity ogives were modelled in the same manner. However, no capped logistic maturity ogive was used for the macroscopic maturity data, because males did reach $100 \%$ maturity in the larger length classes.

The GLMs were fitted using a binomial distribution and a logit link, with the response variable being the proportion of mature fish (m) at length. The GLM had the form:

$$
\log (E[m])_{i}=a+b l_{i}
$$

Where $\log (E[m])_{i}=$ the logarithm of the expected proportion of mature fish (stage $3+$ ) at size class $i$;

$$
\begin{aligned}
& a=\text { the intercept; } \\
& b=\text { the slope; and } \\
& l_{i}=\text { size class i (in } \mathrm{cm} \text { ). }
\end{aligned}
$$

Estimates of $\mathrm{L}_{50}$ were calculated by dividing the negative of the model parameter for the intercept by the slope $\left(\frac{-a}{b}\right)$.

A gonadosomatic index (GSI) was calculated as an objective measure of the reproductive condition of each fish. GSI was calculated as:

$$
G S I=\left(\frac{G W}{W}\right) \times 100
$$

Where $\mathrm{GW}=$ gonad weight, and

$\mathrm{W}=$ the whole fish weight (minus the gonad weight). 
For fecundity analysis, ovaries that contained hydrated oocytes and did not contain POFs were selected. A total of 9 females were identified for fecundity analysis using this method. Additionally, fecundity estimates for a random subsample of 11 ovaries that contained both hydrated oocytes and early stage POFs were also carried out.

Fecundity was estimated using the gravimetric method (Hunter \& Macewicz 1985). A c. $1 \mathrm{~g}$ section from the right ovary was removed, blotted dry and weighed to the nearest $0.001 \mathrm{~g}$. The section was then teased apart under running water over a $250 \mu \mathrm{m}$ mesh sieve to separate all developing oocytes. The oocytes were transferred to a Bogorov tray and the hydrated oocytes were counted under a dissecting microscope using dark-field light. Hydrated oocytes were easily identified by their comparatively large size, translucent ooplasm and presence of a large yolk sac (Figure 2.5). Batch fecundity was calculated as:

$$
F=F_{S} \times\left(W_{O} / W_{S}\right)
$$

Where $F=$ batch fecundity;

$$
\begin{aligned}
& F_{S}=\text { the number of hydrated oocytes in the ovary section; } \\
& W_{O}=\text { the blotted weight of the ovaries; } \\
& W_{S}=\text { the blotted ovary section weight. }
\end{aligned}
$$

Spawning fraction was calculated by dividing the number of females with early stage POFs by the total number of mature females. The spawning fraction is the daily proportion of mature females that had spawned that day; recent spawning is indicated by early stage POFs. The spawning fraction was then inverted to give an estimate of spawning frequency (Wilson \& Nieland 1994). An estimate of annual fecundity was then calculated as:

$$
A f=\left(\frac{l s}{s f}\right) \times f b
$$

Where $\quad A f=$ the annual fecundity;

$l s=$ the length of the spawning season (days);

$s f=$ the spawning frequency; and

$f b=$ the batch fecundity. 


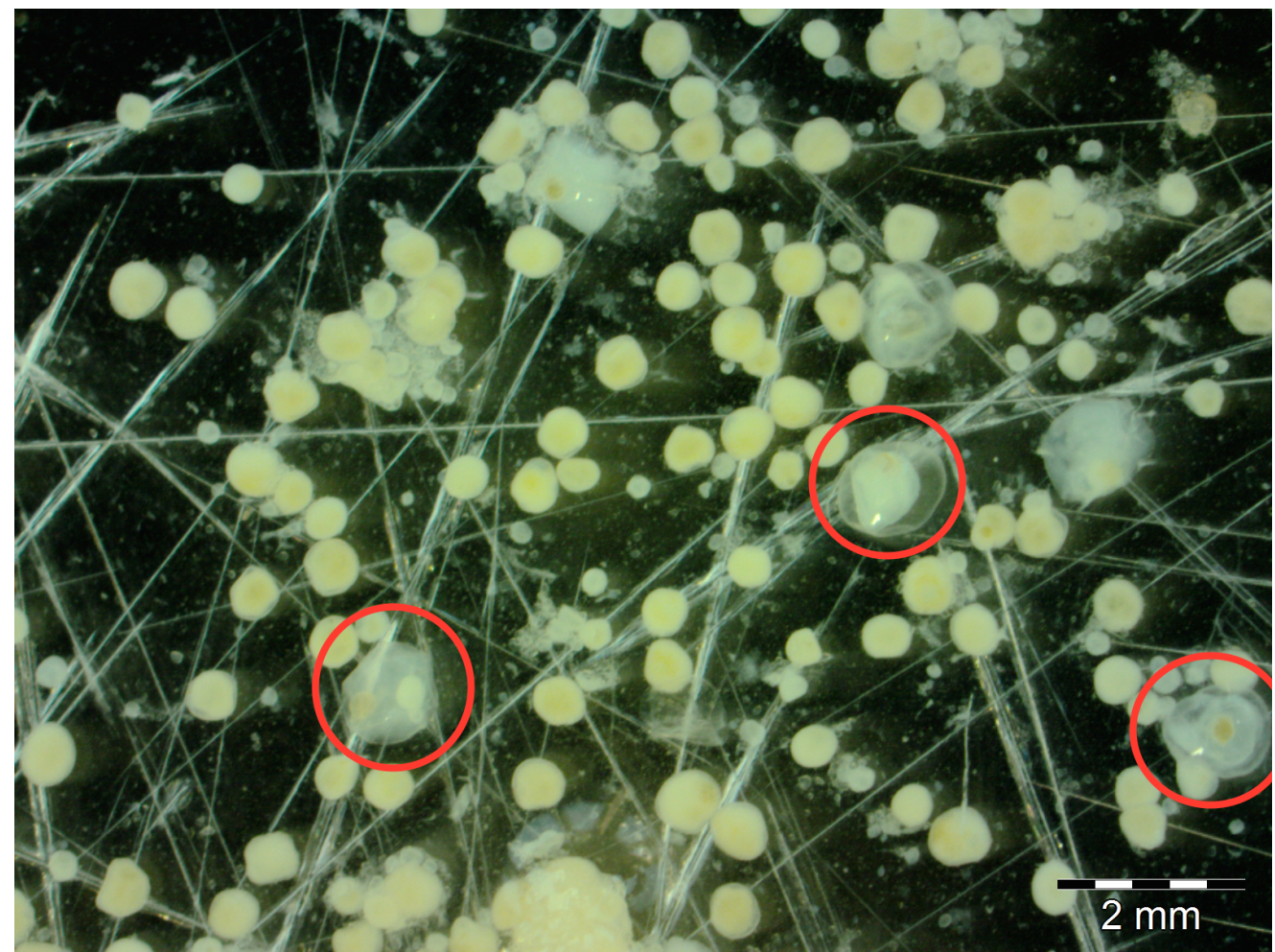

Figure 2.5

A photomicrograph of developing blue cod oocytes. Hydrated oocytes are outlined by red circles and were distinguished by their larger size, translucent ooplasm and presence of a large yolk sac.

Photomicrographs of all samples used in the fecundity analysis were taken. Image analysis software was then used to measure the diameter of the three randomly selected hydrated oocytes from each sample. The mean of the diameters was then taken as the average hydrated oocyte diameter for each individual.

Evidence for hermaphroditism was investigated using the histological sections of blue cod gonads. Evidence for protogynous hermaphroditism in testicular structure can be identified as remnant oocytes and follicles or a testis structure resembling ovarian lamellae or still containing the ovarian lumen (Sadovy \& Shapiro 1987; Siau 1994). Further, sex-changing individuals are recognised by the presence of both ovarian and testicular tissue within the same gonad. It has been noted that in bluehead wrasse (Thalassoma bifasciatum) (another diandric protogynous hermaphrodite), primary males and secondary males differ in gonadal structure. Namely, the presence of a large central cavity in the gonads of secondary males that is not present in primary males (Shapiro \& Rasotto 1993). All samples were examined for these features. 


\section{Results}

\section{Maturity Classification}

Histology showed that $3 \%$ of the fish were assigned to the incorrect sex when staged macroscopically during the survey. Overall agreement between histological and macroscopic classification was $20 \%$. Male agreement was $22 \%$ and female agreement was $19 \%$. Table 2.3 summarises the differences in maturity classification between macroscopic and histological examination of blue cod gonads. After histological examination, the subsample was revealed to contain 125 females, 126 males, and one transitional blue cod. Gonads that were unable to be macroscopically staged were most commonly immature/resting or developing male gonads, although one gonad that was unable to be macroscopically staged was histologically hermaphroditic. Ten males determined histologically to be developing were macroscopically classified as immature/resting, and 31 males that were staged macroscopically as spent were staged histologically as either mature or ripe/running. Females across all histological stages were often macroscopically staged as spent.

Histologically, the proportion of males that were staged as mature and ripe/running generally increased with length (Figure 2.6), and spent males were most common between $26-40 \mathrm{~cm}$ (TL), above which they were not observed. Proportions of immature/resting and developing male gonads decreased with length (Figure 2.6). In females, the histological stages immature/resting and developing were most common below $24 \mathrm{~cm}$ (TL), and mature, ripe/running and spent stages were most common above $24 \mathrm{~cm}$ (TL) (Figure 2.6). There was no obvious pattern in developing atretic (2a) staged gonads in females; they were present in females between 17 and $34 \mathrm{~cm}(\mathrm{TL})$.

In the sample of blue cod gonads macroscopically staged in the survey $(n=3247)$, males were most commonly staged as spent throughout the entire size range (Figure 2.7). In the mid size range $(30-40 \mathrm{~cm}, \mathrm{TL})$, the proportion of immature and maturing male stages decreased. Female blue cod had a high proportion of macroscopically staged spent gonads across all lengths (Figure 2.7). The proportion of females staged as immature and maturing decreased with length and the proportion of mature and ripe/running females increased with length. 


\section{Table 2.3}

Macroscopic maturity classifications compared with histological maturity classification in blue cod. Bold type indicates agreement between histological and macroscopic maturity assessment. In this table individuals that were macroscopically staged as immature or resting are pooled in immature. $\mathrm{M}_{\mathrm{I}}=$ Immature/Resting Male, $\mathrm{M}_{\mathrm{D}}=$ Developing Male, $\mathrm{M}_{\mathrm{M}}=$ Mature Male, $\mathrm{M}_{\mathrm{S}}=$ Spent Male, $\mathrm{F}_{\mathrm{I}}=$ Immature Female, $F_{D}=$ Developing Female, $F_{A}=$ Developing Atretic Female, $F_{M}=$ Mature Female, $F_{R}=$ Ripe/Running Female, $F_{P S}=$ Post Spawning Female, $F_{S}=$ Spent Female, $T=$ Transitional, $U$ = Unknown, $\mathrm{P}_{\text {Agree }}$ is the proportion of agreement between macroscopic and microscopic methods at each maturity stage.

Histological

\begin{tabular}{|c|c|c|c|c|c|c|c|c|c|c|c|c|c|c|}
\hline & & $\mathrm{M}_{\mathrm{I}}$ & $\mathrm{M}_{\mathrm{D}}$ & $\mathrm{M}_{\mathrm{M}}$ & $\mathrm{M}_{\mathrm{R}}$ & $\mathrm{M}_{\mathrm{S}}$ & $\mathrm{F}_{\mathrm{I}}$ & $F_{D}$ & $\mathrm{~F}_{\mathrm{A}}$ & $F_{M}$ & $\mathrm{~F}_{\mathrm{R}}$ & $\mathrm{F}_{\mathrm{PS}}$ & $\mathrm{T}$ & $\mathrm{P}_{\text {Agree }}$ \\
\hline \multirow[t]{11}{*}{ Macroscopic } & $\mathrm{M}_{\mathrm{I}}$ & 7 & 10 & 3 & 1 & 7 & & & & & & & & 0.25 \\
\hline & $\mathrm{M}_{\mathrm{D}}$ & 3 & 2 & 7 & 12 & & & & & & & & & 0.08 \\
\hline & $\mathrm{M}_{\mathrm{M}}$ & & & 1 & 9 & & & & & & 1 & & & 0.09 \\
\hline & $\mathrm{M}_{\mathrm{R}}$ & & & 3 & 10 & & & & & & 1 & & & 0.71 \\
\hline & $\mathrm{M}_{\mathrm{S}}$ & 1 & 2 & 14 & 17 & 6 & & & & & 3 & & & 0.14 \\
\hline & $\mathrm{F}_{\mathrm{I}}$ & 1 & 1 & & & & & & & & & & & 0.00 \\
\hline & $\mathrm{F}_{\mathrm{D}}$ & & & & & & 1 & 2 & 1 & & & 1 & & 0.40 \\
\hline & $\mathrm{F}_{\mathrm{M}}$ & & & & & & 1 & 1 & & 6 & 9 & 12 & & 0.20 \\
\hline & $\mathrm{F}_{\mathrm{R}}$ & & & & & & & & & 1 & 3 & & & 0.75 \\
\hline & $\mathrm{F}_{\mathrm{S}}$ & & 1 & & & & 13 & 1 & 22 & 15 & 19 & 13 & & 0.15 \\
\hline & $\mathrm{U}$ & 3 & 4 & & & 1 & & & & & & & 1 & 0.00 \\
\hline
\end{tabular}




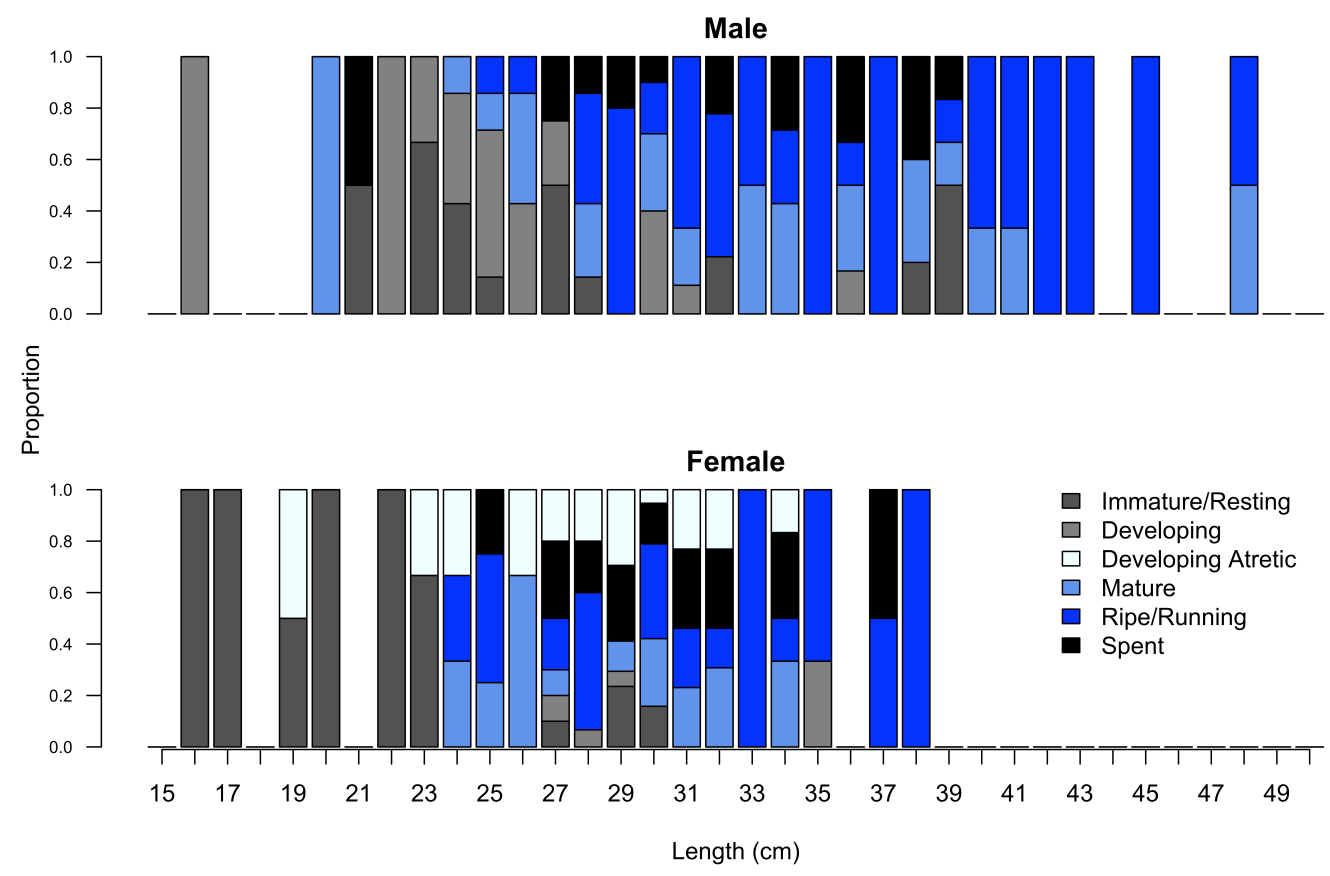

Figure 2.6

The proportions of histologically staged maturity at length for male (top) and female (bottom) blue cod.

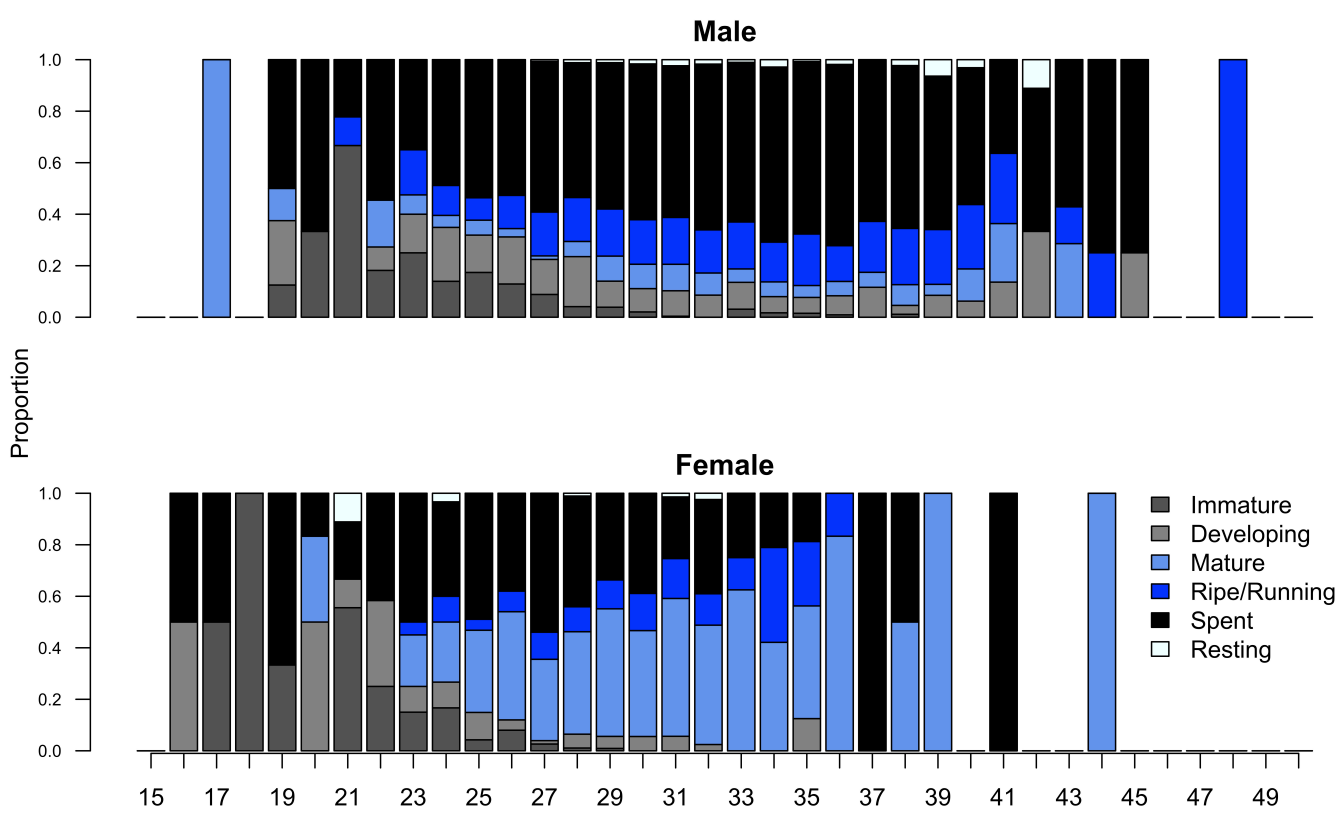

Figure 2.7

Proportions of macroscopically staged gonads at length for male (top) and female (bottom) blue cod from the entire sample. 


\section{Length-at-Maturity}

There was a marked difference in maturity ogives and associated $\mathrm{L}_{50}$ estimates between macroscopic and histologically determined models (Figures 2.8 and 2.9). When comparing between histological and macroscopic data from the same set of gonads (the histological subsample), female $\mathrm{L}_{50}$ was underestimated by $c .18 \mathrm{~cm}$ when macroscopic data were used, and male $\mathrm{L}_{50}$ was overestimated by c. $5 \mathrm{~cm}$ when macroscopic data were used (Tables 2.4 and 2.5). When comparing the histological data and the macroscopic data for the entire sample, male $\mathrm{L}_{50}$ estimates were underestimated by $c .18 \mathrm{~cm}$ when macroscopic data were used, and female $\mathrm{L}_{50}$ estimates were underestimated by $c .6 \mathrm{~cm}$ when macroscopic data were used (Tables 2.4 and 2.6). Maturity ogives and model fits for each model technique and dataset are illustrated in Appendix I.

Male $\mathrm{L}_{50}$ was $c .26 \mathrm{~cm}$ from histological data $(\mathrm{n}=119)$ (Table 2.4). There was no major difference in male $\mathrm{L}_{50}$ when estimated from the GLM or the least-squares logistic model (Table 2.4). Female $\mathrm{L}_{50}$ was estimated at $c .26 \mathrm{~cm}$ when histological data were used $(\mathrm{n}=124)$. Female $\mathrm{L}_{50}$ differed by $c .1 \mathrm{~cm}$ between the GLM and least-squares logistic models when histologically estimated maturity was used. When female proportion mature was modelled with a capped logistic model, the $\mathrm{L}_{50}$ was estimated as $23.6 \mathrm{~cm}$, and the model estimate for the Cap indicated that the proportion of females that were mature reached an asymptote at 0.78 . The capped logistic model for female maturity had an $\mathrm{L}_{\text {to9s }}$ parameter estimate of 0.01 that corresponded to knife-edged maturity. The three-parameter capped logistic model was better fitted to the female histological maturity data than the two-parameter logistic model, with AIC values of -14.20 and -1.785 , respectively.

\section{Table 2.4}

Estimates of $\mathrm{L}_{50}, \mathrm{~L}_{\mathrm{t} 095}$, Cap and AIC values for histological maturity ogives using different modelling approaches. The top table summarises male maturity ogives and the bottom females. These estimates are calculated from the histological subsample $(n=252)$.

\begin{tabular}{|lrrrr|}
\hline Histological models & $\mathbf{L}_{\mathbf{5 0}}(\mathbf{c m})$ & $\mathbf{L}_{\mathbf{t 0 9 5}}(\mathbf{c m})$ & $\mathbf{C a p}$ & AIC \\
Female binomial GLM & 26.5 & 10.3 & - & - \\
Female logistic least-squares & 25.6 & 8.5 & - & -1.8 \\
Female capped logistic least-squares & 23.6 & 0.01 & 0.78 & -14.2 \\
Male binomial GLM & 25.9 & 14.1 & - & - \\
Male logistic least-squares & 26.0 & 11.6 & - & - \\
\hline
\end{tabular}


Macroscopic maturity model parameters $\mathrm{L}_{50}$ and $\mathrm{L}_{\text {t095 }}$ from the histology subsample are shown in Table 2.5. Male $\mathrm{L}_{50}$ was estimated at $c .31 \mathrm{~cm}$ when macroscopic data were used. As with histological maturity estimates, there was no major difference in $\mathrm{L}_{50}$ between the two models used. Female $\mathrm{L}_{50}$ was estimated at $5.8 \mathrm{~cm}$ (binomial GLM) and 8.5 (logistic least-squares) when macroscopic data were used (Table 2.5). $\mathrm{L}_{\text {to95 }}$ parameters for all macroscopic models using the subsample data were high, indicating very shallow curves. The observation of macroscopic Stage 5 fish across a wide range of length bins in the entire sample suggested Stage 5 might have been poorly determined, or used as a default stage when macroscopic staging was uncertain. To evaluate the sensitivity of the $\mathrm{L}_{50}$ estimates to the use of this stage, the analyses were repeated after excluding all Stage 5 fish. With Stage 5 removed from the macroscopic data, the $\mathrm{L}_{50}$ estimates were $27.7 \mathrm{~cm}$ and $24.2 \mathrm{~cm}$ for males and females, respecitvely (Table 2.6). It is apparent from the propotion mature at length plots, and associated maturity ogives illustrated in Appendix 1, that estimates of $\mathrm{L}_{50}$ that are below $16 \mathrm{~cm}$ are extrapolations from observations of larger fish. These estimates are therefore best interpreted as being $<16 \mathrm{~cm}$.

Table 2.5

Model estimates for $\mathrm{L}_{50}$, and $\mathrm{L}_{\mathrm{t} 095}$ of macroscopically estimated maturity ogives for blue cod. These estimates are calculated from the histological subsample $(n=252)$. Both logistic least squares and GLM estimates are reported.

\begin{tabular}{|lcr|}
\hline Macroscopic models & $\mathbf{L}_{\mathbf{5 0}}(\mathbf{c m})$ & $\mathbf{L}_{\mathbf{t 0 9 5}}(\mathbf{c m})$ \\
Female binomial GLM & 5.8 & 29.2 \\
Female logistic least-squares & 8.5 & 24.6 \\
Male binomial GLM & 31.1 & 21.9 \\
Male logistic least-squares & 30.7 & 22.99 \\
\hline
\end{tabular}


Table 2.6

Sensitivities and model estimates for $\mathrm{L}_{50}$, and $\mathrm{L}_{\text {to95 }}$ of macroscopically estimated maturity ogives for blue cod. These estimates are calculated from the larger sample $(n=3247)$. Both logistic least squares and GLM estimates are reported.

\section{Macroscopic sensitivities}

Male logistic least-squares (larger sample)

Female logistic least-squares (larger sample)

Male binomial GLM (larger sample)

Female binomial GLM (larger sample)

Male binomial GLM (Stage 5 removed)

\section{$\mathbf{L}_{50}(\mathbf{c m}) \quad \mathbf{L}_{\mathrm{t} 095}(\mathbf{c m})$}

7.9

48.4

20.3

12.0

8.0

49.0

20.1

12.5

27.7

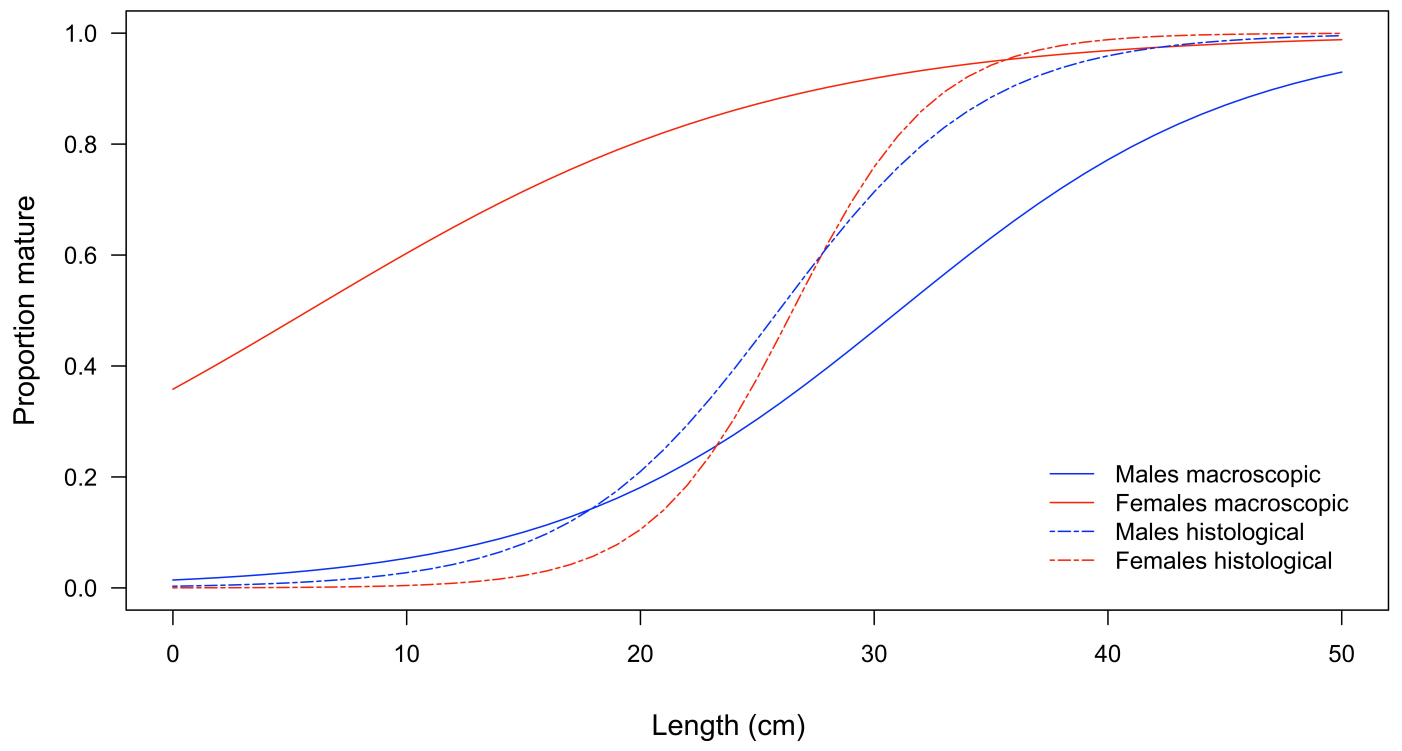

Figure 2.8

Comparison of maturity ogives between macroscopic (histology subsample) and histologically staged gonads. Ogives were derived from generalised linear models with binomial family and logit link. 


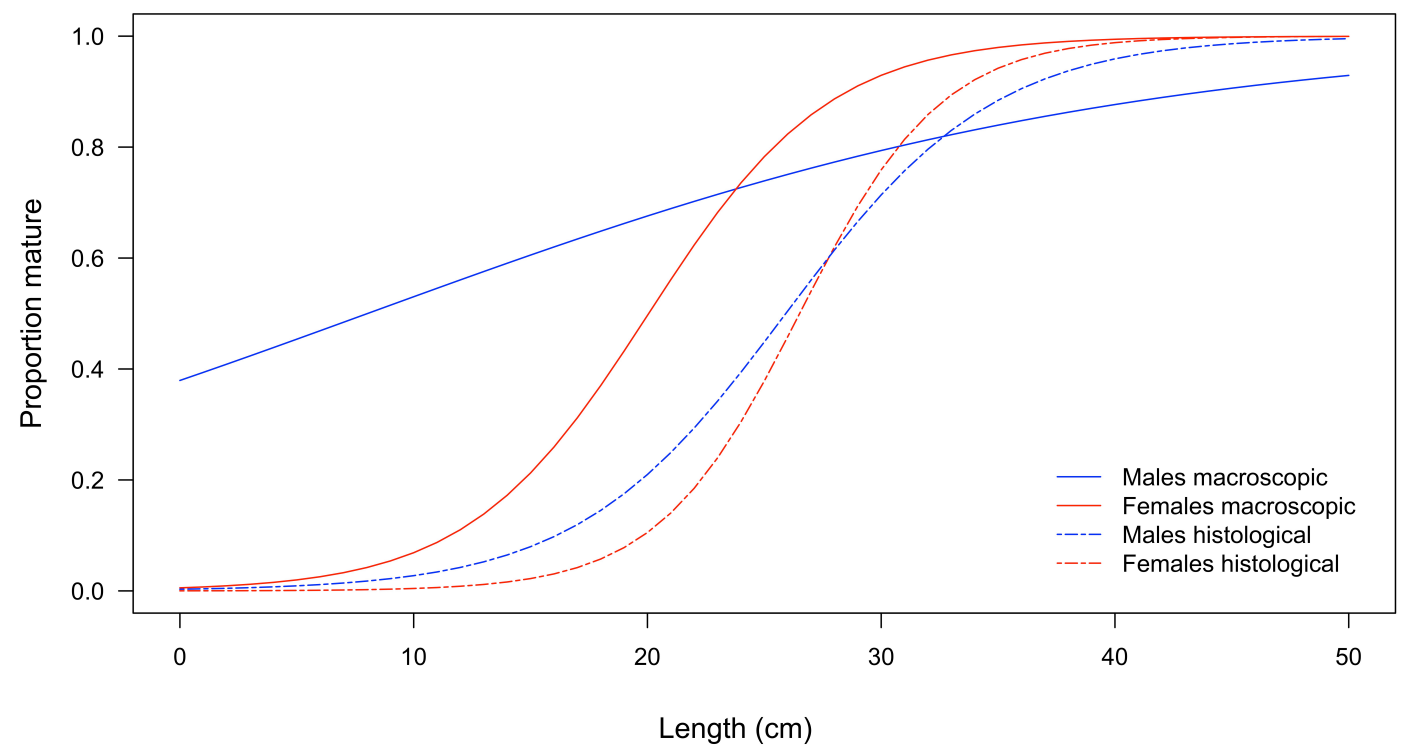

Figure 2.9

Comparison of ogives between macroscopically staged (larger sample) and histologically staged gonads. Ogives were derived from generalised linear models with binomial family and logit link.

\section{Gonadosomatic Index}

Analysis of variance (ANOVA) revealed that female GSI values were significantly higher in the mature class (Stages 3, 4, and 5) than the immature class (Stages 1, 2, and 2a) $\left(\mathrm{F}_{4,108}=4.305, \mathrm{p}<\right.$ 0.001) (Figure 2.10A). Mean GSI values for mature and ripe/running females (Stages 3 and 4) were $2.4 \%(\mathrm{SD}=0.28)$ and $2.7 \%(\mathrm{SD}=0.25)$, respectively. Spent female (Stage 5) GSI decreased slightly to $2.1 \%$ ( $\mathrm{SD}=0.28$ ). Mean GSI values for all "immature" stages were < $0.5 \%$. Male GSI values were greater in the mature and ripe/running stages (Stages 3 and 4) than the immature and spent stages (Figure 2.10B). Stage 4 males had a significantly greater mean GSI value than all other stages combined $\left(\mathrm{F}_{5,116}=33.92, \mathrm{p}<0.01\right)$. 
Chapter II | Blue Cod Maturity, Fecundity, and Sex Change
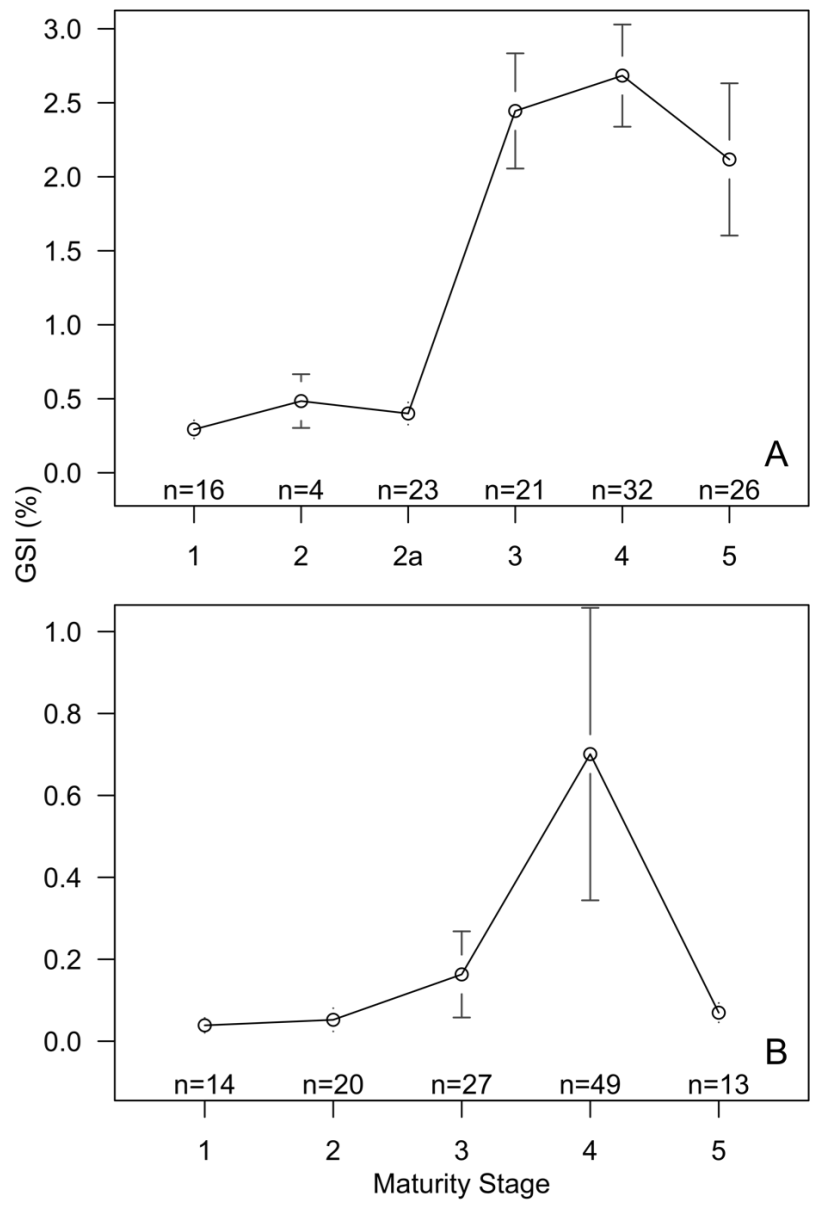

Figure 2.10

Gonadosomatic index (GSI) values with $95 \%$ confidence intervals for histologically determined maturity stages of (A) female and (B) male blue cod. 


\section{Fecundity}

Nine fish were sampled for fecundity. The average relative batch fecundity was 6.5 ( $\mathrm{SD}=3.3$ ) $\mathrm{HO} \mathrm{g}^{-1}$ body weight. The average batch fecundity for a female between 25 and $38 \mathrm{~cm}$ was 2650 ( $\mathrm{SD}=916)$ HO. No relationship between fish size, or fish weight, and batch fecundity was revealed. Figure 2.11 illustrates the relationship between fish length and batch fecundity, gonadfree weight and batch fecundity, and length and relative fecundity $\left(\mathrm{HO} \mathrm{g}^{-1}\right.$ gonad-free body weight). There was a significant negative relationship between relative fecundity and length (Adjusted R-squared: $0.6147, \mathrm{~F}_{1,8}=15.36, \mathrm{p}<0.01$ ) and weight (Adjusted R-squared: 0.6914 $\left.\mathrm{F}_{1,8}=21.16, \mathrm{p}<0.01\right)$. Relative fecundity decreased with fish size and weight. The most fecund individual was the heaviest and longest female.

It was observed that in histological sections of spawning females, ovaries containing POFs also contained many $\mathrm{HO}$; this observation further prompted the analysis of fecundity in females containing POFs. Mean batch fecundity of ripe/running females without POFs was $2690 \mathrm{HO}$ $(\mathrm{SD}=1013)$ and ranged from 1060 to 4329 eggs. Mean batch fecundity in ripe/running females with POFs was $2360 \mathrm{HO}(\mathrm{SD}=1882)$ and ranged from 262 to $6445 \mathrm{HO}$. There was no significant difference in the mean number of $\mathrm{HO}$ between females with and without POFs $\left(\mathrm{t}_{15}=\right.$ $0.176, \mathrm{p}=0.862$ ). When data were combined, the overall mean fecundity was $2445 \mathrm{HO}$ per female, and the fecundity frequency distribution was unimodal centred on the mean (Figure 2.12). Batch fecundity by length relationships did not indicate any trend in fecundity for fish length for females with or without POFs (Figure 2.13). 

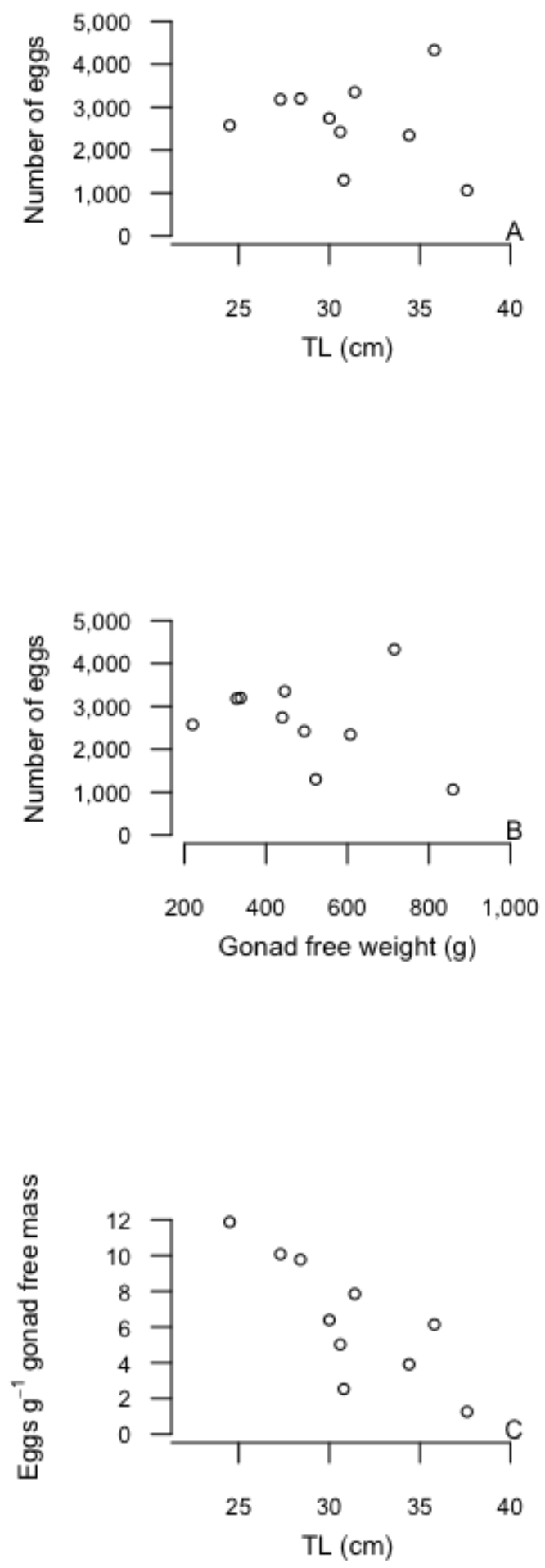

Figure 2.11

Relationships between (A) blue cod length $(\mathrm{cm})$ and batch fecundity (total number of hydrated oocytes in females not containing POFs) (no significant relationship: $F_{1,19}=0.0045, p=0.947$ ); (B) gonad free mass (g) and batch fecundity (no significant relationship: $F_{1,19}=0.6824 \mathrm{p}=0.419$ ); and $(\mathrm{C})$ length $(\mathrm{cm})$ and relative batch fecundity (hydrated oocytes $\mathrm{g}^{-1}$ gonad free mass) (significant negative relationship: $\mathrm{F}_{1,19}=$ $4.641, \mathrm{p}=0.044)$. 


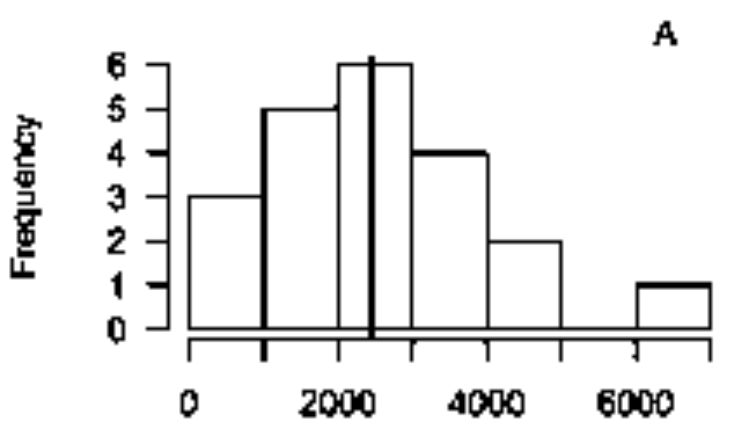

Number of egps - POFs \& no POFs
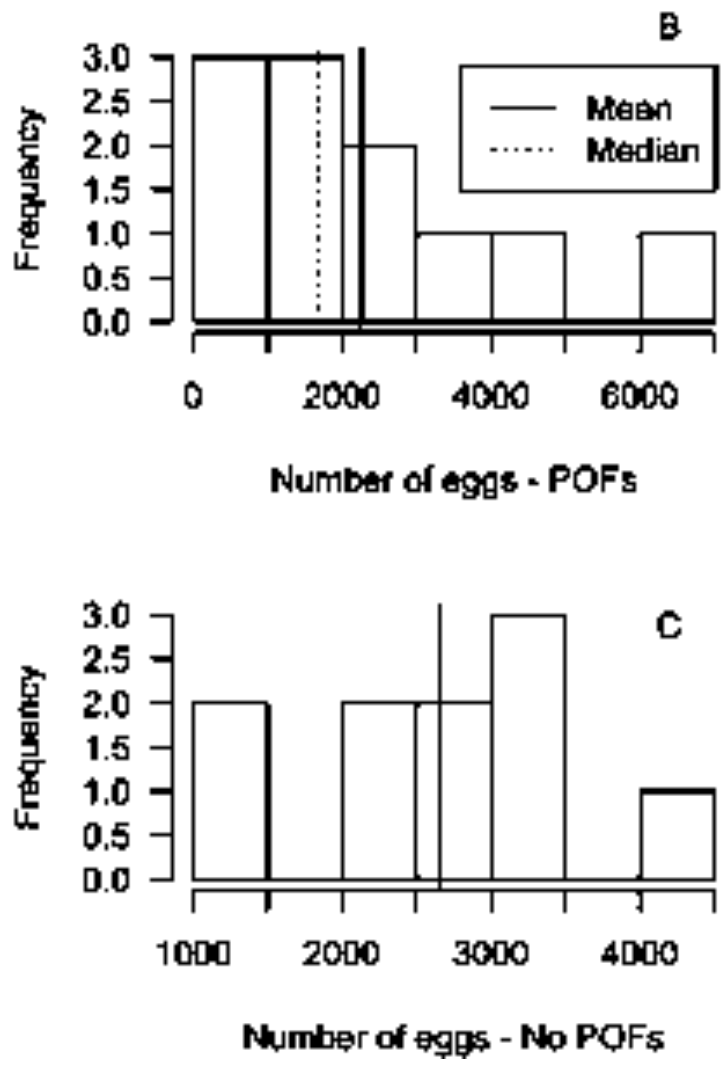

Figure 2.12

The frequency distribution of batch fecundity counts in (A) females with POFs and without POFs combined, (B) females with POFs, and (C) females without POFs. Solid vertical lines indicate the mean number of hydrated oocytes per female, and dotted vertical lines indicate the median hydrated oocyte values. 


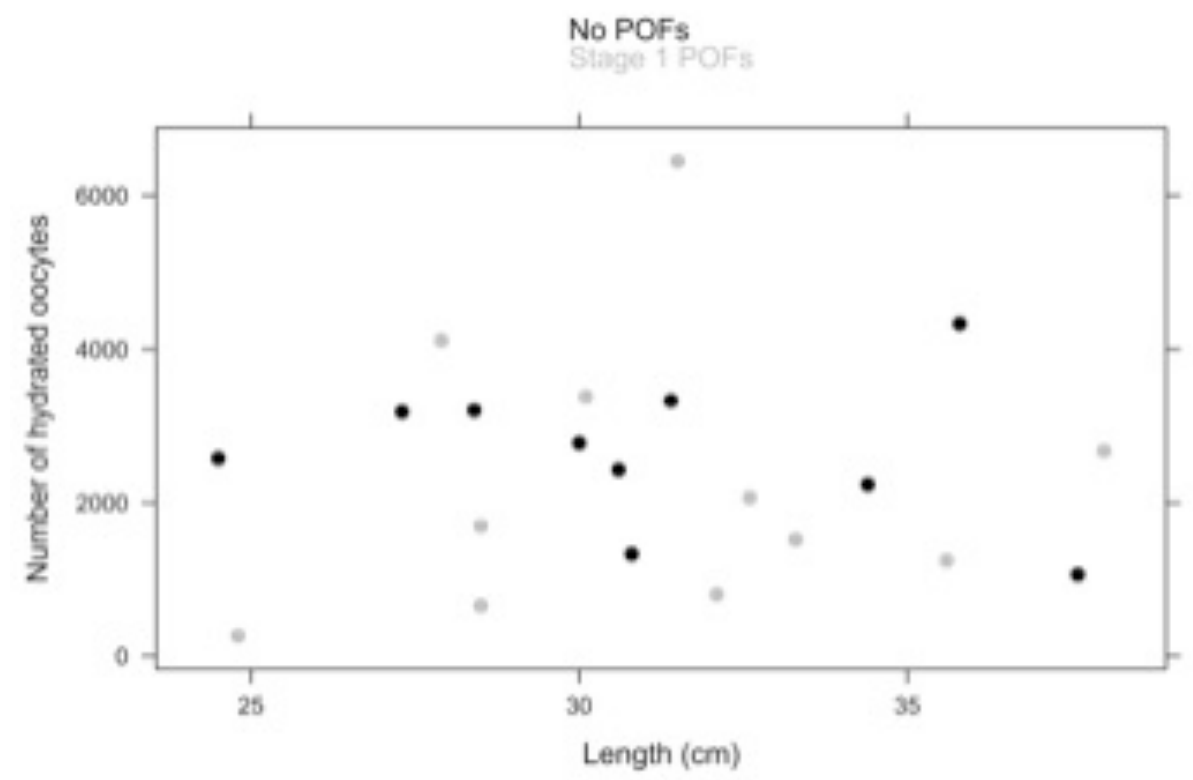

Figure 2.13

Relationship between fish length ( $\mathrm{x}$ - axis) and batch fecundity ( $\mathrm{y}$ - axis) in female blue cod. Black dots are ripe/running females without POFs; grey dots are ripe/running females with POFs. The presence of POFs indicated that some ovulation of eggs has occurred.

Due to the number of females with stage 1 POFs $(n=49)$, it was not possible to get an accurate estimate of spawning frequency over a number of days. The only day of the survey that had a large sample size was day 5, where 27 mature and ripe/running females were included in the histological sample (Table 2.7). Of these females, $29.6 \%$ had stage 1 POFs, corresponding to a spawning frequency of 4.6 days. The analysis indicated that fish between 25 and $30 \mathrm{~cm}$ (TL) spawned every three days, whereas, fish over $30 \mathrm{~cm}$ (TL) spawned every four days (Table 2.8). With the combined spawning frequency, average overall batch fecundity and the estimated spawning season of seven months (From early June to late November; 182 days) (Rapson 1956) are used, and assuming that spawning frequency and batch fecundity are constant over the spawning season, the average annual fecundity of a blue cod between 25 to $38 \mathrm{~cm}$ (TL) was $104,848 \mathrm{HO}$. 
Table 2.7

Spawning frequency, spawning fraction, day of the survey (from 26/09/13) and sample size of mature and ripe/running blue cod.

\begin{tabular}{|cccc|}
\hline Day & $\begin{array}{c}\text { Spawning } \\
\text { Fraction }\end{array}$ & $\begin{array}{c}\text { Spawning } \\
\text { Frequency }\end{array}$ & Sample Size \\
16 & 0.75 & 1.3 & 4 \\
15 & 1.00 & 1.0 & 1 \\
13 & 1.00 & 1.0 & 4 \\
12 & 1.00 & 1.0 & 1 \\
9 & 0.71 & 1.4 & 6 \\
5 & 0.30 & 4.6 & 27 \\
6 & 1.00 & 1.0 & 4 \\
2 & 1.00 & 1.0 & 2 \\
\hline
\end{tabular}

Table 2.8

Spawning fraction and spawning frequency by length for fish caught on day five $(n=27)$.

\begin{tabular}{|lrr|}
\hline \multicolumn{1}{|c}{$\begin{array}{c}\text { Fish Length } \\
(\mathbf{c m}, \text { TL) }\end{array}$} & $\begin{array}{c}\text { Spawning } \\
\text { Fraction }\end{array}$ & $\begin{array}{c}\text { Spawning } \\
\text { (days) }\end{array}$ \\
$25-30$ & 0.33 & 3.0 \\
$30+$ & 0.25 & 4.0 \\
Combined & 0.30 & 3.4 \\
\hline
\end{tabular}


In the sample of blue cod eggs measured (Stage 4 females without POFs), there was no significant relationship between fish length and egg size $\left(F_{1,7}=0.3682\right.$, Adjusted $\mathrm{R}$-squared $=$ $0.08575, \mathrm{p}=0.5632$, Figure $2.14 \mathrm{~A})$ or fish weight and egg size $\left(\mathrm{F}_{1,7}=0.3682\right.$, Adjusted $\mathrm{R}$ squared $=-0.08575, \mathrm{p}=0.5631$, Figure 2.14B).
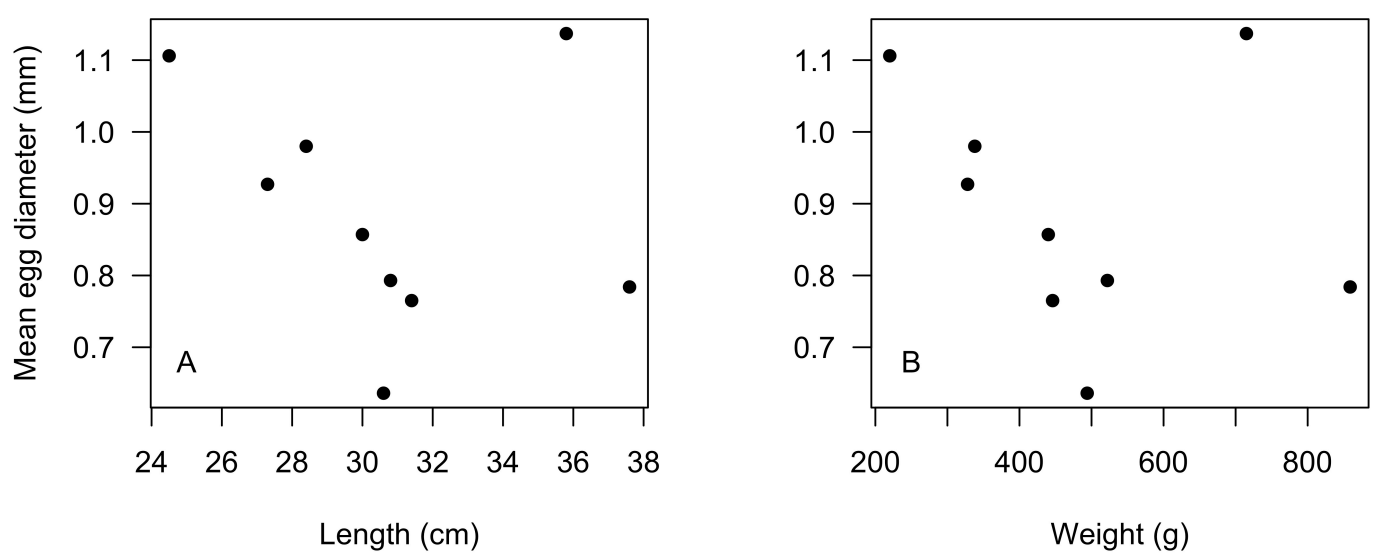

Figure 2.14

Relationships between egg diameter and fish length (A) and weight (B) of pre-spawning ripe/running blue cod (with hydrated oocytes and without POFs).

\section{Hermaphroditism}

Histology demonstrated that blue cod are a protogynous hermaphroditic species; testicular tissue is present in one lobe and ovarian tissue in the other (Figure 2.15). The ovarian lobe contained atretic vitellogenic oocytes. Early vitellogenic oocytes (no migratory nucleus) were the most advanced stage of oocyte development. The presence of atretic oocytes in the ovarian lobe suggested that it was regressing. The testicular tissue resembled that of a developing male. It is unclear if this individual could have spawned in that year's spawning season because the duration of the sex change process in not known. The sex changing individual was $31.2 \mathrm{~cm}$ and weighed $475 \mathrm{~g}$. Macroscopic inspection of the transitional gonad revealed that this stage of transition can be determined by the naked eye (Figure 2.16). The transitional individual was captured near Port Underwood, at the southern end of the Cook Strait. 


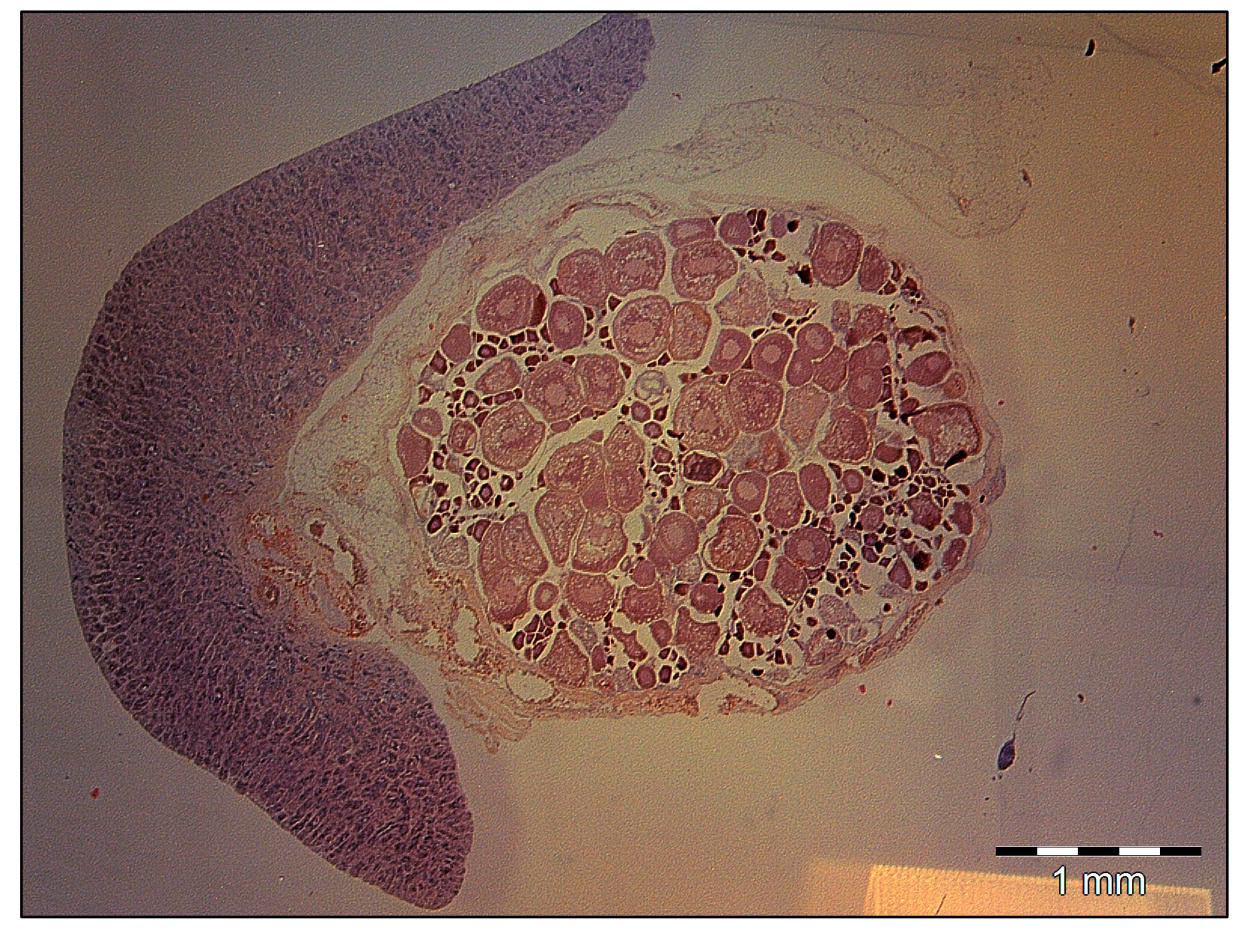

Figure 2.15

Histological section of a hermaphroditic blue cod gonad. The testis lobe (Stage 2) is on the left and the ovarian lobe (Stage 2a) is on the right.

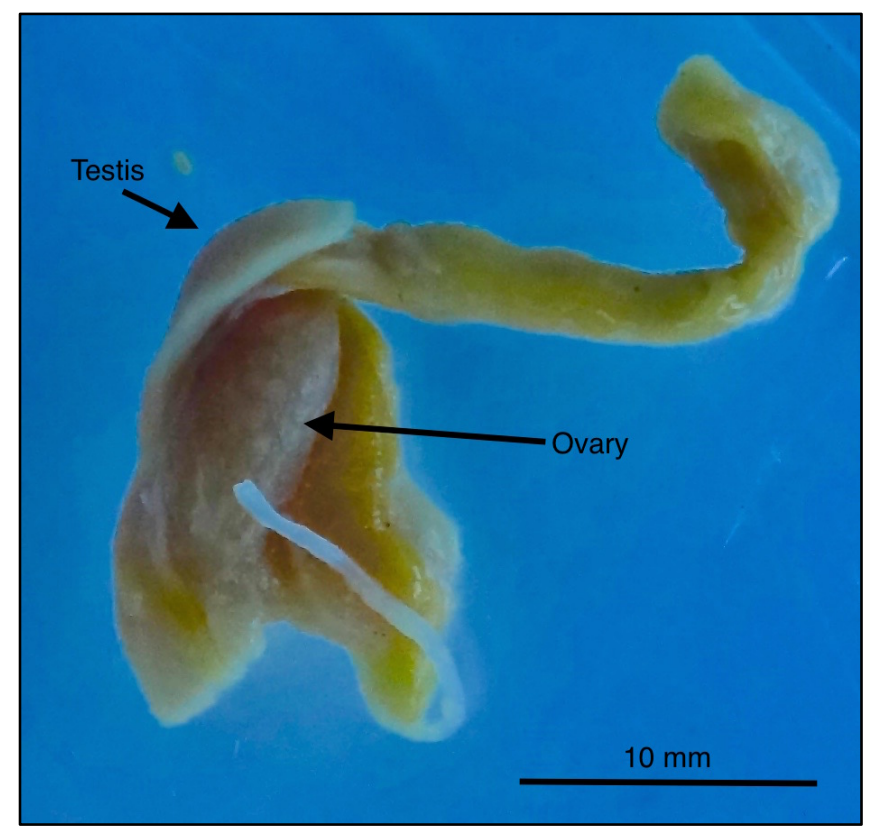

Figure 2.16

A transitional blue cod gonad with macroscopically identifiable testis and ovary. 
Chapter II | Blue Cod Maturity, Fecundity, and Sex Change

Other individuals were found that were functionally male but contained what appeared to be primary oocytes in the chromatin-nucleolus and perinucleolus stage (Figure 2.17). These were assumed to be a product of contamination between samples because the developmental stage of the testes they were found in, along with the location they were found, was not consistent with ovarian development. Possible means of contamination are considered in the Discussion.

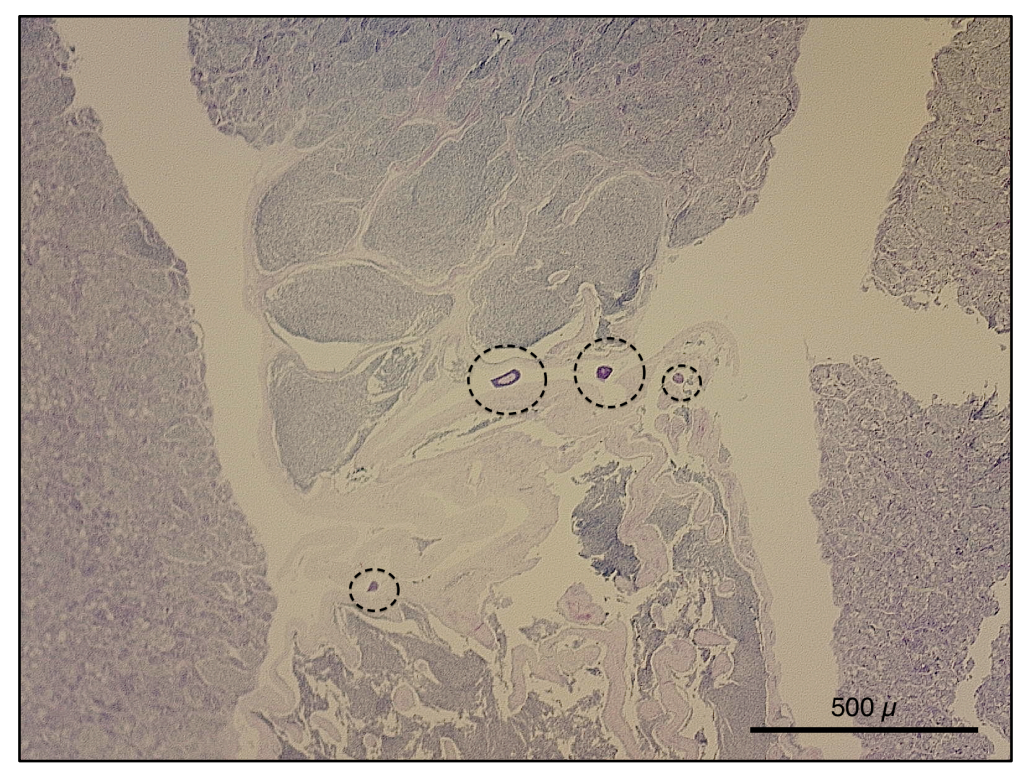

Figure 2.17

Primary oocytes in the chromatin-nucleolus and perinucleolus stage found within the sperm duct of a ripe/running testis 
CHAPTER III

POTENTIAL DRIVERS OF BLUE COD SEX RATIO IN THE MARLBOROUGH SOUNDS 


\section{Introduction}

In this chapter, the data from the 2013 Marlborough Sounds blue cod potting survey were used to test three hypotheses concerning sex ratio: (1) sex ratios are environmentally influenced; (2) sex ratios are density-dependent; and (3) large males suppress sex change in females. Further, the potential effect of sampling method on sex ratio estimates is explored.

\section{Methods}

Blue cod samples were collected by NIWA from Queen Charlotte and Pelorus Sounds, around D'Urville Island, and the Cook Strait side of the South Island from September to November 2013 (Figure 3.1). Fish were caught with baited cod pots that were set for approximately 60 minutes. Blue cod were weighed, measured from the snout to the tip of the caudal fin (Total Length, TL), sexed, and maturity was staged by macroscopic inspection of the gonad. At each sampling station, latitude, longitude, cloud cover, sea condition, bottom type, bottom contour type, and depth were recorded. There were 561 pots used in the survey, 501 of which were allocated to one of 12 strata, and 60 pots were not allocated to a stratum. Pots not allocated to strata were not used in the stratum level analyses. 


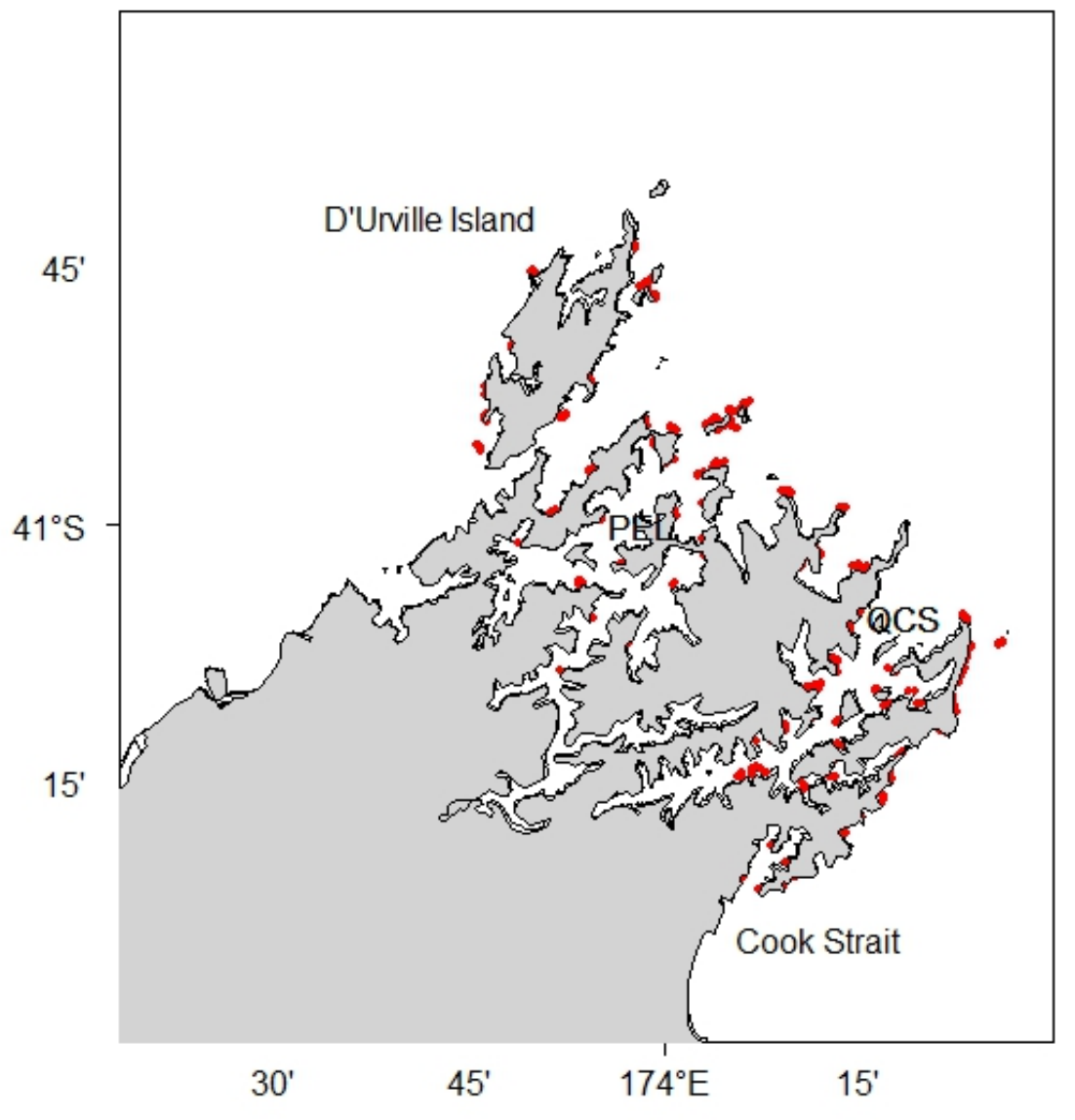

Figure 3.1

Map of the sampling sites (red dots) in the Marlborough Sounds area, including the Cook Strait, Queen Charlotte Sound (QCS), Pelorus Sound (PEL), and D'Urville Island, from the 2013 blue cod survey carried out by NIWA. 
To analyse data at the small-scale $(1-2 \mathrm{~km})$, sampling pots were grouped. The locations of all pots were plotted on a map, and pots that were within $1 \mathrm{~km}$ of each other and that were not separated by a land barrier were grouped. Figure 3.2 illustrates where pots were placed (colourcoded by stratum), with an example of how groups were defined.

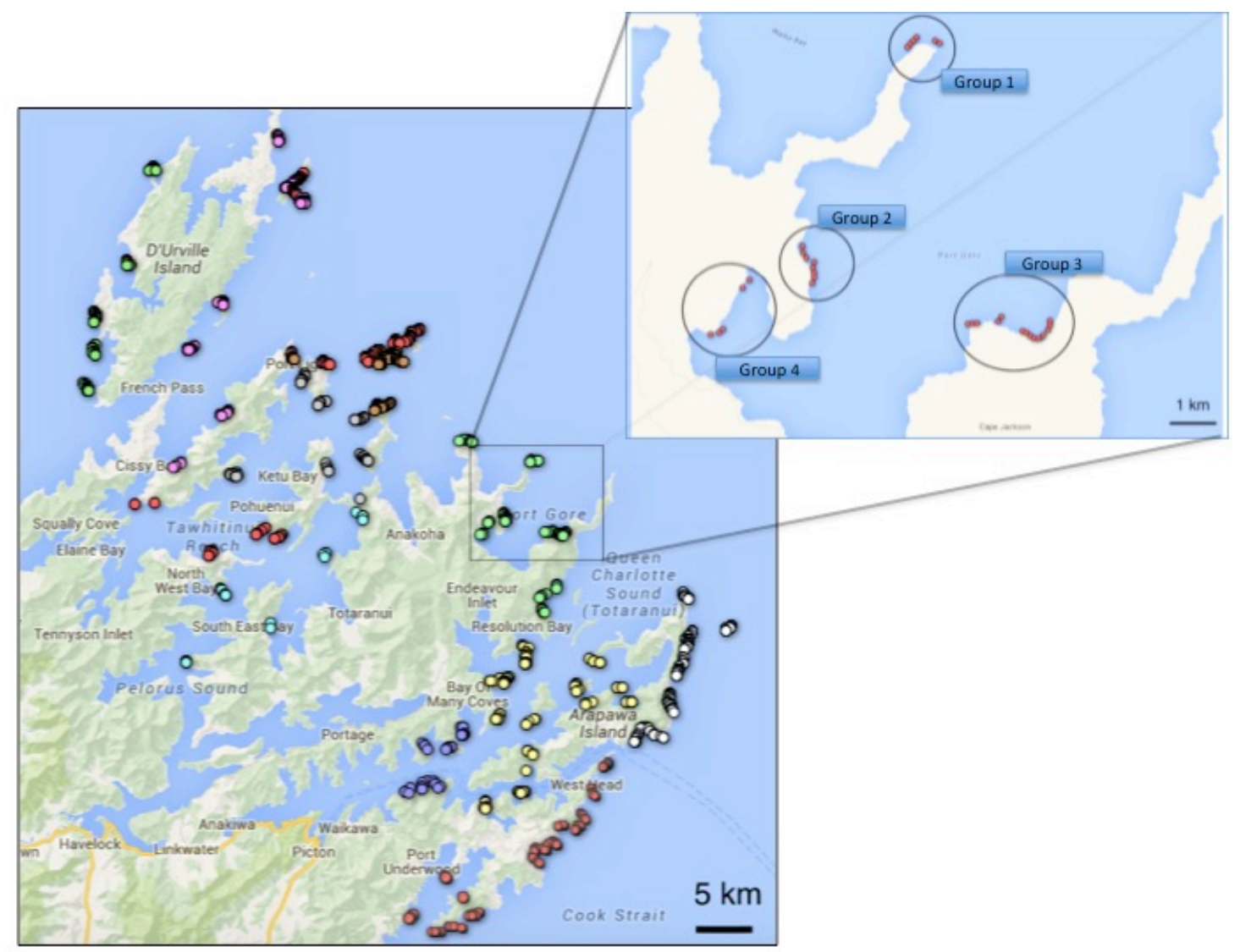

Figure 3.2

Pot sampling sites and groups in the Marlborough Sounds area. Sampling sites are coloured by stratum. Purple: Queen Charlotte Inner, Yellow: Queen Charlotte Outer, Green: Queen Charlotte Extreme Outer, Brown: Pelorus Extreme Outer, Grey: Pelorus Outer, Pink: East D'Urville Island, Teal: Pelorus Inner, Red: Pelorus Middle, Dark Green: D'Urville West, White: Arapawa Island East, Red: Cook Strait, Red: Port Underwood. 
CPUE was used as a measure of blue cod density for pots, groups and strata, and was calculated as:

$$
C P i=N i / T i,
$$

where: $C P i=$ the CPUE for pot $i$,

$N i=$ the number of fish caught in pot $i$, and

$T i=$ the time (in hours) that pot $i$ was submerged.

$$
C G j=N j / T j
$$

where: $C G j=$ the CPUE for group $j$,

$N j=$ the total number of fish caught in group $j$, and

$T j=$ the sum of all the $T i$ in group $\mathrm{j}$.

$$
C S k=N k / T k,
$$

where: $C S k=$ the CPUE for stratum $k$,

$N k=$ the total number of fish caught in stratum $k$, and

$T k=$ the sum of all $T i$ in stratum $k$.

\section{Hypothesis 1: Environmental Influences on Sex Ratio}

A Generalized Linear Model (GLM) was used to investigate the influence of environmental variables on sex ratio. This analysis was possible only at the pot level, because the environmental variables differed between pots within the same group and stratum. Continuous variables were offered as $1^{\text {st }}, 2^{\text {nd }}$ and $3^{\text {rd }}$ order polynomials. The GLM was binomial with a logit link function. Catch per unit effort $(\mathrm{CP})$ was included in the model as a potential predictor to account for density effects. 
A stepwise model selection by Akaike Information Criterion (AIC) was used to determine the best model predictors. This was done in $\mathrm{R}$ with the function stepAICmodified, a modified version of stepAIC from the MASS package. A forward selection process was used, where predictors were included in the final model only if their addition decreased the AIC. To guard against over-fitting when data sets were large (as here), predictor variables were accepted into the final model only if they explained at least $0.5 \%$ of the deviance and their predicted effects were sensible (Vignaux 1993). The starting model was:

$$
\begin{array}{r}
\text { Pmale }=\text { stratum }+ \text { cloud cover }+ \text { number of fish }+ \text { latitude }+ \text { weight } \\
+\log (\text { CPUE })+\text { depth }+ \text { bottom contour type }+ \text { bottom type }+ \text { sea condition }
\end{array}
$$

where: $\quad$ Pmale $=$ the proportion of male blue cod in the pot,

stratum $=$ the stratum where the pot was located (factor),

cloud cover $=$ a classification for the amount of cloud cover (factor),

number of fish $=$ the number of fish in the pot (continuous),

weight $=$ the total weight of all blue cod in the pot (continuous),

$C P U E=$ the number of fish caught per hour (continuous),

$$
\text { depth }=\text { the pot depth (continuous), }
$$

bottom contour type $=$ a classification for bottom contour type at sampling location (factor), bottom type $=$ a classification for type of substrate at the sampling location (factor), sea condition $=$ a classification for sea condition at the sampling location (factor).

Predicted effects of individual predictor variables were plotted by creating a data frame with all model predictors, except the predictor of interest, set to their median values. The predict function in $\mathrm{R}$ was used to create a vector of predicted values by the GLM model using the new data frame. In this way, predicted values of proportion male, with standard deviations, were plotted to illustrate the individual effect of each predictor variable when all other effects were set to their median value.

\section{Hypothesis 2: Density and Sex Ratio}

The influence of density on sex ratio was investigated at the pot, group, and stratum level. CPUE (CP, CG, or CS) was used as a proxy for density. Scatter plots and linear regression 
analyses were used to investigate any effects of density on sex ratio. Loess curves were added to the pot and group plots to help identify trends in the sex ratio and CP and CG. Loess curves were fitted in $\mathrm{R}$ with $\operatorname{span}=1$. A loess smoother is a method of locally-weighted least squares regression, essentially a moving average of y-values over the $x$-axis, used to help illustrate trends (Cleveland 1979).

\section{Hypothesis 3: Influence of Large Males on Sex Ratio}

The influence of large males on sex ratio at both the group and the pot level was investigated. Linear regression was used to examine how mean male size per pot and per group was related to sex ratio. Further, to investigate the effect that large males had on sex ratio, pots and groups were categorised according to the length of the largest male in each pot or group. The size categories were where the largest male was: (1) less than $29 \mathrm{~cm}$, (2) $30-34 \mathrm{~cm}$, (3) $35-39 \mathrm{~cm}$, (4) 40-44 cm, or (5) 45-48 cm. Sex ratios of all categories were compared using a non-parametric Kruskal-Wallis test (McKight \& Najab 2010). Post-hoc non-parametric rank-sum Dunn's tests (Dunn 1964) were used to test for differences in group medians. A non-parametric approach was used because of non-normality in the data, and because there were many outliers, which were determined from box-plots of the data (see results).

\section{Sampling Accuracy}

To investigate the effect of group size (number of pots) on the estimates of sex ratio, three groups with a large number of fish and approximately equal numbers of pots were analysed. The chosen groups were from the north of Forsyth Island (16 pots, 186 fish), south of Puangiangi Island (17 pots, 162 fish), and the north of Rangitoto Island (15 pots, 152 fish). Populations were resampled without replacement 1000 times, and the cumulative proportion male by pot was calculated over increasing sample (pot) sizes, for each resample. Median proportion male was plotted with $95 \%$ credible limits. The $95 \%$ credible limits were the $25^{\text {th }}$ and $975^{\text {th }}$ of the 1000 ordered resamples. The coefficient of variation (CV) for the three groups was plotted against the number of pots in the sample. The CV was used as a measure of relative variability between the groups and was calculated as:

$$
C_{V}=\frac{s}{X}
$$

Where: $C_{V}=$ the sample Coefficient of Variation,

$s=$ the sample standard deviation, and

$X=$ the sample mean. 


\section{Results}

Size Structure, CPUE, and Sex Ratios

A total of 3,247 blue cod were caught in the survey. The catch data are summarised by stratum in Table 3.1. Overall, the sample was strongly male-biased (3.3:1, male: female) with the proportion of males increasing with length, where in all length classes above $35 \mathrm{~cm}$, excluding the $44 \mathrm{~cm}$ length bin, the sex ratio was $>90 \%$ male (Figure 3.3). The overall length-frequency distribution was unimodal and bell-shaped (Figure 3.3). Mean overall length was $31 \mathrm{~cm}$ (SD = 4.25). Mean female length was $28.94 \mathrm{~cm}(\mathrm{SD}=3.89)$ and mean male length was $31.75 \mathrm{~cm}$ (SD = 3.55). Length-frequency distributions and sex ratios appeared to differ by stratum (Figure 3.4). Strata which had higher proportions of females, namely D'Urville West, D'Urville East, Outer Queen Charlotte, and Inner Queen Charlotte had length-frequency distributions centered slightly lower, and each had a small mode of males in the higher length classes (Figure 3.4).

Mean length was significantly different between strata $\left(\mathrm{F}_{11,2480}=8.157, \mathrm{p}<0.001\right)$. The biggest blue cod on average were in extreme outer Queen Charlotte Sound and Port Underwood, whereas, the smallest blue cod on average were in inner and middle Pelorus Sound (Figure 3.4). Inner and middle Pelorus Sound and Cook Strait South had the lowest CPUE (Table 3.1). The highest CPUE was in West and East D'Urville Island, and extreme outer Pelorus Sound (Table 3.1). Queen Charlotte Inner and Queen Charlotte Outer had the highest proportions of females by stratum ( 0.43 and 0.52 , respectively). Inner Pelorus Sound and Southern Cook Strait had the highest proportions of males by stratum (0.88 and 1.00, respectively) (Table 3.1). 


\section{Table 3.1}

Summary the catch data from the 2013 Marlborough Sounds blue cod survey. CPUE is the number fish per pot hour.

\begin{tabular}{|c|c|c|c|c|c|}
\hline Stratum & Stratum Area & No. Fish & CPUE & Proportion Male & No. Pots \\
\hline 1 & Inner Queen Charlotte & 51 & 2.01 & 0.57 & 24 \\
\hline 2 & Outer Queen Charlotte & 211 & 3.20 & 0.48 & 63 \\
\hline 3 & Extreme Outer Queen Charlotte & 177 & 3.30 & 0.84 & 52 \\
\hline 4 & Extreme Outer Pelorus & 526 & 8.58 & 0.88 & 57 \\
\hline 5 & Outer Pelorus & 201 & 4.68 & 0.78 & 40 \\
\hline 6 & D'Urville East & 307 & 5.86 & 0.67 & 49 \\
\hline 7 & Inner Pelorus & 36 & 2.21 & 0.83 & 15 \\
\hline 8 & Middle Pelorus & 54 & 2.44 & 0.80 & 19 \\
\hline 9 & D'Urville West & 425 & 8.72 & 0.63 & 39 \\
\hline 11 & Arapawa Island East & 317 & 4.23 & 0.80 & 71 \\
\hline 12 & Cook Strait & 179 & 2.44 & 0.86 & 66 \\
\hline 13 & Port Underwood & 8 & 1.27 & 1.00 & 6 \\
\hline
\end{tabular}
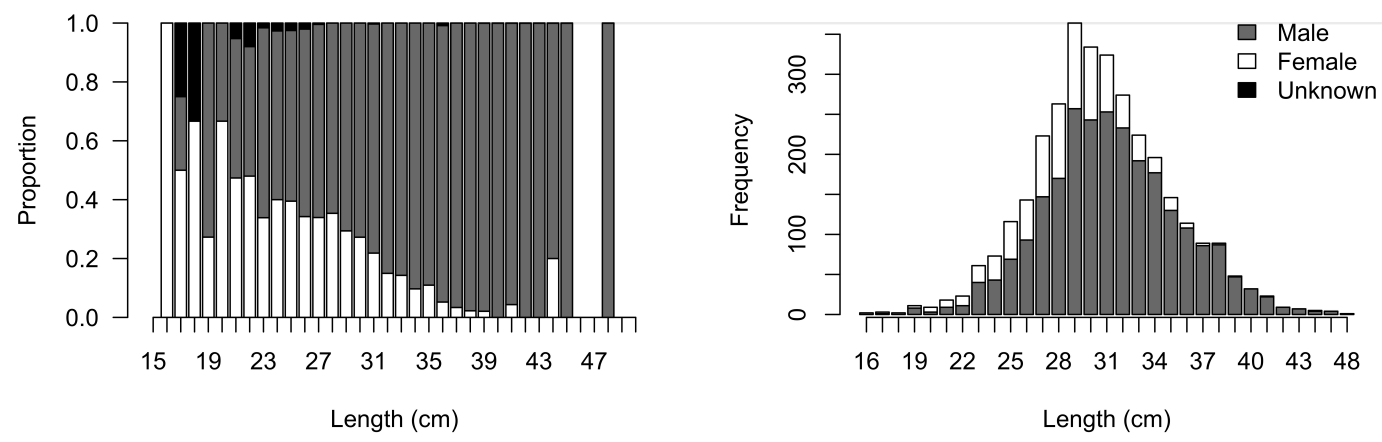

Figure 3.3

Proportions (Left) and size-frequency distribution (Right) of male, female, and unknown sex blue cod at length from the Marlborough Sounds area, including the Cook Strait and D'Urville Island 

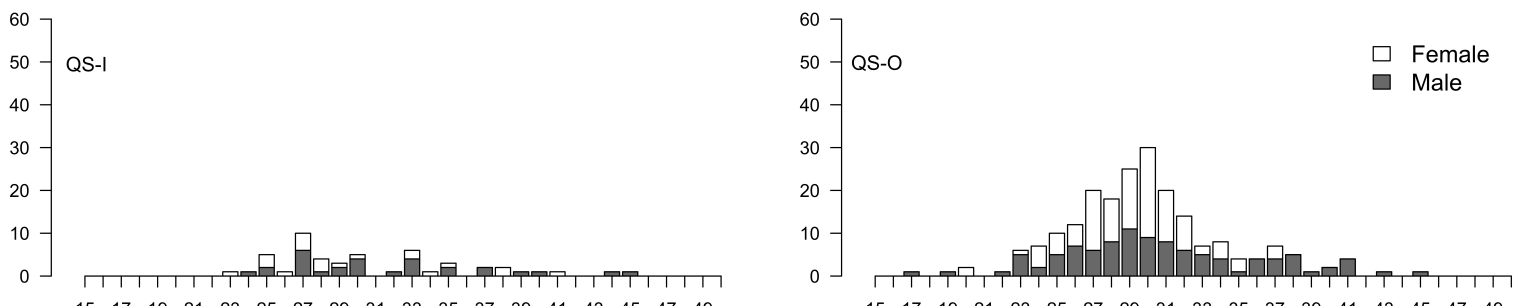

$\begin{array}{llllllllllllllllll}15 & 17 & 19 & 21 & 23 & 25 & 27 & 29 & 31 & 33 & 35 & 37 & 39 & 41 & 43 & 45 & 47 & 49\end{array}$
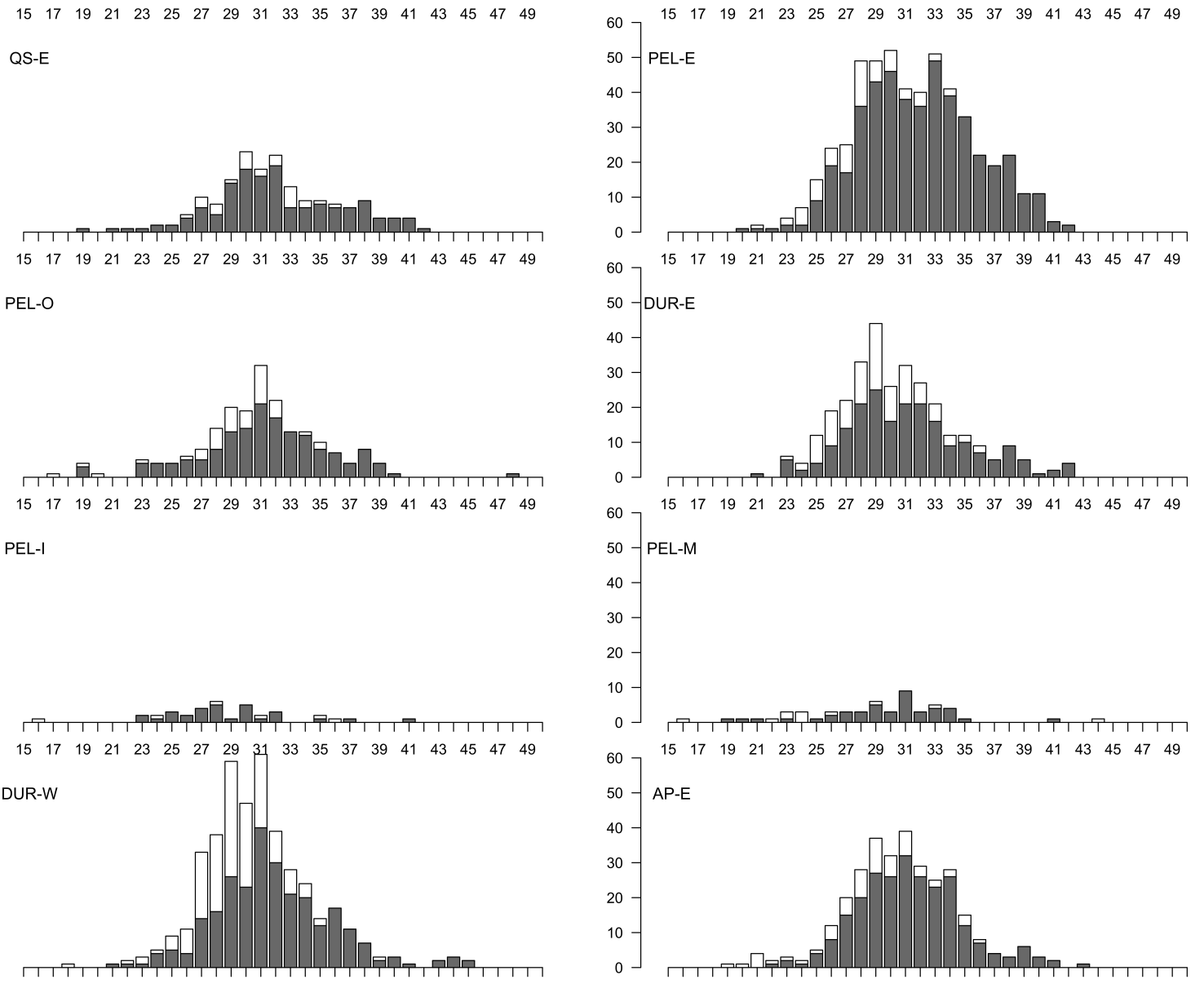

$\begin{array}{llllllllllllllllll}15 & 17 & 19 & 21 & 23 & 25 & 27 & 29 & 31 & 33 & 35 & 37 & 39 & 41 & 43 & 45 & 47 & 49\end{array}$

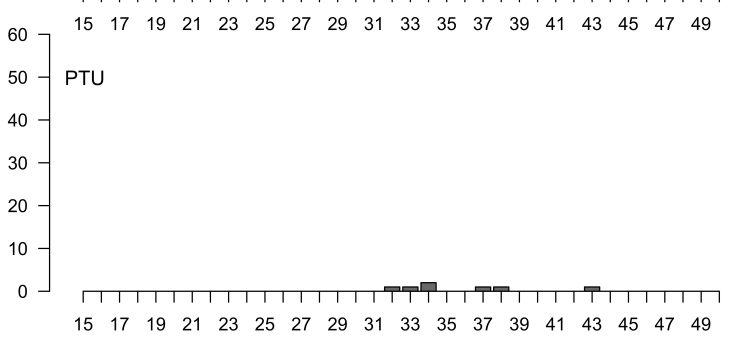

$\begin{array}{llllllllllllllllll}15 & 17 & 19 & 21 & 23 & 25 & 27 & 29 & 31 & 33 & 35 & 37 & 39 & 41 & 43 & 45 & 47 & 49\end{array}$

Length (cm)

Figure 3.4

Size frequency distributions of blue cod by stratum. Grey bars represent males and white bars represent females. The area codes for each graph are: Inner Queen Charlotte sound QS-I, Extreme outer Queen Charlotte sound QS-E, Outer Pelorus sound PEL-O, Inner Pelorus sound PEL-I, West D'Urville Island DUR-W, Cook Strait CS, Outer Queen Charlotte sound QS-O, Extreme outer Pelorus sound PEL-E, East D'Urville Island DUR-E, Middle Pelorus sound PEL-M, Arapawa Island East AP-E, Port Underwood PTU. Note that these graphs represent total catch, not CPUE. 
The CPUE frequency distributions at the pot and group level were approximately log-normally distributed, whereas, the frequency distribution of CPUE at the stratum level was bimodal (Figure 3.5). Therefore, log-transformations were appropriate for analyses at the pot and population level,
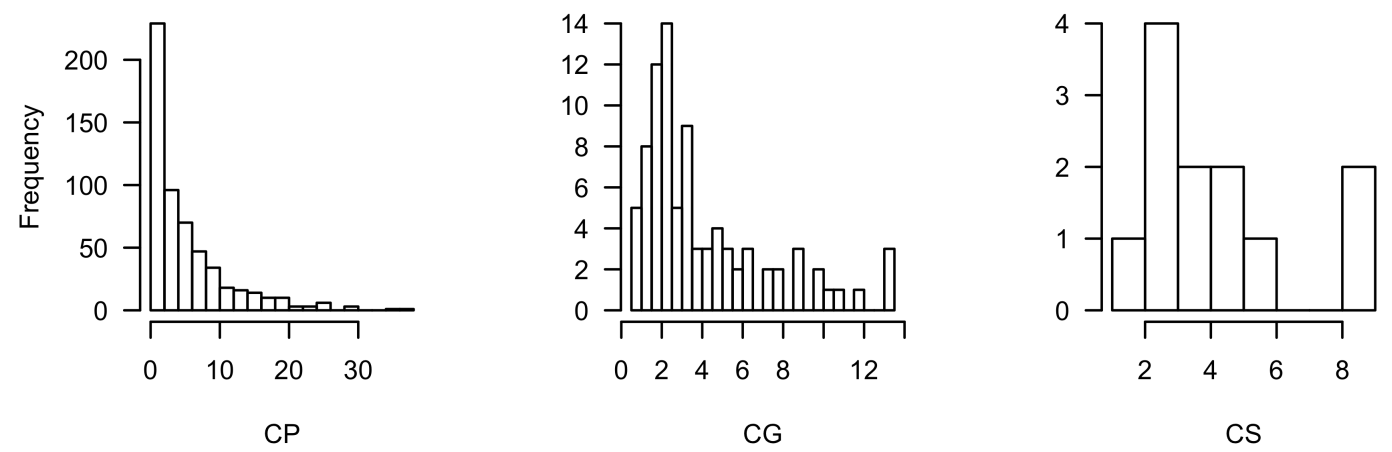

Figure 3.5

Frequency distribution of CPUE at the pot (Left), group (Middle), and stratum (Right) level.

\section{Hypothesis 1: Environmental Influences on Sex Ratio}

Of the environmental variables measured, longitude and latitude were strongly negatively correlated; bottom type was moderately positively correlated with latitude and weakly negatively correlated with longitude; stratum was weakly negatively correlated with latitude, and also weakly positively correlated with bottom contour type. Number of fish was weakly negatively correlated with latitude, and sea condition was moderately correlated with bottom contour type and longitude (Figure 3.6). 


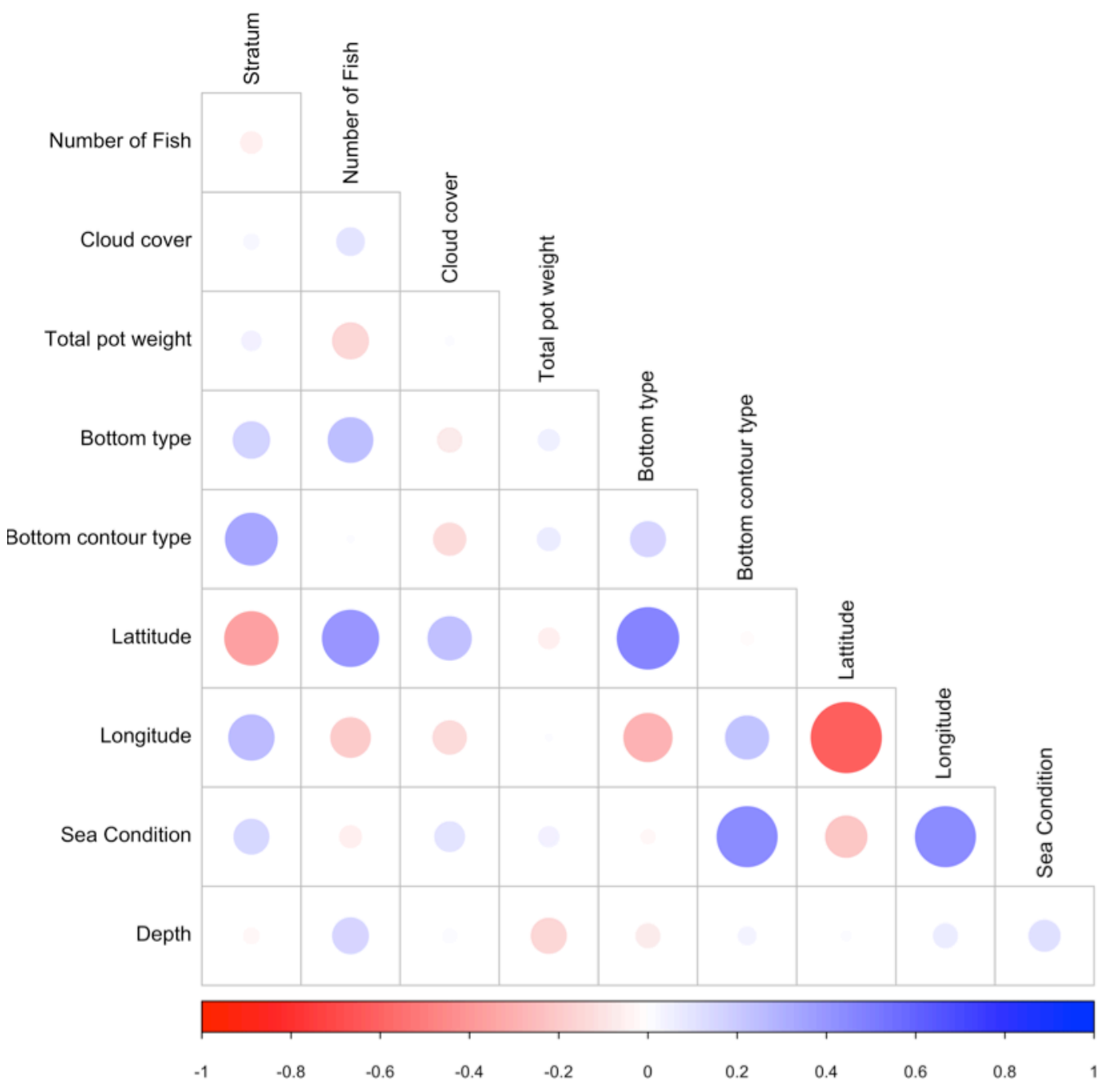

Figure 3.6

Correlation plot of variables measured in the 2013 Marlborough Sounds blue cod survey. Large solid blue dots represent strong positive correlations, and large solid red dots represent strong negative correlations, Faded dots represent weak correlations $($ red $=$ negative, blue $=$ positive $)$. 
The best model selected by AIC and deviance explained was:

$$
\begin{aligned}
& \text { Pmale }=\text { stratum }+ \text { Latitude } \\
& + \text { number of fish }+ \text { sea condition }
\end{aligned}
$$

Latitude was fitted as a third order polynomial.

The model explained $16.4 \%$ of deviance and had an AIC value of 569. The most influential predictors of the proportion of male blue cod caught in cod pots were therefore stratum, latitude, number of fish per pot, and sea condition. Of these, stratum was the most influential predictor, explaining $11.8 \%$ of deviance. Table 3.2 shows the degrees of freedom, AIC and deviance explained of each predictor in the model. Proportion male was highest when the sea condition was moderate to rough, and lowest when sea condition was very rough and high (Figure 3.7A, see sea condition descriptions in Table 3.3). Proportion male increased as number of fish in the pot increased (Figure 3.7B). The proportion male was highest at lower latitudes, decreased to an equal sex ratio at about -40.9 degrees south, then increased northward (Figure 3.7C). The model predicted the lowest proportion male in strata 1,2 and 12, which were the inner Queen Charlotte Sound, the outer Queen Charlotte Sound, and the Cook Strait areas, respectively. The strata with the highest proportion male were 4 and 13, which are the extreme outer Pelorus Sound and Port Underwood. The predicted versus observed values did not deviate markedly from the line of best fit, indicating a good model fit (Figure 3.7E).

Table 3.2

The binomial GLM model $($ Pmale = stratum + latitude + number of fish + sea condition $)$ predictors and diagnostics explaining the proportion of male blue cod in pots caught in the Marlborough Sounds area. AIC values are cumulative as predictors are added to the model.

\begin{tabular}{lcccc|}
\multicolumn{1}{|c}{ Predictor } & d.f. & AIC & $\begin{array}{c}\text { \% Deviance Explained } \\
\text { (Cumulative) }\end{array}$ & $\begin{array}{c}\text { \% Deviance } \\
\text { explained }\end{array}$ \\
Stratum & 10 & 578 & 11.8 & 11.8 \\
+ Latitude & 2 & 573 & 13.3 & 1.5 \\
+ Number of fish & 1 & 570 & 14.1 & 0.8 \\
+ Sea condition & 6 & 569 & 16.4 & 2.2 \\
\hline
\end{tabular}



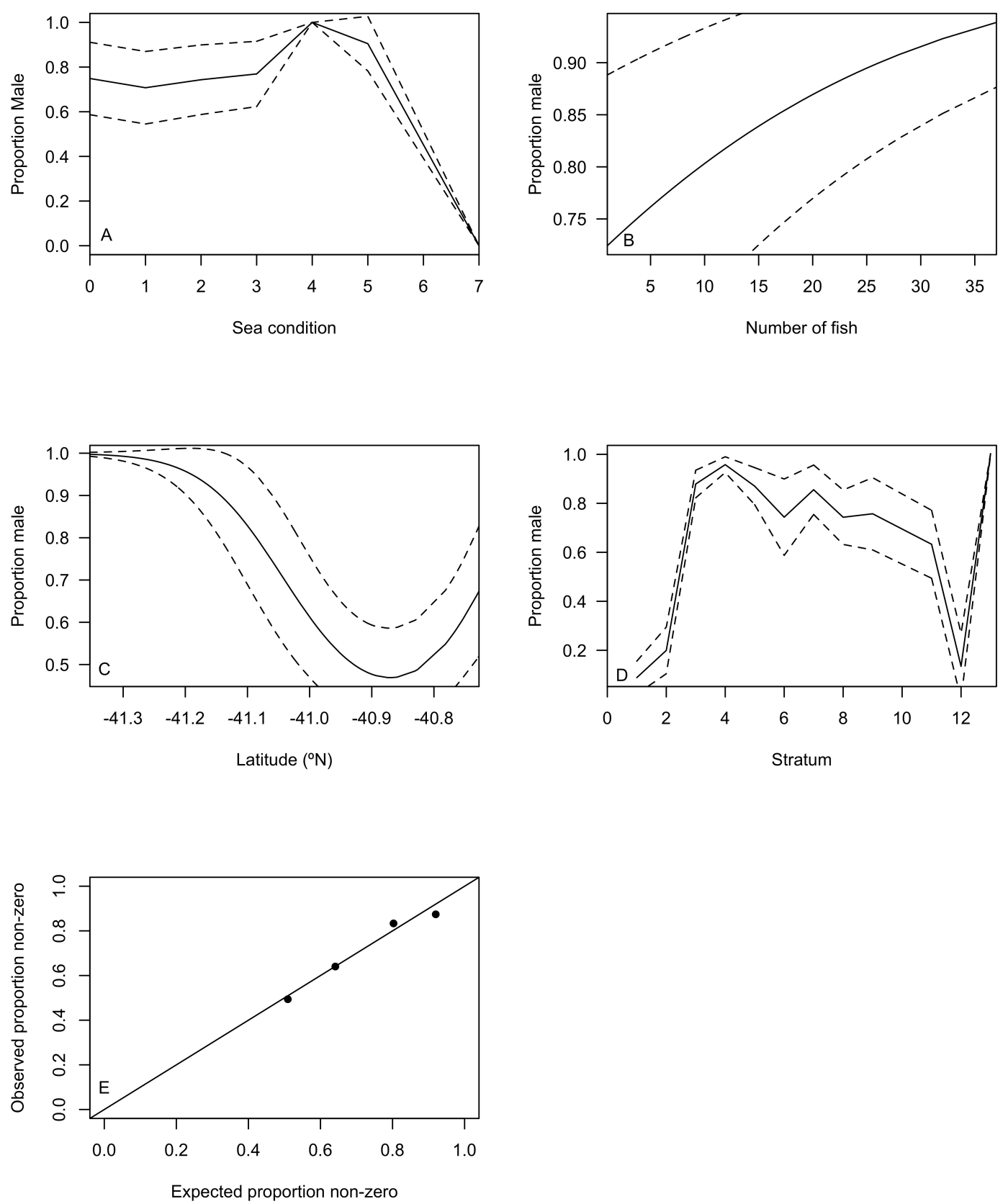

Figure 3.7

$(A-D)$ Predicted individual effects \pm S.D. of model predictors for the proportion of male blue cod in cod pots. Effects illustrate the individual effect of the predictor when all other model predictors are set to their median value. (E) QQ-plot of expected versus observed proportion non-zero for the model. In figure D, stratum numbers are $1=$ inner Queen Charlotte, $2=$ outer Queen Charlotte, $3=$ extreme outer Queen Charlotte, 4 = extreme outer Pelorus, $5=$ outer Pelorus, $6=$ East D’Urville Island, $7=$ Inner Pelorus, $8=$ middle Pelorus, $9=$ West D'Urville Island, $11=$ Arapawa Island East, $12=$ Cook Strait, $13=$ Port Underwood. Refer to table 3.3 for sea condition codes. 
Table 3.3

Description of sea condition codes.

\begin{tabular}{|lll|}
\hline Sea Condition & Description & Swell height \\
0 & Calm, Glassy & $0 \mathrm{~m}$ \\
1 & Calm & $0-0.1 \mathrm{~m}$ \\
2 & Smooth & $0.1-0.5 \mathrm{~m}$ \\
3 & Slight & $0.5-1 \mathrm{~m}$ \\
4 & Moderate & $1-2.5 \mathrm{~m}$ \\
5 & Rough & $2.5-4 \mathrm{~m}$ \\
6 & Very Rough & $4-6 \mathrm{~m}$ \\
7 & High & $6-10 \mathrm{~m}$ \\
8 & Very High & $10-15 \mathrm{~m}$ \\
9 & Huge & Over $15 \mathrm{~m}$ \\
\hline
\end{tabular}

Hypothesis 2: Density and Sex Ratio

There were no significant relationships between sex ratio and CPUE at any sampling level (Table 3.4). Scatterplots indicated marked variability in the CPUE, and loess curves did not reveal any notable trends, linear or otherwise, in the data (Figure 3.8).

Table 3.4

Linear regression analyses of sex ratio and CPUE, by pot, group, and stratum.

\begin{tabular}{|lcccc|}
\hline & D.f. & F-statistic & p-value & Adjusted $\mathbf{R}^{2}$ \\
Pots & 559 & 1.474 & 0.225 & 0.001 \\
Groups & 84 & 0.939 & 0.335 & -0.001 \\
Strata & 10 & 0.501 & 0.495 & -0.048 \\
\hline
\end{tabular}



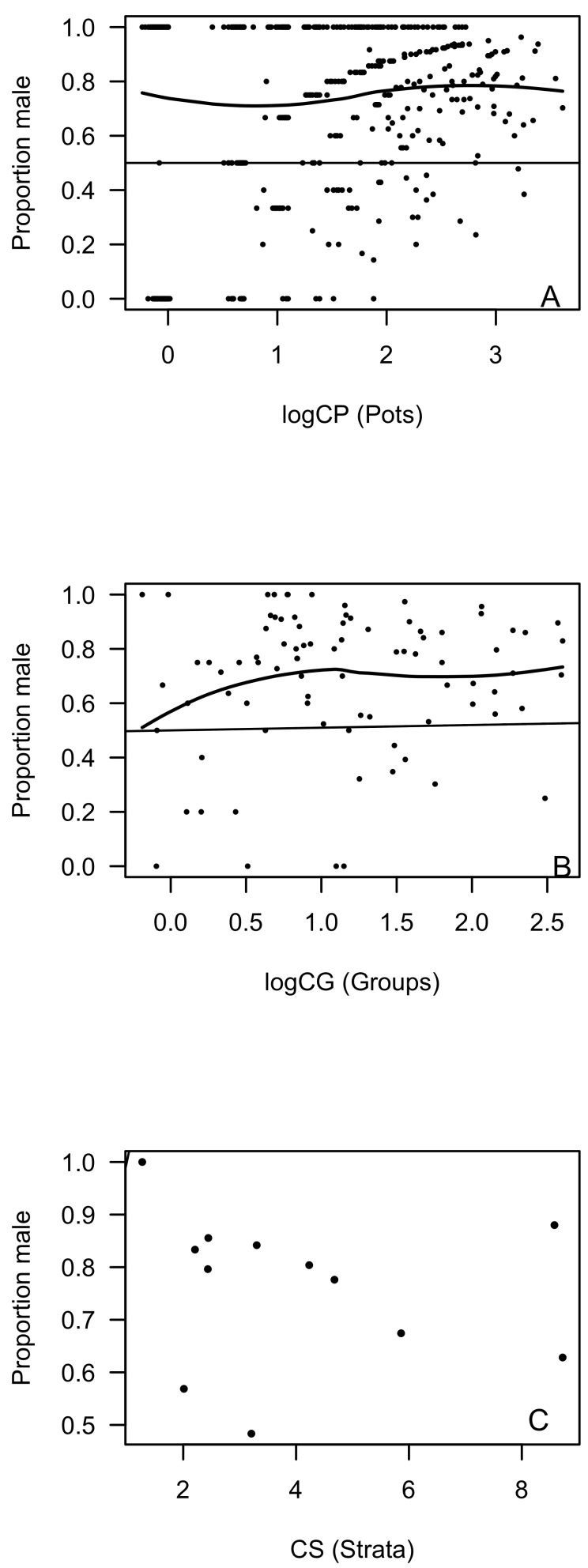

Figure 3.8

Relationship between sex ratio (proportion male) and density (logCPUE) at the pot (A), group (B) and stratum (C) levels. The solid lines in the pot and population graphs are loess smoothers. 


\section{Hypothesis 3: Influence of Large Males on Sex Ratio}

The proportion male differed significantly between pots (Kruskal-Wallis chi-squared $=364.69$, $\mathrm{df}=4, \mathrm{p}<0.001, \mathrm{n}=561)$ and groups (Kruskal-Wallis chi-squared $=19.082, \mathrm{df}=4, \mathrm{p}<0.001$ ) with differing largest male size. In pots and groups where a male blue cod between 45 and $49 \mathrm{~cm}$ was caught, the median proportion male was lower compared with pots and groups without large males (Figure 3.9). An exception was the median proportion male for groups not containing at least one male above $30 \mathrm{~cm}$, which was significantly lower than the $30-34 \mathrm{~cm}, 35-39 \mathrm{~cm}$ and 40 $44 \mathrm{~cm}$ groups at both the group and pot level (Table 3.5). Further, median proportion male in pots containing a male above $44 \mathrm{~cm}$ was significantly lower than the $30-34 \mathrm{~cm}, 35-39 \mathrm{~cm}$, and 40-44 cm groups (Table 3.5).
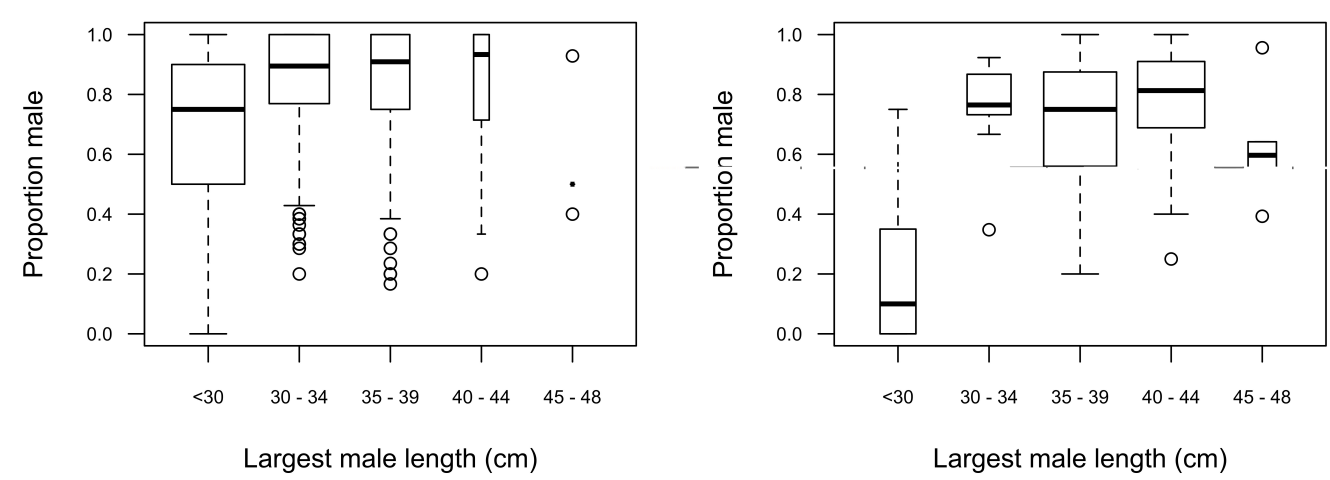

Figure 3.9

Box-plots of proportion male in pots (Left) and groups (Right) where observations are grouped according to the largest male size in that pot or group. The width of the boxes is proportional to the sample size in each category 
Table 3.5

Pairwise non-parametric rank-sum Dunn's test results for difference in median proportion male between groups containing different largest male size. Results for pots and groups are reported. Test significance levels are reported as '***' $<0.001$, '**' $<0.01,{ }^{\prime} *$ ' $<0.05$, ' ' $<0.1$, 'n.s.' $>0.1$.

\begin{tabular}{|c|c|c|c|c|c|c|c|c|}
\hline & Pot & Group & Pot & Group & Pot & Group & Pot & Group \\
\hline & \multicolumn{2}{|c|}{$<30 \mathrm{~cm}$} & \multicolumn{2}{|c|}{$30-34 \mathrm{~cm}$} & \multicolumn{2}{|c|}{$35-39 \mathrm{~cm}$} & \multicolumn{2}{|c|}{$40-44 \mathrm{~cm}$} \\
\hline $30-34 \mathrm{~cm}$ & $* * *$ & $* * *$ & & & & & & \\
\hline $35-39 \mathrm{~cm}$ & $* * *$ & $* * *$ & n.s. & n.s. & & & & \\
\hline $40-44 \mathrm{~cm}$ & $* * *$ & $* * *$ & n.s. & n.s. & n.s. & n.s. & & \\
\hline $45-48 \mathrm{~cm}$ & . & . & $* *$ & n.s. & $* *$ & n.s. & $* *$ & . \\
\hline
\end{tabular}

The marked difference in the proportion male in the smallest group $(<30 \mathrm{~cm})$ when compared between the pot and group sampling levels (Figure 3.9) prompted further analysis of the sampling method. It was hypothesized that female aggregation might explain the difference in proportion male between pot and population level sampling in the $<30 \mathrm{~cm}$ groups; if females aggregate in certain areas then the group sex ratio in those areas would be female dominated, however, individual pots within those groups might only catch males or be male dominated. The frequency distribution of female fish caught in pots did not indicate any aggregation of females; rather, it was approximately log-normally distributed (Figure 3.10A). If there were clustering or shoaling of fish then a bimodal frequency distribution would be expected. The relationship between number of fish caught per pot and proportion male (Figure 3.10B) indicated that in pots with a small number of fish the sex ratio was most variable, and the variability decreased with increasing number of fish per pot. When three groups with many fish were analysed, proportion male was highly variable when few pots were analysed (Figure 3.10C). Variability decreased when more pots were added, and sex ratio was stable after 5 pots in each of the three groups (Figure 3.10C). The CV decreased steadily as more pots were included in the proportion male estimate, and was well below 15\% when 5 or more pots were used (Figure 3.11). The 95\% credible limits illustrate the high variability in proportion males estimates when few pots were used in the estimates (Figure 3.11). 

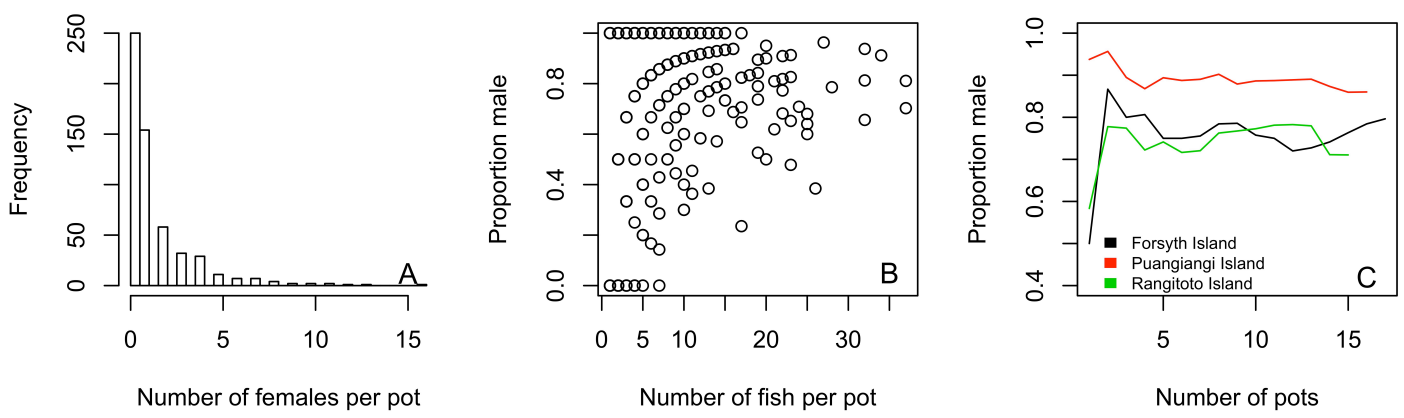

Figure 3.10

(A) Frequency distribution of number of females per pot; (B) relationship between number of fish per pot and proportion male, and; (C) cumulative proportion male plot of three populations of blue cod in the Marlborough Sounds area.
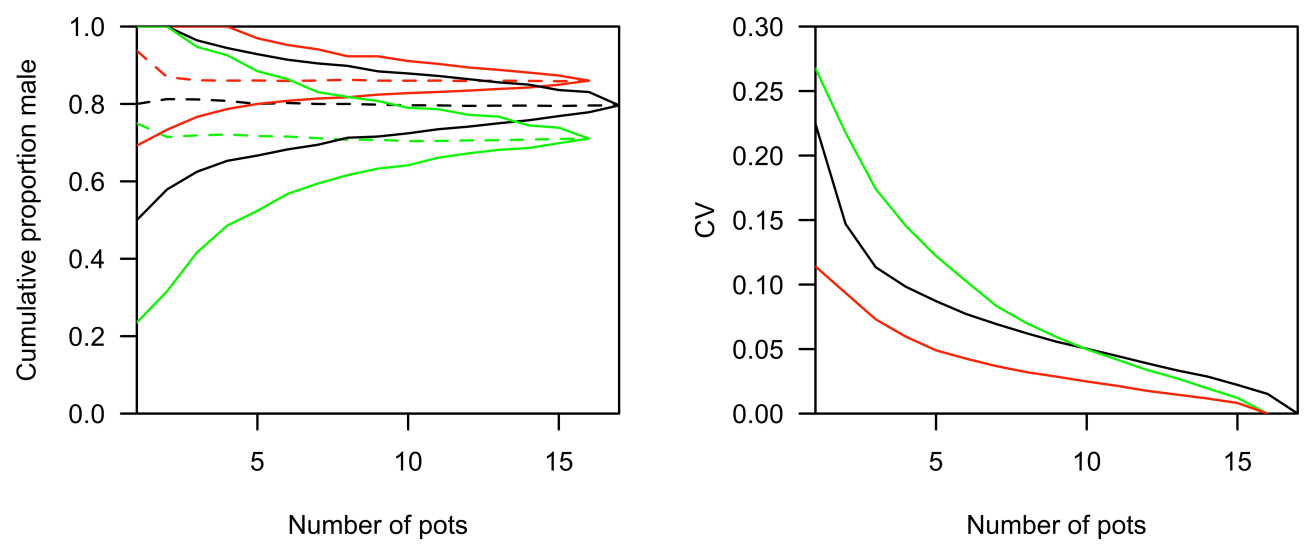

Figure 3.11

Median proportions male $\pm 95 \%$ credible-limits for Forsyth Island (Black), Puangiangi Island (Red) and Rangitoto Island (Green) (left). Populations were sampled without replacement 1000 times. The $25^{\text {th }}$ and $975^{\text {th }}$ quantiles equated to the $95 \%$ credible limits and the $50^{\text {th }}$ quartile was the median. The relationship between Coefficient of Variation (CV) and number of pots for Forsyth Island (Black), Puangiangi Island (Red), and Rangitoto Island (Green) (right). 
Due to the high variability in the proportion male estimates at low sample sizes, the analysis for sex ratio in relation to presence of large males was repeated. Pots containing less than 10 fish were removed from the pot level analysis and groups with less than 5 pots were removed from the group level analysis. The 5-pot minimum limit for groups was chosen because at this point, all three groups were well below a CV of 0.15 (Figure 3.11).

When pot and groups with a minimum of 10 fish (pots) and five pots (groups) were used, there was no significant difference in proportion male between size classes of largest males in pots (Kruskal-Wallis chi-squared $=1.66, \mathrm{df}=2, \mathrm{p}=0.44)$, or groups (Kruskal-Wallis chi-squared $=$ $3.60, \mathrm{df}=3, \mathrm{p}=0.31$ ). When only groups with at least five pots were considered, there was no trend for a higher proportion of females in groups with males less than $35 \mathrm{~cm}$ (Figure 3.12). In fact, there were no groups with at least five pots that had males less than $30 \mathrm{~cm}$. Therefore, if groups lacking in large male presence do have a more female-biased sex ratio, it could not be detected in this analysis. When only pots with at least 10 blue cod were considered, there was a trend of sex ratio steadily increase with largest male size, the proportion male then dropped in the 40-44 cm category (Figure 3.12). It was evident that at both the pot and group sampling level, when very large males were present $(>45 \mathrm{~cm}$ ), the median sex ratio was closer to 1:1 than when males of this size were not present. However, this effect was not statistically significant.

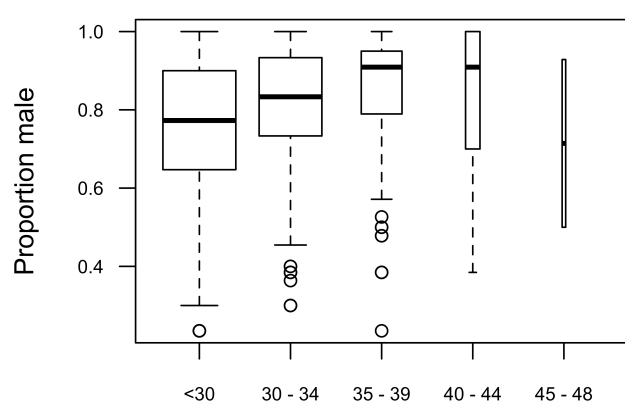

Length $(\mathrm{cm})$

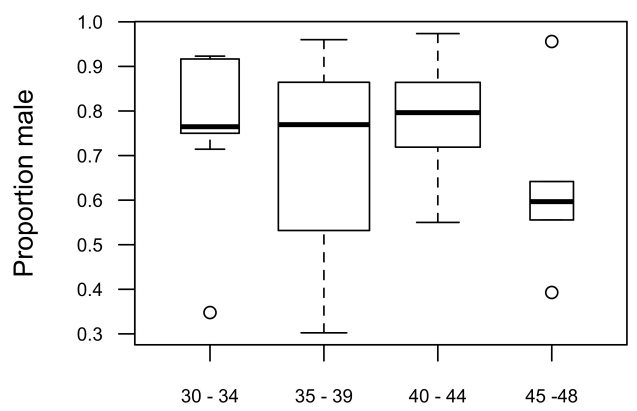

Length $(\mathrm{cm})$

Figure 3.12

Box plots of proportion male in pots (Left) and groups (Right) where observations are grouped according to the largest male size in that pot or group. Data for pots with less than 10 fish and populations with less than 5 pots were omitted in this analysis. 
CHAPTER IV

ANALYSIS OF OTOLITH READING SOFTWARE WITH BLUE COD OTOLITHS 


\section{Introduction}

Comparisons of blue cod age measurements from an expert otolith reader and from imaging software was carried as part of the conditions of the NZ Seafood Masters by Thesis Scholarship. The analyses investigated the performance and accuracy of imaging software in interpreting otolith growth zones. The aims were (1) analyse the ability of imaging software to interpret yearly growth zones in blue cod sagittal otoliths, (2) determine how sensitive age estimation is to transect placement, and (3) investigate Image-Pro Premier's ability to find the nucleus and first yearly increment in the otolith. A historical otolith collection was obtained from NIWA and used for these analyses.

\section{Methods}

Blue cod sagittal otoliths were sectioned through the nucleus at about $1 \mathrm{~mm}$ thickness and mounted onto glass microscope slides. Photomicrographs of the otolith slides were taken at $5 \times$ magnification with transmitted light. These images were imported into Image-Pro Premier using the Otolith M application. The Otolith M application allows users to manually draw a transect line across the otolith image, and thereafter it uses the changes in light intensity along the transect line to determine light and dark areas of growth zones (Figure 4.1). Three transect lines were made on each otolith from the nucleus to the outer margin. The initial transect was made from the nucleus to the farthest outer margin from the centre of the otolith. Thereafter, two additional transect lines were made according to an angle from the initial transect line determined from randomly generated numbers between 0 and 180 (Figure 4.2). The find peak function was used to count light bands along each transect line; this function recognises regions along the transect line with high light intensity and of these peaks it allocates them as growth zones according to user-specified settings. 
The OtolithM application settings are:

- Smoothing - averages out the actual changes in light intensity measured by the software (Dark red line, Figure 4.1), and captures the overall trends (The thin red line, Figure 4.1). The amount of smoothing applied is set from 1-100.

- $\quad$ Min edges - the minimum number of peaks to be found by the software.

- Max edges - the maximum number of peaks that can found by the software.

- Threshold - a measure of light intensity set from 1-100 that when exceeded by the smoothing line, allows the software to recognize a peak (Dashed red line, Figure 4.1).

In these analyses, the standard settings of the find peak function were set to: Smoothing $=100$, Min edges $=0$, Max edges $=30$, offset $=0$, Threshold $=50$. These settings were chosen from initial trials that calibrated the software as accurately as possible to read a randomly chosen blue cod otolith.

An expert blue cod otolith reader (Peter Horn, NIWA) estimated age for 50 blue cod otoliths by manual microscopic analysis under transmitted light at $40 \times$ magnification. Expert read otolith counts were then compared with software-generated estimates. In order to assess the ability of the imaging software to find the nucleus and the first growth zone, transect lines were drawn across otoliths through the nucleus. The find peak function was then used to find growth zones along the transect line crossing the nucleus and first growth zone.

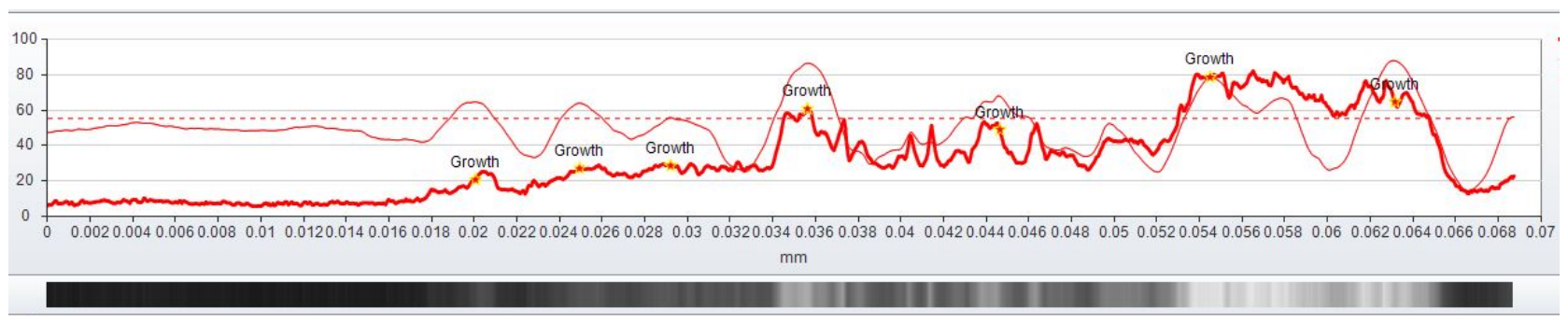

Figure 4.1

Light intensity graph from the Otolith $\mathrm{M}$ application in Image-Pro Premier representing the changes in light along a transect line. The dotted red line is the threshold, the solid dark-red line is the actual light intensity and the light-red line is the smoothed light intensity level. When peak in the smoothed line crosses the threshold it is counted as a growth zone. 
Chapter IV $\mid$ Analysis of Otolith Reading Software with Blue Cod Otoliths

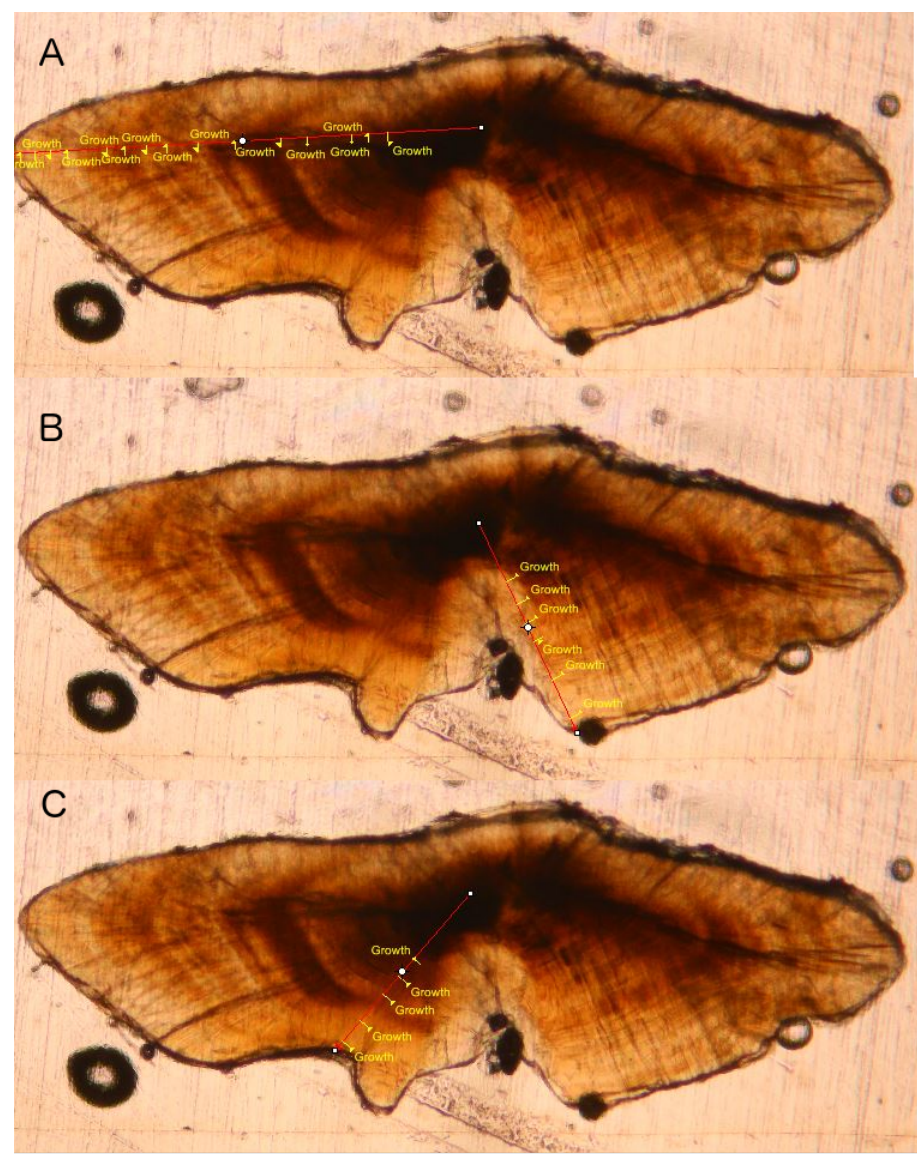

Figure 4.2

(A) Blue cod otolith with a transect line drawn from the nucleus to the farthest outer margin and (B \& C) the same blue cod otolith with transect lines drawn on randomly selected angles from the initial transect line. The software's interpretation of growth zones (peaks in light intensity) are represented as yellow "Growth" marks along the transect line. 


\section{Results}

The mean age estimates from the imaging software were both inaccurate compared to the expert age estimates, and imprecise (Figure 4.3). Compared with the expert age estimates, the imaging software consistently overestimated age. When age estimates between transect lines of the same otolith were compared, they were highly variable with low to moderate correlation (Figure 4.4).
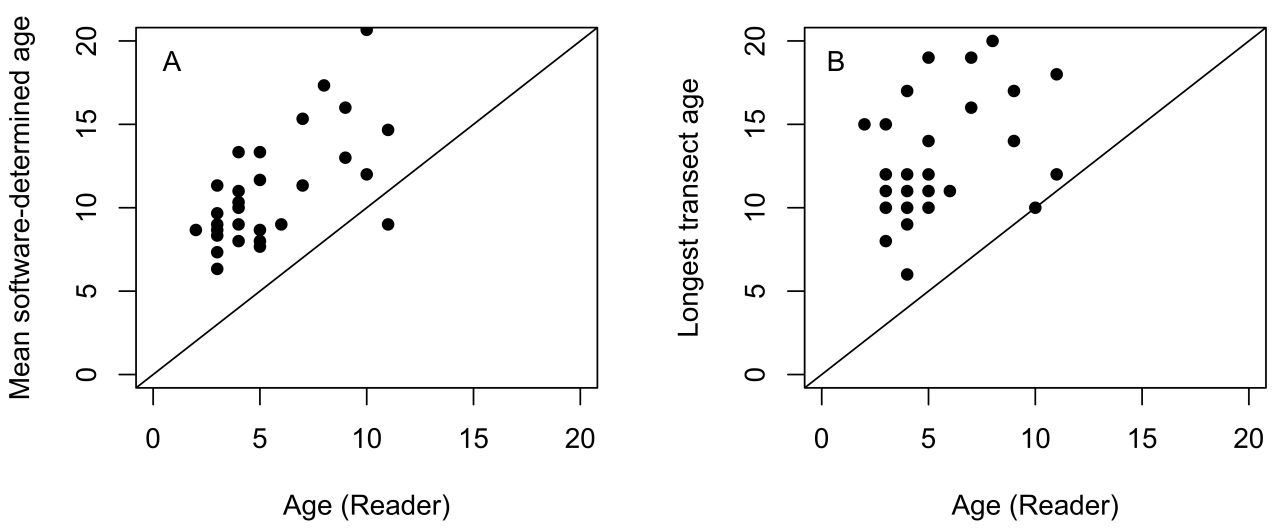

Figure 4.3

Relationships with ideal match lines of (A) expert read blue cod otolith age and the average software age estimates from Image-Pro Premium Otolith M imaging software, and (B) expert read blue cod age and age estimates from the longest transect line from Image-Pro Premium Otolith M imaging software.
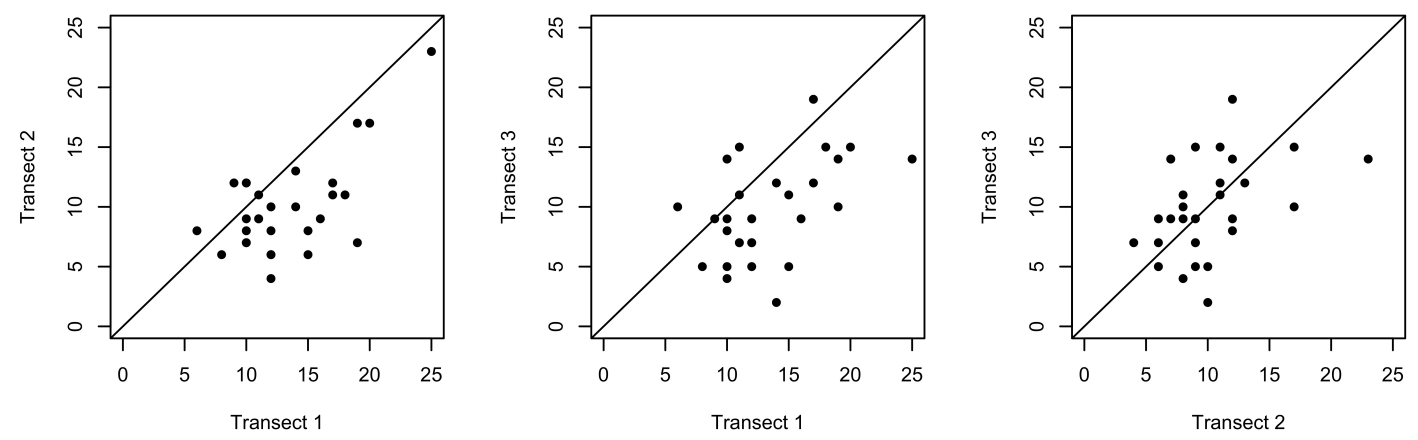

Figure 4.4

Relationships with ideal match lines between the ages estimated from three transect lines on each otolith by Image-Pro Premier Otolith M imaging software. 


\section{Accuracy of Software: Age Estimates Between Transect Lines}

In figures 4.5-4.16 4 different otoliths are analysed using the find peak function in the otolithM application. The images are in sets of three. In the first image in each set, a transect line is drawn from the nucleus to the farthest outer margin of the otolith and the find peak function is activated. The software is then calibrated by changing the threshold setting so that the software's age estimate is equal to the expert age estimate. These settings are then used on two other randomly drawn transect lines to test the accuracy of the calibrated settings between transect lines of the same otolith.

\section{Otolith Number 1}

Expert estimate: 9, Software estimates: 9, 12, and 5.

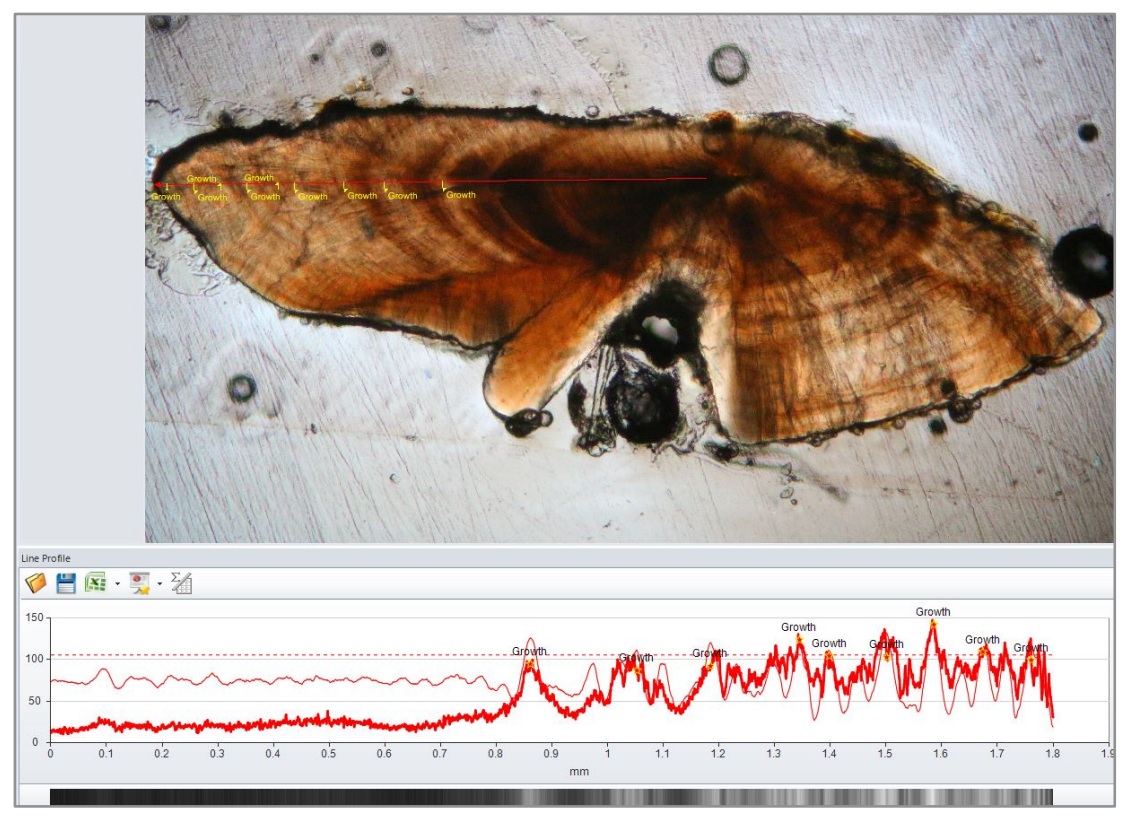

Figure 4.5

Otolith number 1 Imaging software's settings were adjusted to read the same age as the expert estimate. The threshold was set to 53. Manually read age $=9$, Software's age estimate $=9$. 


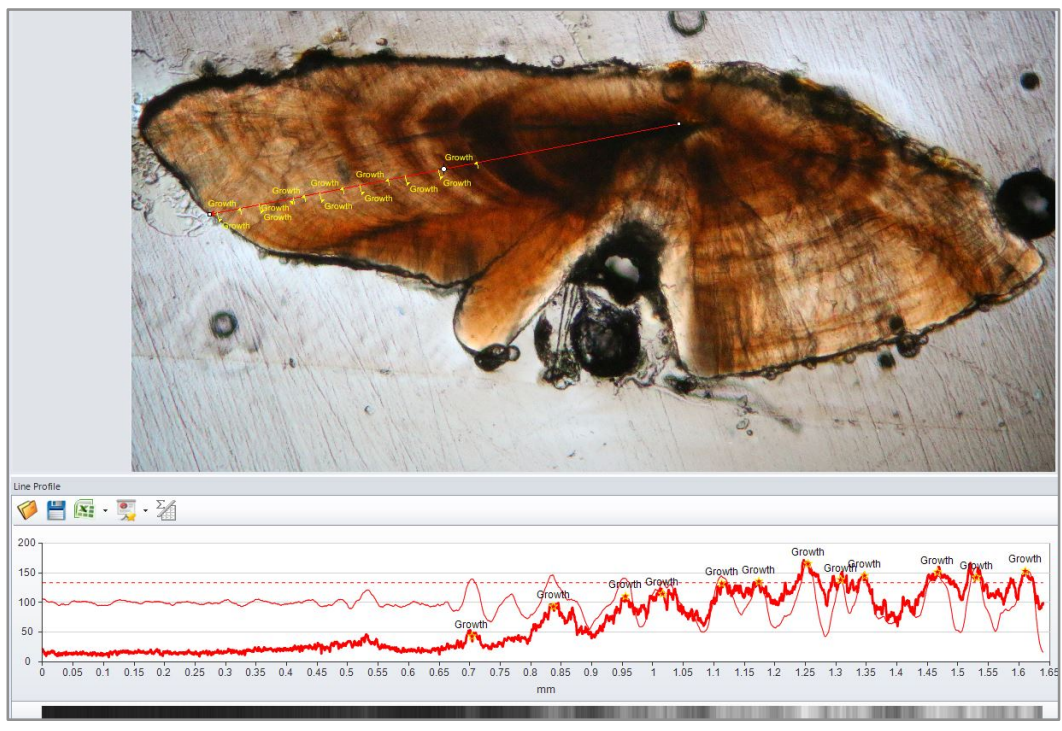

Figure 4.6

Otolith number 1 the same settings used to match the expert estimate were used for the second transect line on the same otolith. Manually read age $=9$, software's age estimate $=12$.

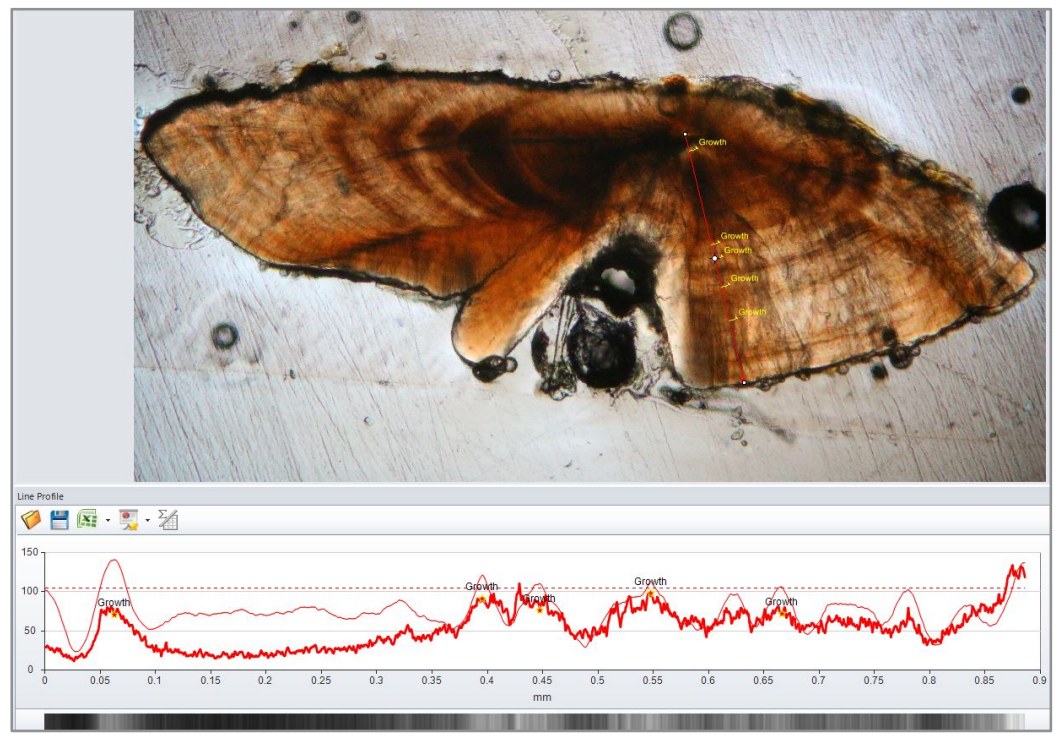

Figure 4.7

Otolith number 1 the same settings used to match the expert estimate were used for the third transect line on the same otolith. Manually read age $=9$, software's age estimate $=5$. 
Chapter IV $\mid$ Analysis of Otolith Reading Software with Blue Cod Otoliths

\section{Otolith Number 2}

Expert estimate: 4, Software estimates: 4, 3, and 2

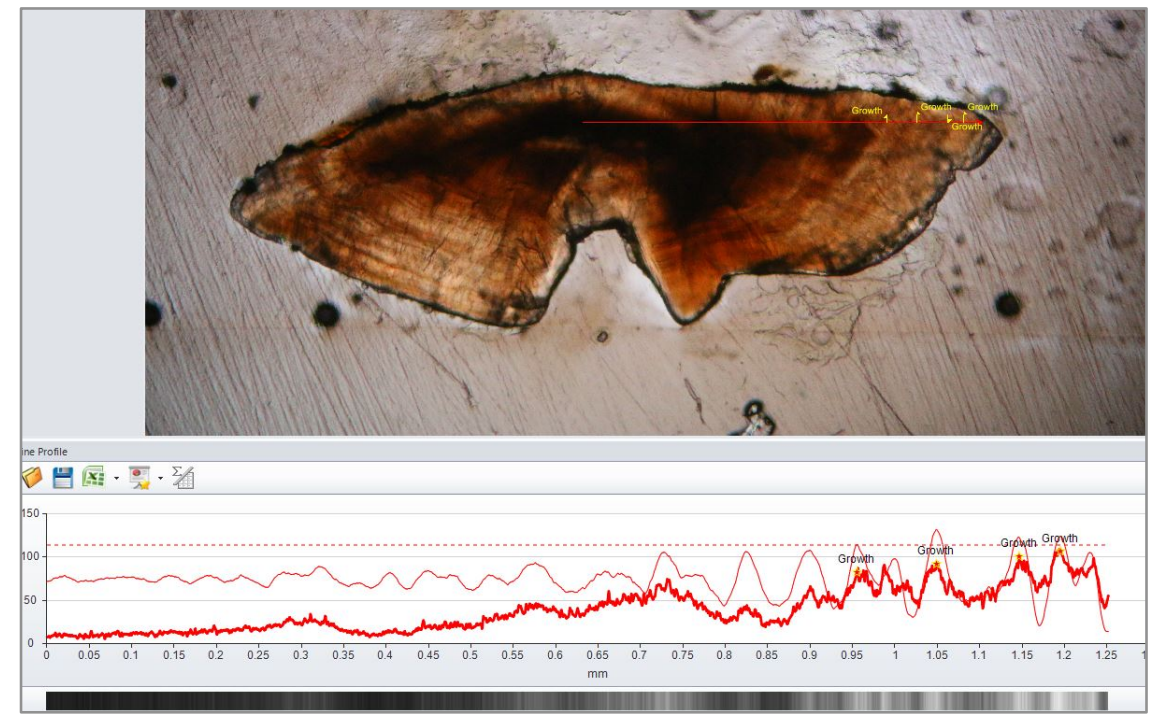

Figure 4.8

Otolith number 2 Calibration to match manual age: Smoothing $=100$, Min edges $=0$, Max edges $=30$, Threshold $=78$. Manually read age $=4$, software's age estimate $=4$.

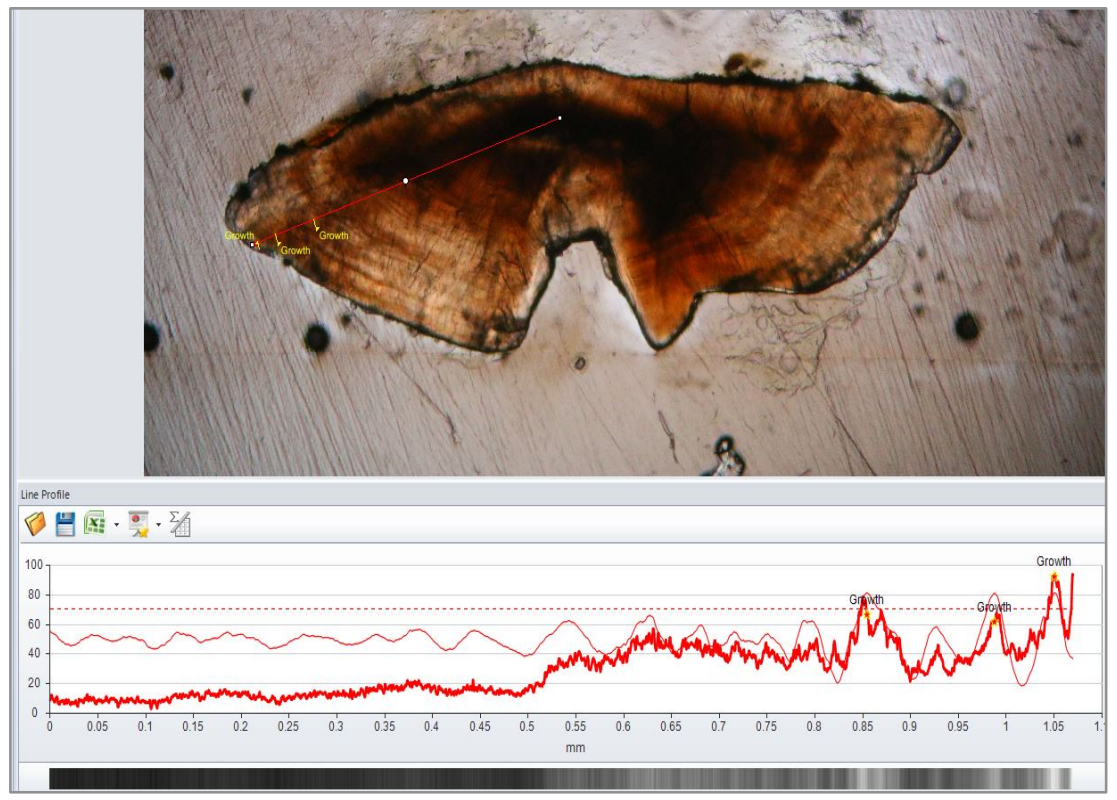

Figure 4.9

Otolith number 2 Calibrated settings from above used for the second transect line. Manually read age $=4$, software's age estimate $=3$. 


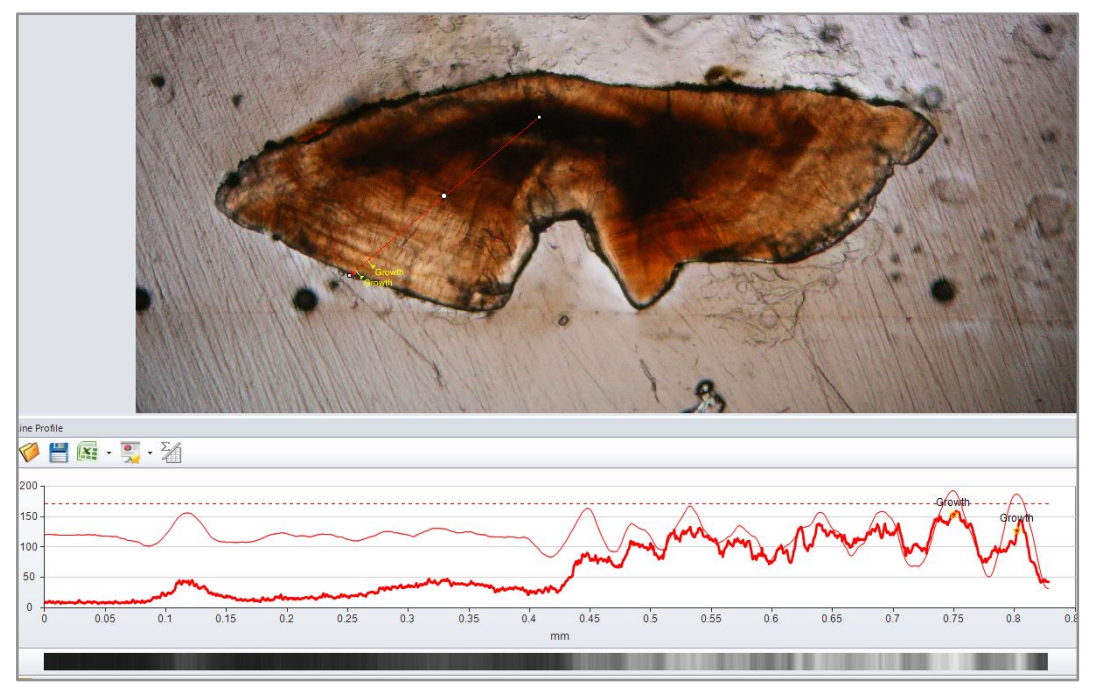

Figure 4.10

Otolith number 2 Calibrated settings from above used the third transect line. Manually read age $=4$, software's age estimate $=2$.

\section{Otolith Number 3}

Expert estimate: 7, Software estimates: 7, 7, and 6

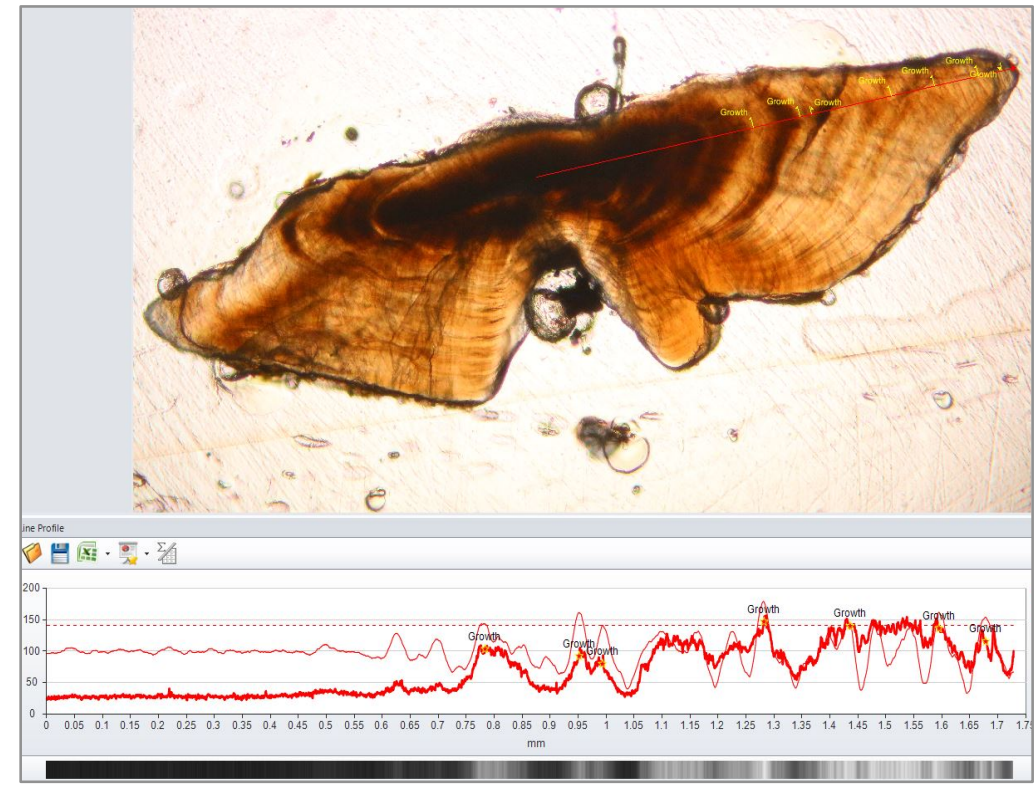

Figure 4.11

Otolith number 3 Calibration to match manual age: Smoothing $=100$, Min edges $=0$, Max edges $=30$, Threshold $=61$. Manually read age $=7$, software's age estimate $=7$. 


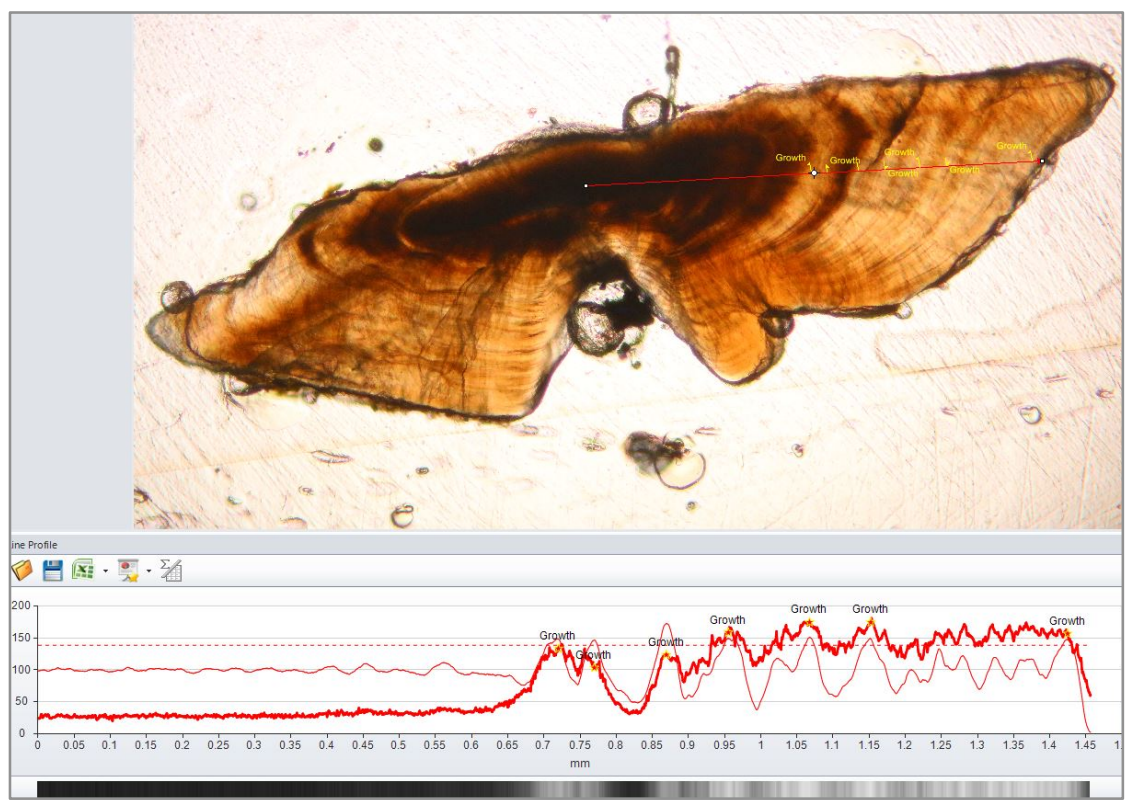

Figure 4.12

Otolith number 3 Calibrated settings from above used for the second transect line. Manually read age $=7$, software's age estimate $=7$.

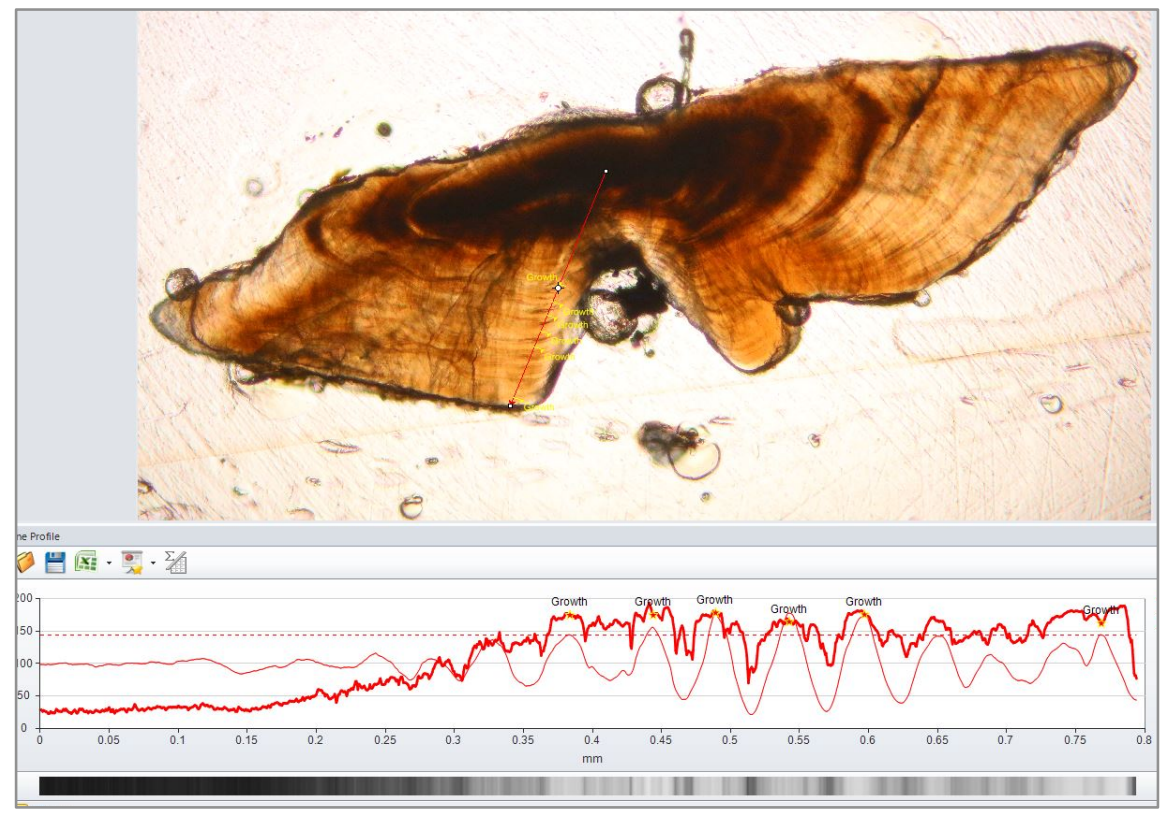

Figure 4.13

Otolith number 3 Calibrated settings used for the third transect line. Manually read age $=7$, software's age estimate $=6$. 


\section{Otolith Number 4}

Expert estimate: 2, Software estimates: 2, 2, and 5

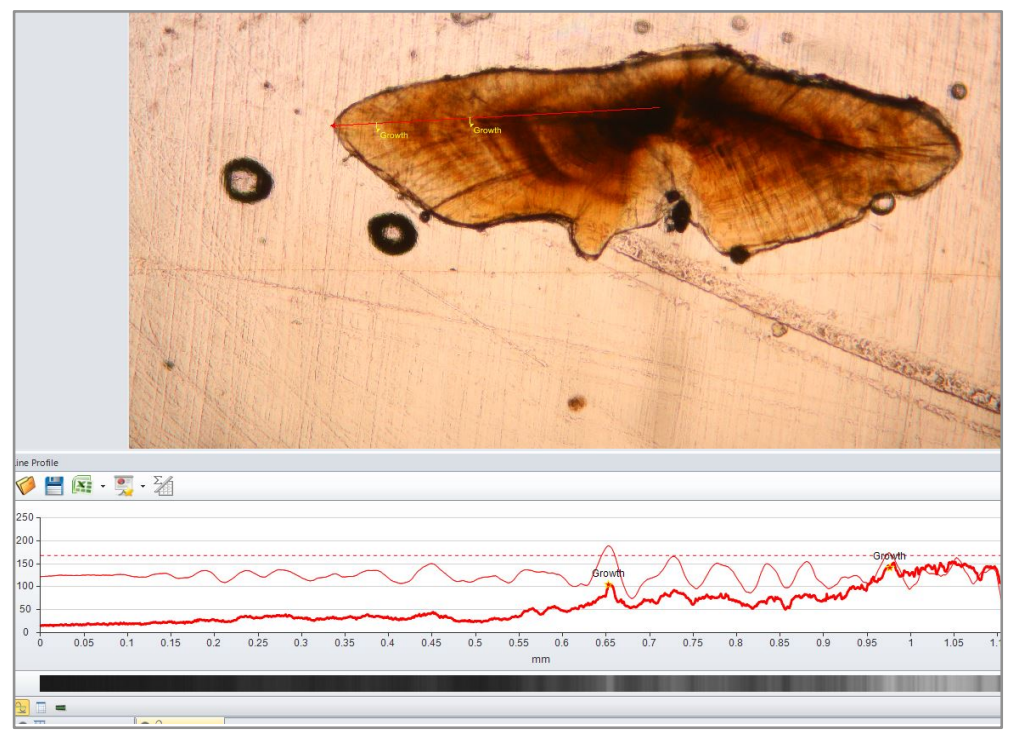

Figure 4.14

Otolith number 4: Settings were calibrated to match manual age: Smoothing $=100$, Min edges $=0$, Max edges $=30$, Threshold $=53$. Manually read age $=2$, software's age estimate $=2$.

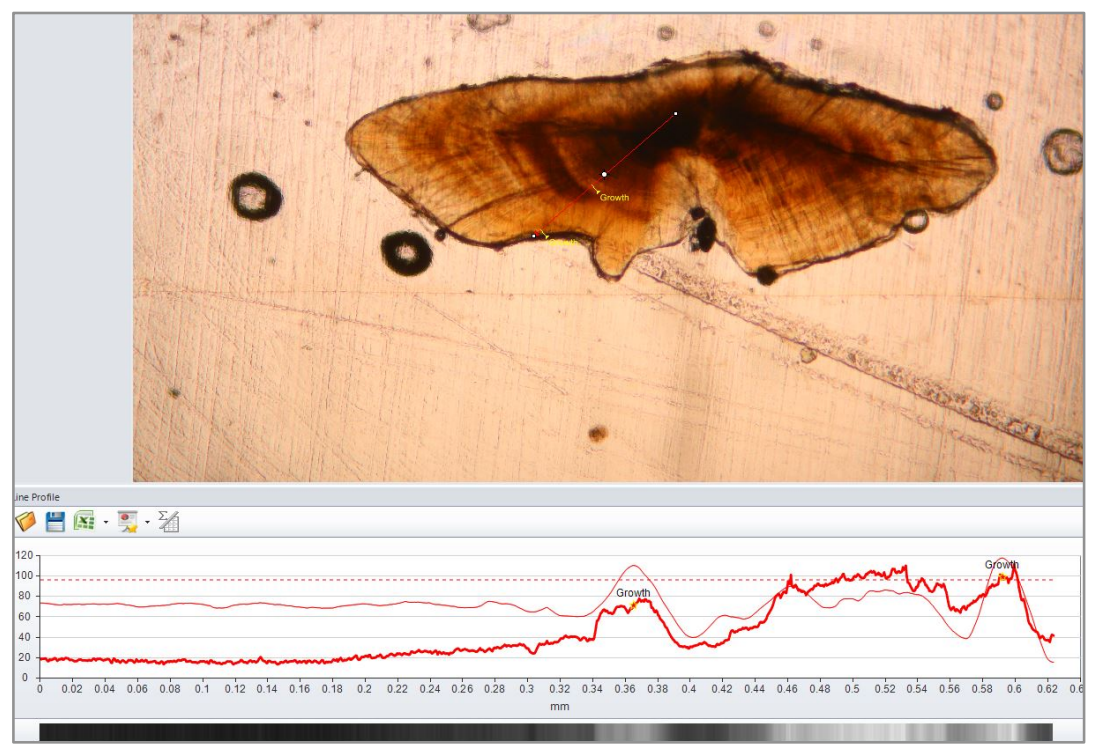

Figure 4.15

Otolith number 4: Calibrated settings were used for the second transect line. Manually read age $=2$, software's age estimate $=2$. 


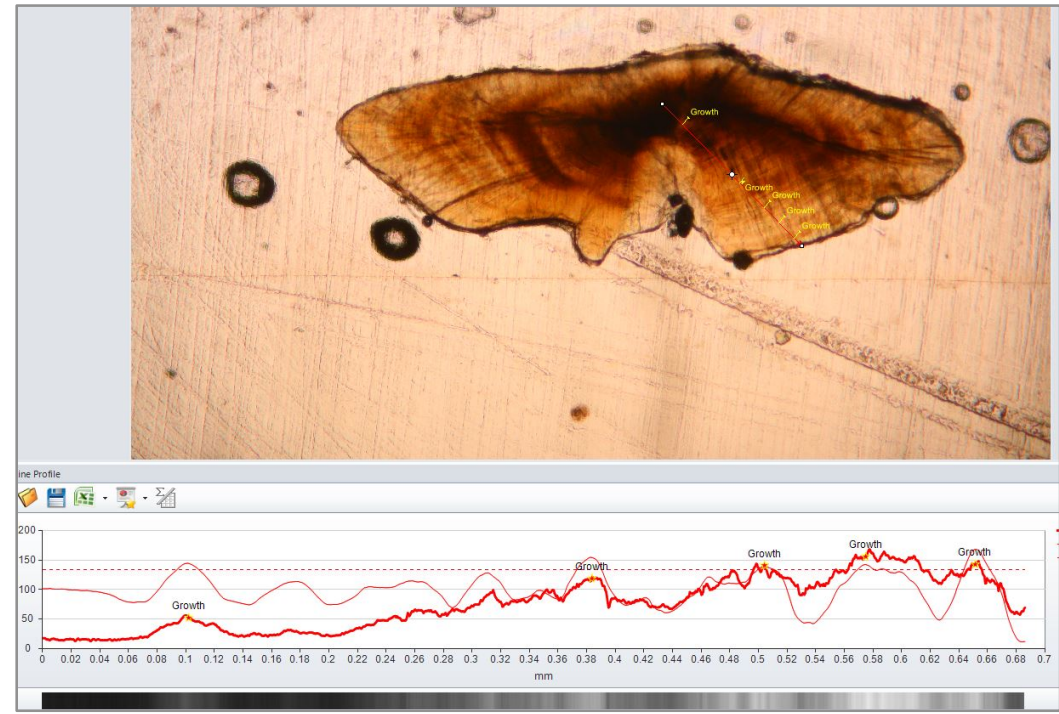

Figure 4.16

Otolith number 4: Calibrated settings used for the third transect line. Manually read age $=2$, software's age estimate $=5$.

\section{Accuracy of Software: Equivalent Settings Between Otoliths}

In figures 4.17-4.19 settings calibrated to accurately estimate age of one otolith are tested for other otoliths. These figures and associated age estimates show how well settings perform when used between otoliths. Three otoliths are analysed, the expert ages are 4, 7, and 2 years. 
Software settings accurate for otolith 1 are used to age otolith 2

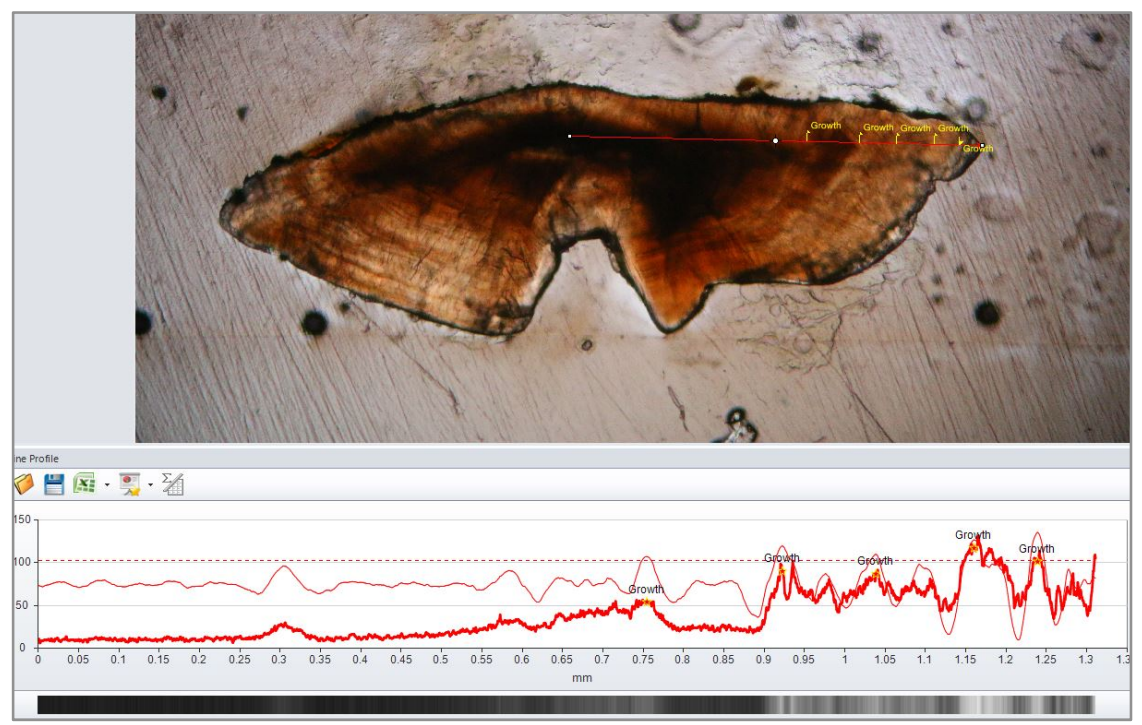

Figure 4.17

Otolith number 2: Settings calibrated to age the otolith number 1 are used to age this one. Expert age $=4$, software's age estimate $=5$.

Software setings accurate for otolith 4 are used to age otolith 3

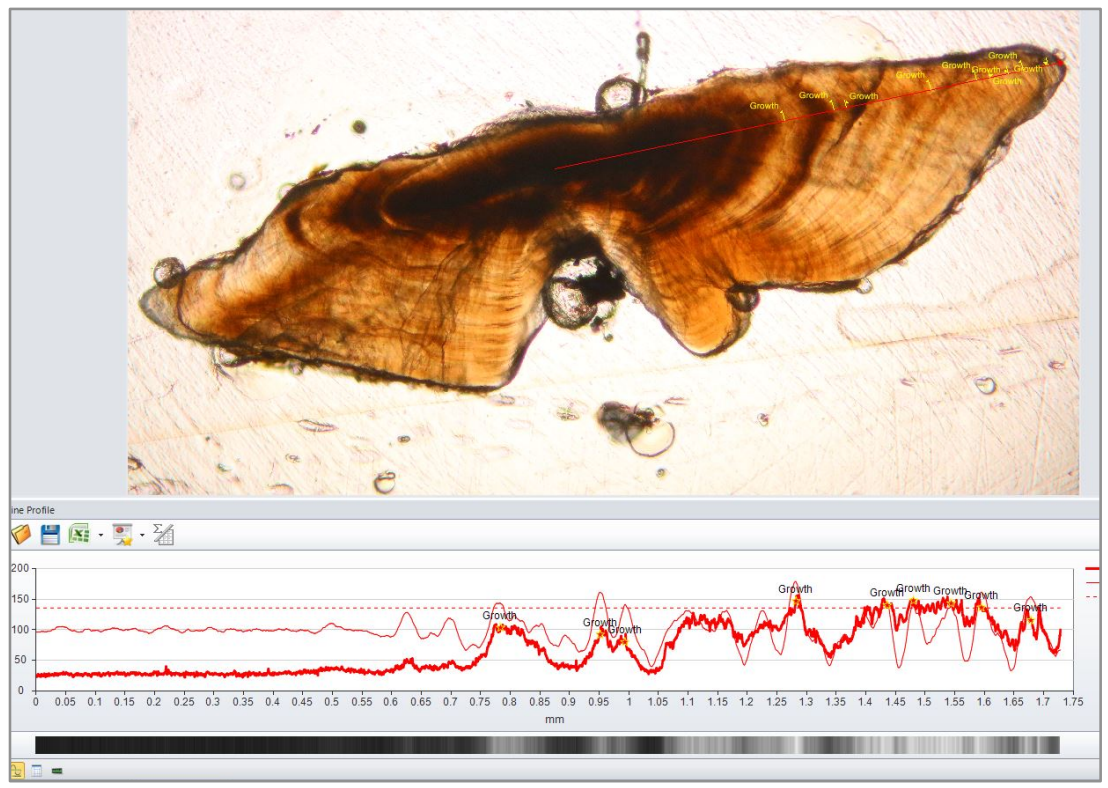

Figure 4.18

Otolith number 3 Settings calibrated to age otolith number 4 are used to age this one. Manually read age $=$ 7, software's age estimate $=9$. 
Software settings accurate for otolith 2 are used to age otolith 4

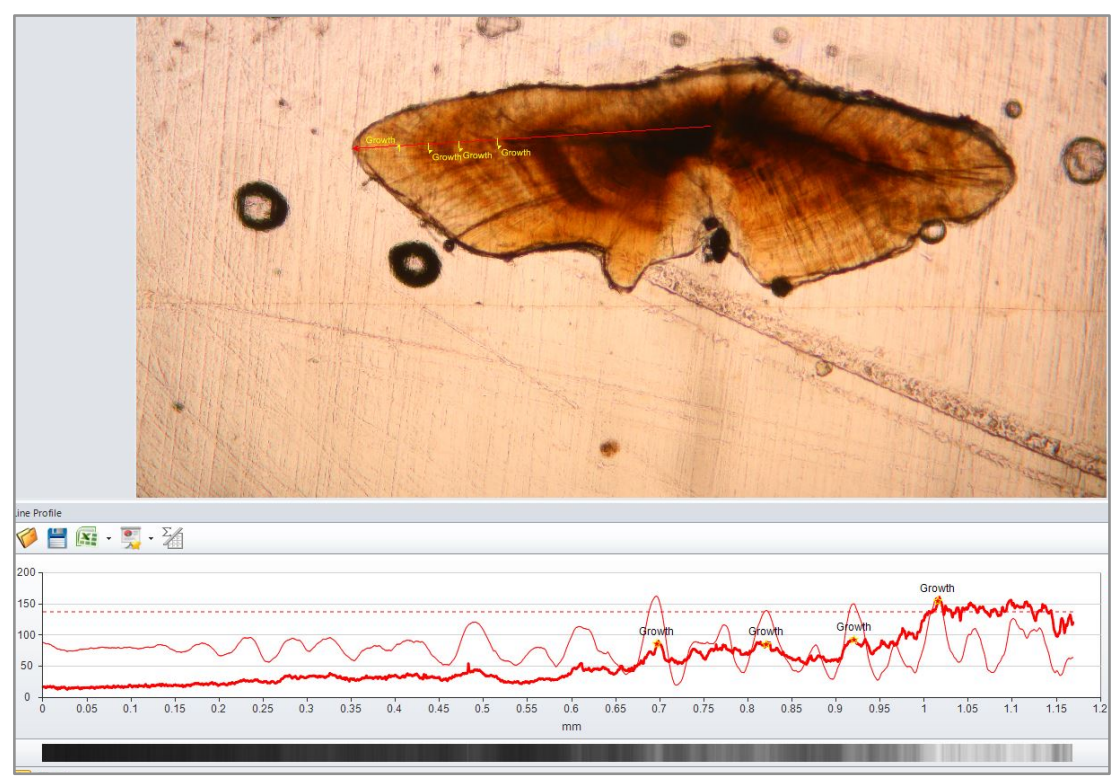

Figure 4.19

Otolith number 4 Settings calibrated to age otolith number 2 are used to age this one. Manually read age = 2 , software's age estimate $=4$.

\section{Finding the Nucleus and the First Growth Zone}

Figures 4.20 and 4.21 show transect lines drawn the length of the otolith through the nucleus. Each figure has two otolith images; the first otolith of each figure shows how the software interprets growth zones with general find peak settings (the same used in the reader-software analysis), the second where the settings have been calibrated to identify the first yearly growth ring. In both cases, the software recognised blemishes or marks within the nucleus as growth zones, and therefore was unable to accurately identify the nucleus. The settings had to be adjusted so that small peaks in light from within the nucleus did not go above the threshold. These adjusted settings are illustrated in each example. 


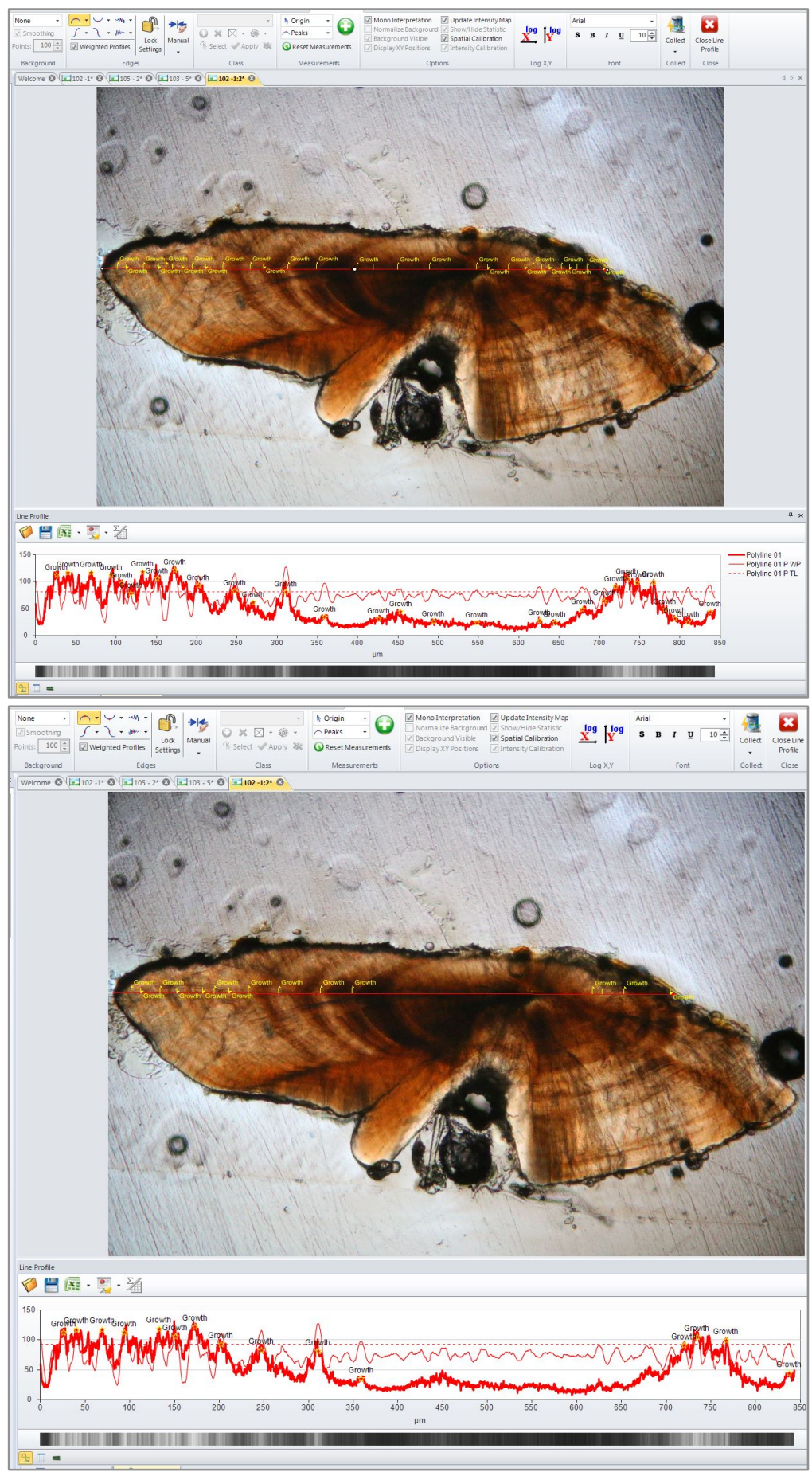

Figure 4.20

Identical transects through the nucleus of a blue cod otolith. The bottom photo shows how changing the threshold settings can reduce the number of growth zones counted by the software. 
Chapter IV $\mid$ Analysis of Otolith Reading Software with Blue Cod Otoliths
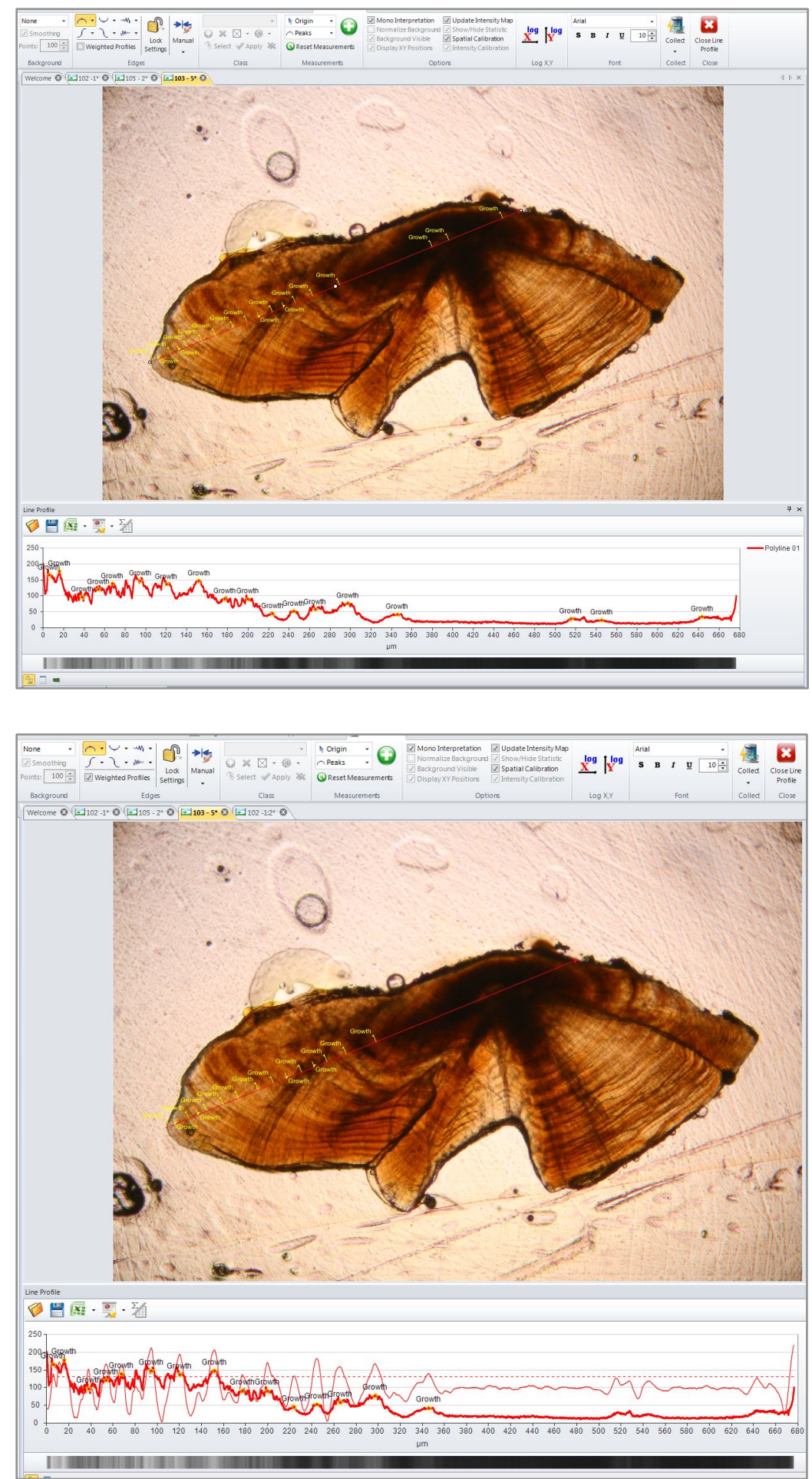

Figure 4.21

Identical transects through the nucleus of a blue cod otolith. The bottom photo shows how changing the threshold settings can reduce the number of growth zones counted by the software. 


\section{OtolithM Growth Zone Finding Functions}

In the Otolith $\mathrm{M}$ application users decide whether peaks, valleys, increasing light, or decreasing light intensity areas along the transect line are counted as growth zones. The following images are examples of these different growth-zone finding functions on the same blue cod otolith image, along an identical transect line. Figures 4.22-4.25 illustrate the different age estimation functions within the Otolith M application. The different functions are used on the same otolith, which is manually aged as 10 years old.

\section{Find peak function}

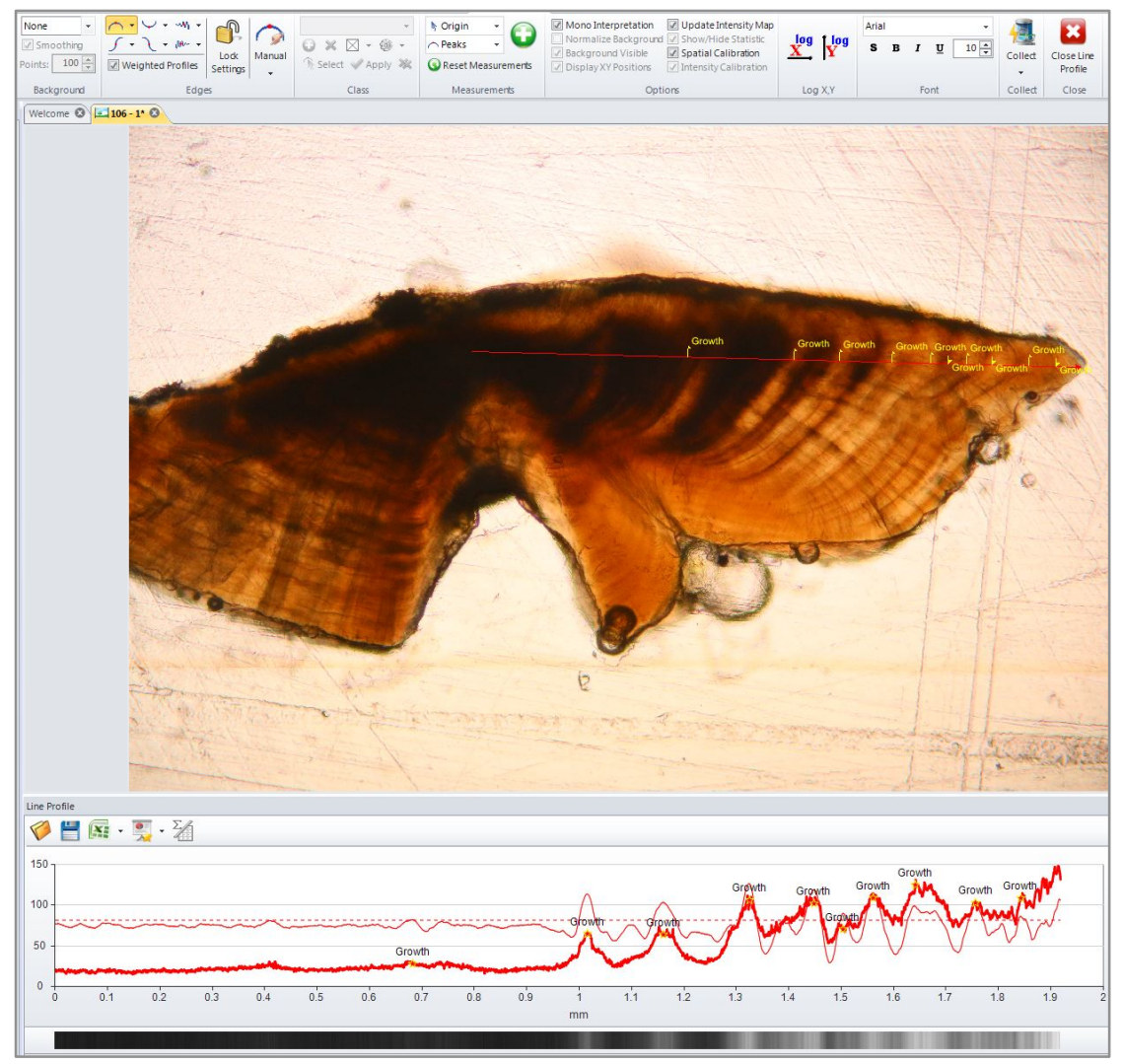

Figure 4.22

The find peak function is used to estimate otolith age along a transect line. Manually estimated age $=10$, peaks found by imaging software $=10$. 


\section{Find valleys function}

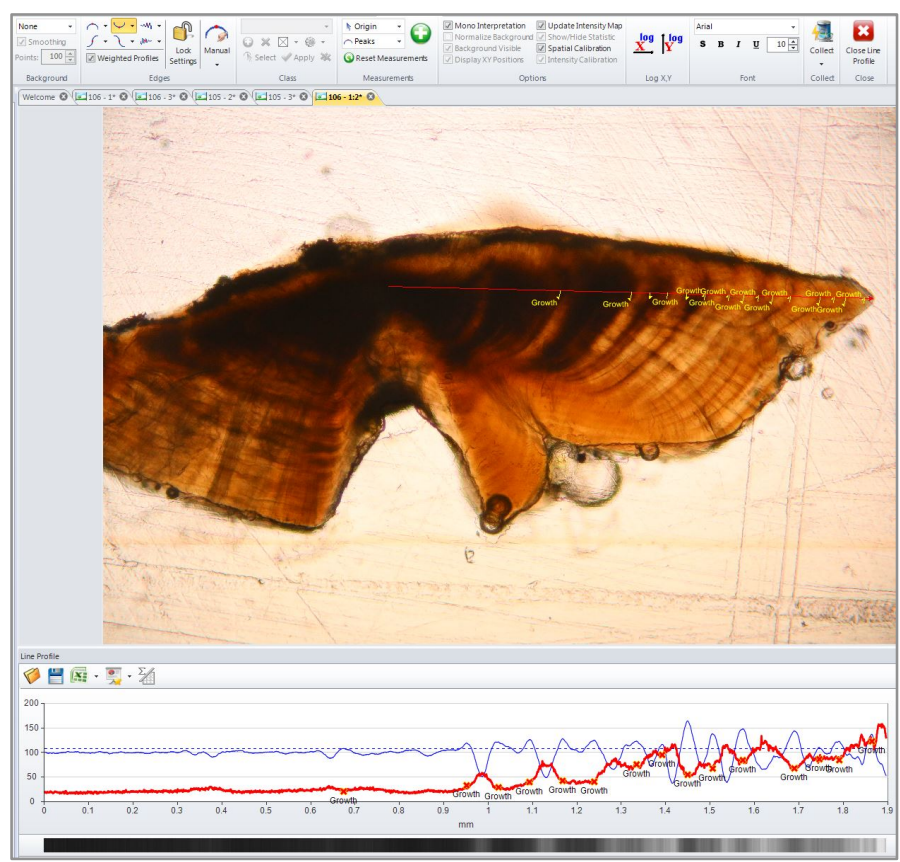

Figure 4.23

The find valleys function is used to estimate otolith age along a transect line. Manually estimated age = 10 , valleys found by imaging software $=15$.

Find lowering values function

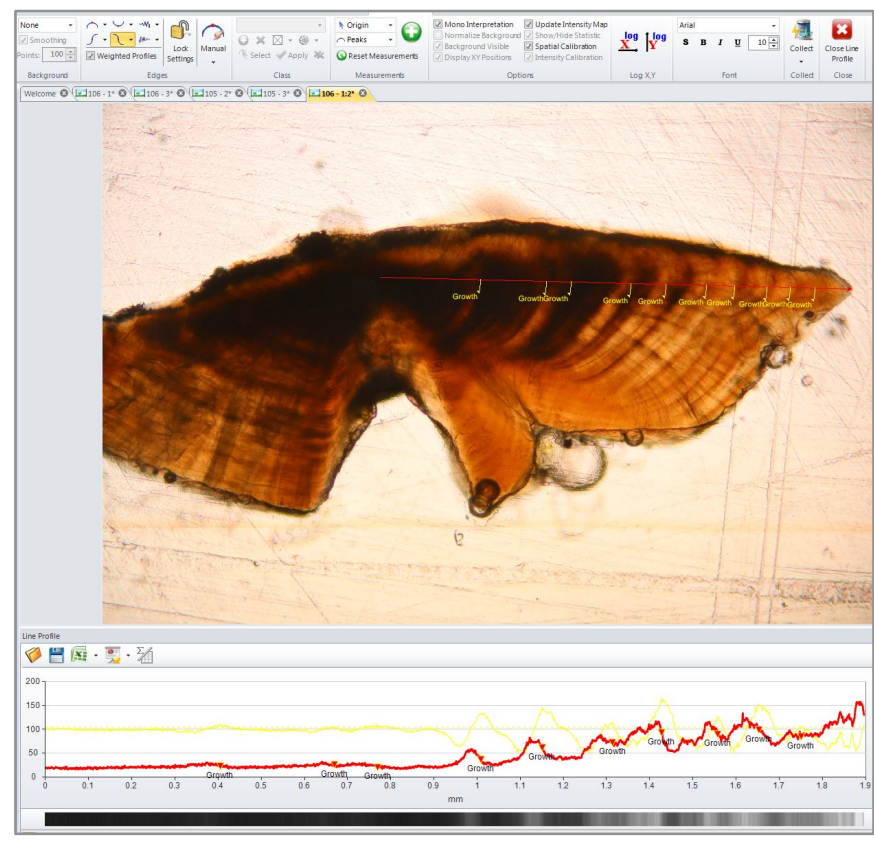

Figure 4.24

The find lowering values function is used to estimate otolith age along a transect line. Manually estimated age $=10$, lowering values points found by imaging software $=10$. 
Finding increasing values function

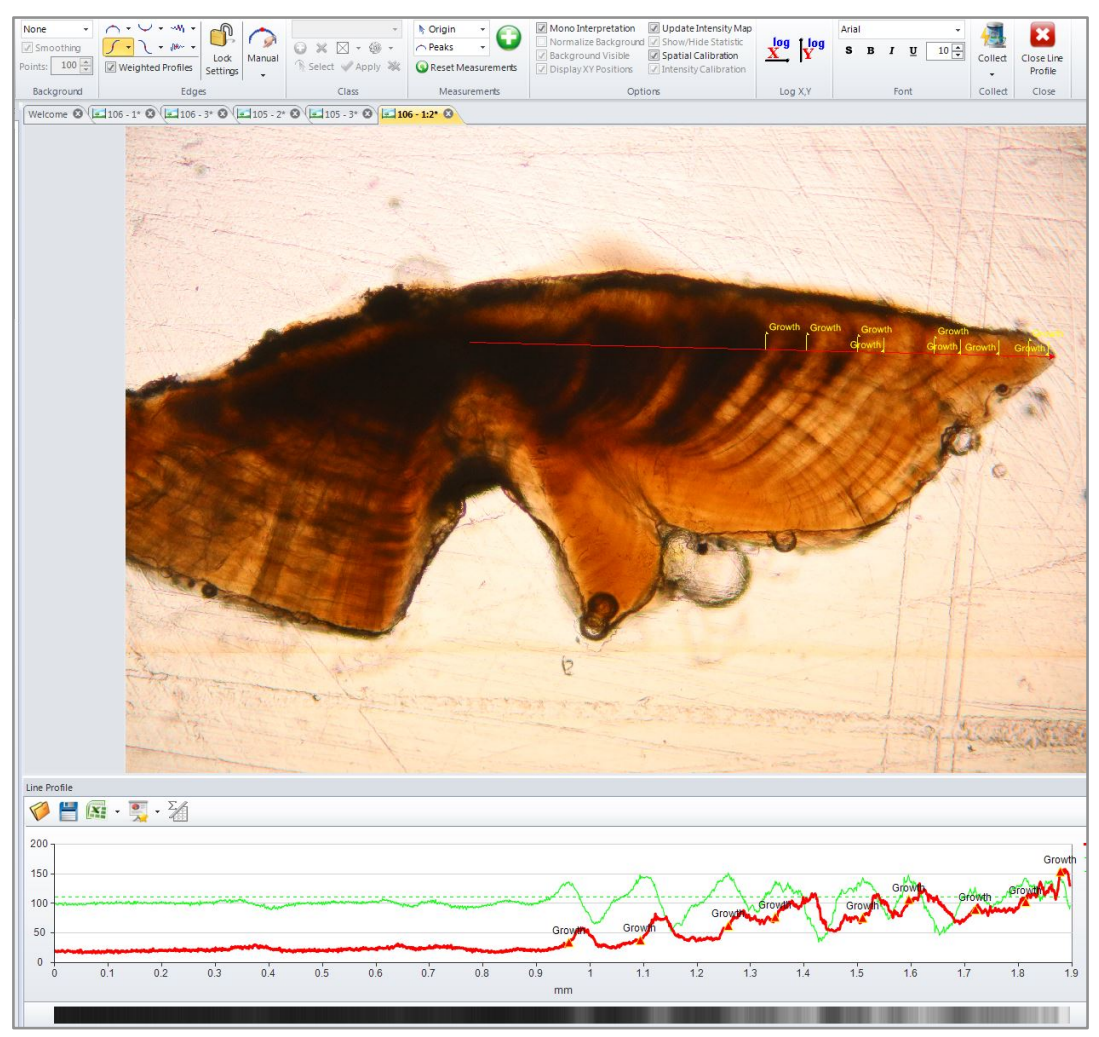

Figure 4.25

The find increasing values function is used to estimate otolith age along a transect line. Manually estimated age $=10$, increasing value points found by imaging software $=9$.

\section{'Good' and 'Bad' Otoliths}

The software performed well when otolith images were clear and otolith growth zones were clearly defined (Figure 4.26). In contrast, the software performed poorly with unclear or blurry images, and with otoliths with check marks and obvious microstructure (Figure 4.27). When the cross-section of the otolith missed the nucleus, additional pseudo-growth rings appear within the actual area of the nucleus and are counted as growth zones by the software (Figure 4.27). 
Chapter IV $\mid$ Analysis of Otolith Reading Software with Blue Cod Otoliths
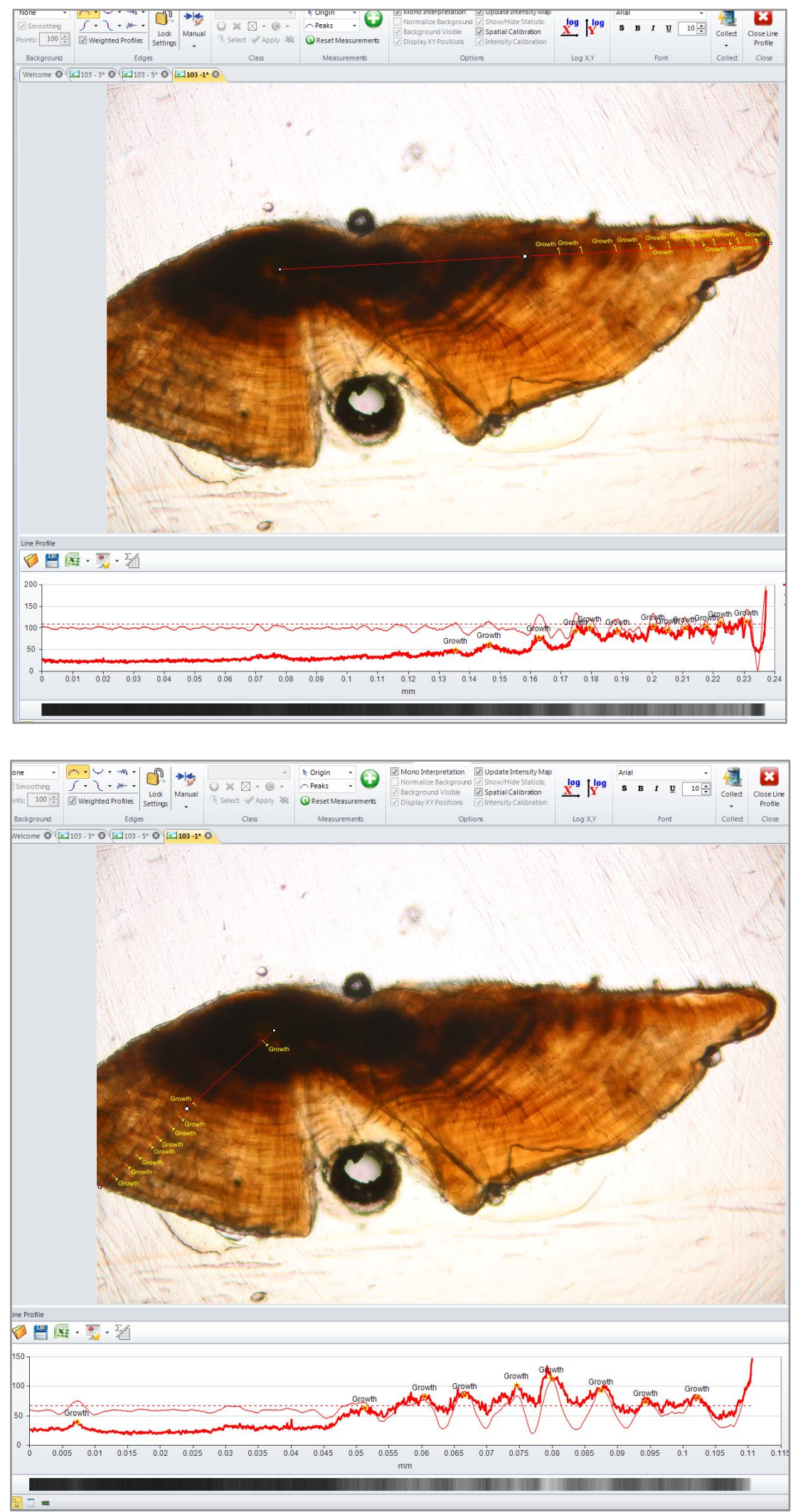

Figure 4.26

Image of an otolith that the software could interpret well. This otolith has clearly defined growth rings, is not blurry, and the section goes through the nucleus. The expert and software estimates were within two years of one another. The expert estimate was 11 years and the software estimates from transects shown above were 10 (top) and 9 (bottom). 

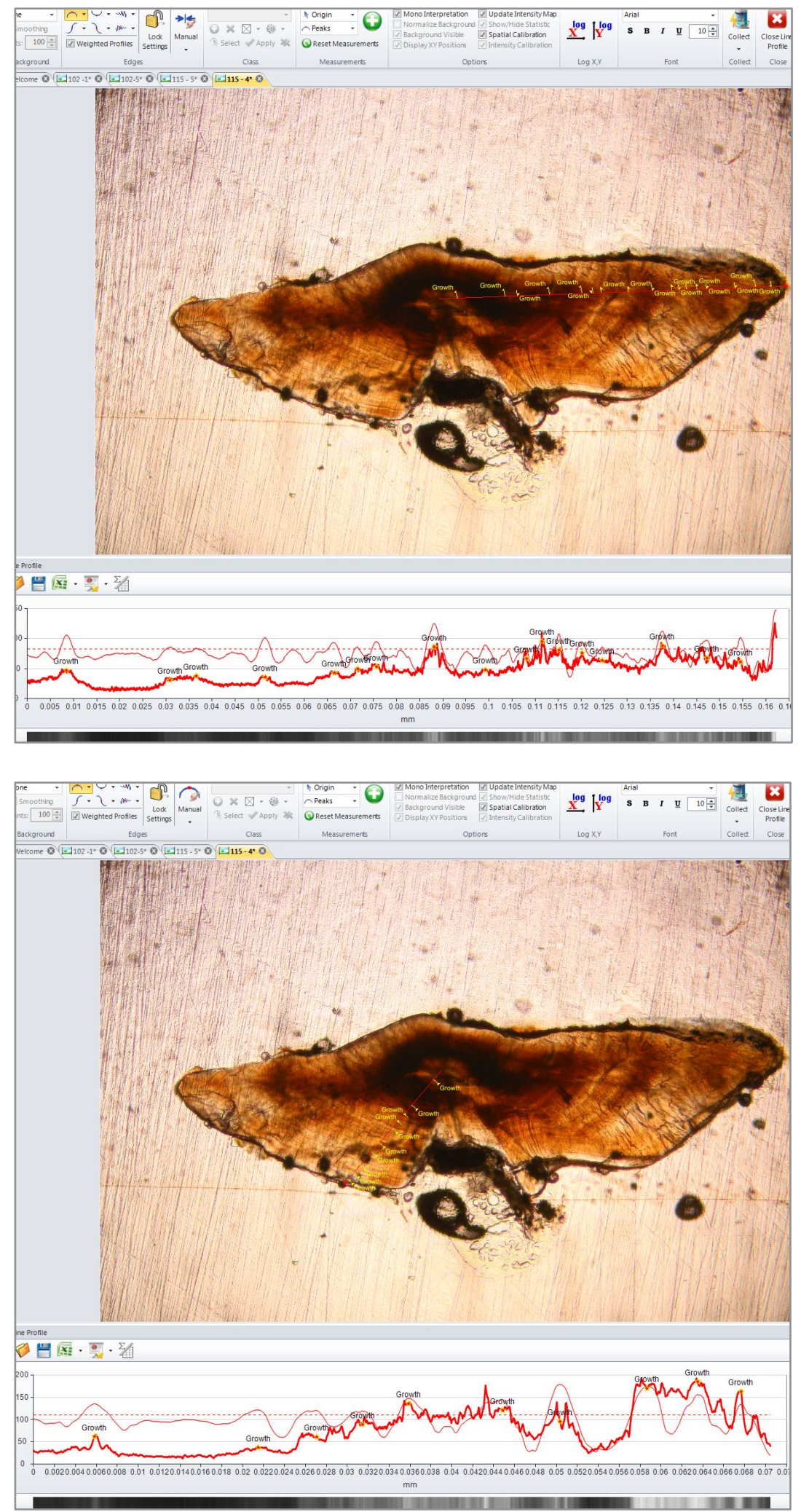

Figure 4.27

Image of an otolith that the software could not interpret well; this otolith has poorly defined growth rings, many check marks and microstructures that were interpreted as growth rings by the software. Furthermore, the cross-section of the otolith has slightly missed the nucleus, exposing a pseudo-growth ring within the nucleus area. The expert estimate was 4 years and the software estimates from above were 17 (top) and 10 (bottom). 
Chapter $V \mid$ Discussion

CHAPTER V

DISCUSSION 


\section{Maturity, Fecundity, and Sex Change in Blue Cod}

The reproductive biology of blue cod was studied using blue cod gonads collected during the 2013 NIWA Marlborough Sounds survey. Maturity classification was carried out by macroscopic inspection of the gonads at sea. A new species-specific histological maturity key was developed and used to classify a subsample of blue cod gonads. These were compared to the macroscopic classifications. There was low agreement between histological and macroscopic maturity classifications (20\% overall). This led to a discrepancy between macroscopic and histological maturity ogives and estimates of length-at-50\% maturity $\left(\mathrm{L}_{50}\right)$. Fecundity was estimated by histological and gravimetric methods, which yielded a far lower estimate of batch fecundity than previously reported, and provided the first estimates of annual fecundity and spawning frequency for blue cod. Relationships between batch fecundity and size, and average egg size and fish size were explored. Finally, compelling evidence for sex change in blue cod was found.

Maturity ogives were fitted to macroscopic and histological maturity data from the subsample, and to the macroscopic maturity data from the larger survey sample. These were used to estimate maturity $\mathrm{L}_{50}$. In the subsample, macroscopic staging underestimated the proportion of mature males in smaller length bins and overestimated $L_{50}$ (macroscopic $=31 \mathrm{~cm}$, histology $=26 \mathrm{~cm}$ ). Macroscopic staging overestimated the proportion of mature females in the smaller length bins and underestimated $\mathrm{L}_{50}$ (macroscopic $=8 \mathrm{~cm}$, histology $=26 \mathrm{~cm}$ ). In the larger sample, a large proportion of males across all length bins were classified as mature which resulted in a considerably lower $\mathrm{L}_{50}(8 \mathrm{~cm})$ than the histology estimate $(26 \mathrm{~cm})$. Female $\mathrm{L}_{50}$ from the larger sample was lower $(20 \mathrm{~cm})$ compared to histology $(26 \mathrm{~cm})$. Misuse of macroscopic stage 5 was suspected, and therefore macroscopic analyses of the larger sample were repeated with this stage removed; $\mathrm{L}_{50}$ estimates for both males and females with stage 5 removed were considerably closer to the histology estimates than the other macroscopic estimates (male $=28 \mathrm{~cm}$, female $=$ $24 \mathrm{~cm})$.

In terms of macroscopic staging, the composition of the histology sample did not accurately reflect that of the larger sample. This was apparent with comparison of macroscopic $\mathrm{L}_{50}$ estimates from the subsample and larger sample, which differed markedly. Therefore, the relative agreement between the histology estimates and macroscopic estimates with stage 5 removed could not be rejected as just a chance occurrence. The subsample did not contain as high a proportion of small mature males (macroscopic classification) as the larger sample, and contained a higher proportion of small mature females (macroscopic classification) than the larger sample. There may have been some temporal, spatial, or observer bias when gonads were 
collected at sea for histology, as the disparity in length-at-maturity between the macroscopic subsample and the larger sample suggests they were not collected at random. Histology is more definitive and accurate at assessing maturity state than macroscopic staging (Klibansky \& Scharf 2015). The comparison between the histology and macroscopic classifications for the subsample demonstrated the inaccuracy of the macroscopic key.

The likely overuse of stage 5 may be the result of observer bias or of a macroscopic maturity key that does not fit the species well. Stage 5 in the macroscopic key means 'spent', however the interpretation of this stage is ambiguous when macroscopically grading. Gonads of fish that have been squashed or mishandled during sampling can appear bruised when dissected, and because bruising is a common feature of spent gonads in macroscopic keys, this may lead to misclassification of maturity stage. Macroscopic keys are commonly unable to differentiate spent and resting gonads (Klibansky \& Scharf 2015). However, in this study, the macroscopically classified spent gonads were: (1) most often histologically mature or ripe/running in males; or (2) allocated to all histological classifications in females.

The best model fit determined by AIC for the female histological data was the capped logistic. Female $\mathrm{L}_{50}$ estimates were lower when a cap parameter was used $(23.6 \mathrm{~cm})$, and the $\mathrm{L}_{\text {to95 }}$ was very low (0.01), indicating knife-edged maturity. The cap parameter indicated that the proportion of females that were mature reached an asymptote at 0.78 . This was attributed to large proportions of developing atretic females, and some developing females in the higher length classes that were classified as "immature". $\mathrm{L}_{50}$ may be more accurately estimated using this model for female blue cod. Further it would provide an estimate of the proportion of the mature length classes that are spawning, which could change estimates of SSB.

Male and female GSI increased as expected from immature to mature using histological maturity data; female GSI was expected to increase through maturity, because ovary weight should increase relative to somatic weight as lipids form in the oocytes and liquids are incorporated into maturing eggs through the hydration process (McMillan 2007). As observed, Stage 5 females were expected to have lower GSI values from shedding of mature oocytes and the absorption of atretic oocytes (McMillan 2007). The male GSI increased sharply from developing to ripe/running and decreased rapidly from ripe/running to spent. Rapid generation of spermatozoa prior to spawning and subsequent release of spermatozoa at spawning was expected, along with high variability in sperm yield (Billard 1986). GSI differed significantly between immature and mature females, and was significantly higher in ripe/running males compared to other stages. In males, only Stage 4 (ripe/running) GSI was significantly higher than other stages. GSI might be a better predictor of maturity in female blue cod than the macroscopic key, or could be used in concert with a revised macroscopic key to improve accuracy. However, GSI would not be a 
suitable measure of maturity for males, as GSI between all immature and mature stages was not significantly different.

In contrast to previous blue cod fecundity research by Beer et al. (2013), there was no positive relationship between egg size and female size found here. However, few egg size measurements were taken in the present study, so egg size estimates presented here may not be representative. In this research, relative fecundity decreased with fish size, however, there was no trend in batch fecundity by fish size. This indicated that larger females produced fewer eggs in each batch than smaller females. Batch fecundity estimates presented here were much lower than previous estimates (Beer et al. 2013), where estimates were in the range of 1,000-20,000 $\mathrm{HO} \mathrm{g}^{-1}$ body weight, compared to this study, where the greatest batch fecundity estimate was about $12 \mathrm{HO} \mathrm{g}^{-1}$ body weight. Comparatively, batch fecundity estimates for other finfish are 2-44 $\mathrm{HO} \mathrm{g}^{-1}$ body weight for Pinguipes brasilianus, another sandperch of the same family (Venerus et al. 2008), about $420 \mathrm{HO} \mathrm{g}^{-1}$ body weight for northern anchovy Engraulis mordax (Hunter \& Macewicz 1980), and $205 \mathrm{HO} \mathrm{g}^{-1}$ body weight in horse mackerel Trachurus trachurus (Karlou-Riga \& Economidis 1997). Blue cod batch fecundity estimates presented in Beer et al. (2013) therefore seem unrealistically high; for example, using Beer et al. (2013) estimates, one female weighing $933 \mathrm{~g}$ and $40 \mathrm{~cm}$ long (TL) was estimated to be carrying 20,469 $\mathrm{HO} \mathrm{g}^{-1}$ body weight, which equates to about 19 million hydrated oocytes in total. The most advanced group of oocytes (MAGO) in the individual (assumed to be HO) were $0.79 \mathrm{~mm}$ in diameter. Therefore, the volume of eggs that was estimated to be within the ovary of the female was approximately $5 \mathrm{~L}$, which is clearly unrealistic in a fish weighing less than $1 \mathrm{~kg}$. In contrast to the present study where $c .1 \mathrm{~g}$ sections from ovaries were used for batch fecundity estimates, Beer et al. (2013) used $0.03-0.05 \mathrm{~g}$ sections, which were scaled up to the total ovary weight. Their very high estimates may have been from a calculation error. Furthermore, Beer et al. (2013) teased the oocytes apart over a $100 \mu \mathrm{m}$ mesh sieve which may have led to the inclusion of primary and secondary oocytes in the samples.

Although this study did not find evidence for greater egg production in larger females, sample sizes were small, and larger female blue cod have been shown to produce more eggs in other studies (Beer et al. 2013). Furthermore, in some other species, it has been shown that larger, older females not only produce more eggs, but also produce larvae with higher survival success (Bobko \& Berkeley 2002; Berkeley et al. 2004). Therefore, large females should still be viewed as very important contributors to population productivity. However, the reduction of relative fecundity in the larger females may be due to some females reducing egg production prior to sex change. The most fecund individuals in this study were $25-27 \mathrm{~cm}$; this may indicate a size at peak fecundity for females. 
Chapter $V \mid$ Maturity, Fecundity, and Sex Change in Blue Cod

The age of POFs has not been validated for blue cod, and the POF age estimates in this study were done by comparison to known age POFs of carpenter seabream. Therefore, the estimates of spawning fraction and annual fecundity presented in this study are preliminary. The rate of deterioration in POFs can vary between species (Hunter \& Macewicz 1985), and also with temperature (Fitzhugh \& Hettler 1995; Alday et al. 2008). POF ages can be validated by inducing ovulation in ripe/running females, euthanizing them at known times past ovulation, then histologically processing the ovarian tissues and documenting the rate of deterioration in POFs over time (Hunter \& Macewicz 1985; Brouwer \& Griffiths 2005). Spawning frequency may differ between size-classes of females and may change throughout the spawning season (Claramunt et al. 2007). In this study, the estimate of spawning frequency was derived from ripe/running females from one sampling day only; the estimate does not capture potential changes in spawning frequency throughout the spawning season. To get an accurate estimate of spawning frequency, POF degeneration needs to be documented for blue cod, and mature females must be collected throughout the spawning season.

It was noted that some females that had early stage POFs (indicating recent ovulation) also had HOs and later stage POFs. This observation suggested continuity of the spawning process rather than distinct spawning episodes. Methods assume once POFs are seen within the ovary, that ovulation has occurred, and it is possible that spawning has occurred thereby reducing the number eggs available for the fecundity counts, therefore the individual ovary is unfit for fecundity analysis due to likely underestimation of fecundity (Hunter \& Macewicz 1985; Murua et al. 2003). When ovaries containing both HOs and early stage POFs were analysed alongside those with no POFs but with HOs, there was no significant difference in batch fecundity estimates. This may suggest that in blue cod spawning events, eggs are released over some time, rather than in distinct episodes, or hydration occurs rapidly following ovulation. Alternatively, following ovulation, eggs could remain within the ovary for a length of time. On the other hand, it may be that POFs degenerate very slowly in blue cod. This highlights the need for POF age validation for blue cod and additional sampling of ripe/running females.

Blue cod sex change was identified histologically in a single blue cod gonad. The testicular and ovarian tissues of the hermaphrodite gonad were macroscopically identifiable. Therefore, a transitional stage might usefully be added to the macroscopic key. The histological section confirmed the work of Carbines (2004b) that blue cod are protogynous hermaphrodites as the ovarian lobe contained atretic oocytes and the testicular lobe was maturing. The finding of only one transitional gonad, together with the observation of many small males suggests that as previously documented (Carbines 2004b), blue cod are diandric (having two male developmental pathways). The histological analysis indicated that small males observed in this 
sample were unlikely to have previously matured as female however. The capped logistic model ogive for female maturity indicated that there was no size where $100 \%$ of females were mature. This was due to a high proportion of developing, and developing atretic gonads in the higher length classes. Developing atretic females were most likely resting females, but could possibly be undergoing sex change. Alternatively, these could be females at the end of their spawning season, or immature females whose gonads began to develop, but reverted back to resting, with no spawning taking place. Additional histological sections of sex changing gonads at various developmental stages are needed to distinguish between resting ovaries and early sex change gonads.

Primary oocytes were found within ripe/running testicular tissue of a blue cod. Although residual oocytes within testicular tissue are considered evidence for previous sex change (Sadovy \& Shapiro 1987), contamination was suspected in this case. This was because the oocytes were found within the sperm duct, which was packed with spermatozoa. When considered evidence for previous sex change, oocytes were expected to be located near the outer margins of testicular tissue and the testis to be of a much less developed state, as observed in Mutch (1983) and Carbines (2004b). Furthermore, there were no oogonia present which are required for oocyte production (McMillan 2007). The oocytes may have been accidentally transferred from an ovarian tissue sample to the testis sample during processing. After dissections of ovarian and testicular samples were taken, the tissues were stored in plastic cassettes within a container filled with ethanol. It is possible some oocytes may have been transferred between cassettes and were lodged within testis tissue. It is also possible that the oocytes were free-floating in the water bath where thin sections of testis were placed during histological tissue processing. The presence of the oocytes within this particular testis cannot be fully dismissed for evidence of sex change, as the process and duration of sex change has not been well documented in blue cod, but contamination was most likely.

The histological and macroscopic stages do mark equivalent steps in sexual development (developing, mature, ripe/running, etc.), but the maturation process is continuous and does not follow discrete steps. The histological key was designed to be objective and precise, by using distinguished changes in oocyte and spermatocyte development to mark the progression of maturity. These same changes are not identifiable macroscopically, therefore, the comparison of the two sets of maturity stages for the same sample would be expected to differ somewhat due to lack of precision in the macroscopic key. Nevertheless, the observed differences between macroscopic and histological classifications were great enough to conclude that the classifications made by the macroscopic key were both inaccurate and imprecise. There may be an issue with the key, or the ability of technical staff to distinguish between stages of the key. 
The relevance of the maturity stage misclassifications between histological and macroscopic methods is that by using macroscopic maturity estimates from the larger sample, $\mathrm{L}_{50}$ was underestimated. An underestimate of $\mathrm{L}_{50}$ would lead to an overestimate of the proportion of the biomass that is mature (SSB). Furthermore, in the histological data it was evident that female maturity-at-length reached an asymptote at 0.78 when a capped logistic ogive was used, therefore, simply using standard logistic $\mathrm{L}_{50}$ estimates to estimate spawning stock biomass may further bias estimates, because about $22 \%$ of "mature" females were in fact immature or resting. Taken together with the estimates of fecundity calculated in this study, which were markedly lower than previously published estimates, the absolute productivity of blue cod stocks may be considerably lower than previously thought.

The rate of sex change, size-at-sex-change, and length-at-maturity in blue cod may be related to fish density (Walker et al. 2010), population structure (presence of large males) (Walker \& McCormick 2009), and changes to environmental conditions (Devlin \& Nagahama 2002). As fishing pressure of blue cod increases, or targets different sizes of blue cod, there will be changes in the mortality rate, population density, and population structure (Berkeley et al. 2004). As the sex composition of blue cod changes with length, changes to recreational fishing regulations such as the slot-size rule, minimum landing size, and daily bag limits are likely to affect the size and sex-specific mortality rate of blue cod. This may therefore change the rate and size of sex change in blue cod, which might lower the female $\mathrm{L}_{50}$, and proportion of mature females ('Cap' parameter), corresponding to lower female SSB. Blue cod may therefore be very sensitive to changes in fishing regulations and increased fishing pressure.

In conclusion, the macroscopic maturity estimates for blue cod were considerably different from those obtained histologically. This led to disparity in size-at-maturity estimates and supports a review of the macroscopic staging key. Blue cod batch fecundity estimates were considerably lower than previously estimated, although more sampling throughout the spawning season and POF age validation is needed to obtain an accurate estimate of annual fecundity and sizefecundity relationships. Finally, this study confirms that blue cod are diandric protogynous hermaphrodites. The macroscopic maturity key for blue cod should be revised and hermaphrodite should be added as a sex class. 


\section{Potential Drivers of Blue Cod Sex Ratio in the Marlborough Sounds}

The 2013 Marlborough Sounds survey data were analysed to investigate the effects of fish density, large male presence, and environmental variables on sex ratio in blue cod. The 2013 data showed marked differences in blue cod abundance and sex ratio throughout the Marlborough Sounds. In the density analyses, sex ratio was not correlated with CPUE. However, the number of fish per pot was a significant predictor of sex ratio in the GLM. The GLM allowed the effect of each factor to be assessed independently. These effects may have been hidden in the correlation analyses. The GLM revealed that sex ratios were influenced by stratum, latitude, and sea condition. Furthermore, in areas where very large males were present, populations were less male-dominated, which supported the hypothesis of large male sex change suppression. Specifically, groups and pots that contained at least one male above $45 \mathrm{~cm}$ had a higher proportion of females than groups and pots not containing a male greater than $45 \mathrm{~cm}$. This suggests that very large males suppress sex change in females. This effect was significant at the pot level, but not the group level. However, a similar trend was seen at the group level where groups with very large males had a higher proportion of females.

In the GLM analysis, the proportion of males increased as number of fish increased, suggesting that denser areas had more male-biased sex ratios. Sex ratio of blue cod populations may be explained by the frequency of sex change or the relative abundance of primary females and primary males. In some sequential hermaphrodites, frequency of sex change is related to the frequency of conspecific interactions (Lutnesky 1994). This is because: (1) occurrence of sex change is a function of social group size, and sizes of conspecifics within groups; and (2) relative fitness benefits of primary sexes in diandric hermaphrodites (primary male, or female) change with density (Warner \& Hoffman 1980). It is suggested that in more dense populations, the ability of a large male to monopolise mating is reduced due to the decrease in territory size and increase in territory overlap, and the possible increase in sneaker male tactics (Mills \& Reynolds 2003). Therefore, the relative fitness of smaller males may increase in more dense populations, which may explain the observed increase in the proportion of male blue cod in pots with more fish.

Mating tactics of male blue cod may differ between populations and disrupt the normal sex ratio. At low densities, dominant males are able to defend territories and monopolise mating with a number of females, or fend off smaller males during spawning and maximise egg fertilisation (Mills \& Reynolds 2003). On the other hand, male blue cod in the Marlborough Sounds might have adopted sneaker male strategies. That is, to appear as females to larger males, but during 
spawning episodes, 'sneak' in and fertilise eggs (Sinervo \& Lively 1996; Mills \& Reynolds 2003). An increase in sneaker males may also help to explain the heavily male-biased sex ratios in the Marlborough Sounds. Species that employ sneaker mating tactics often display colour polymorphisms; dominant male colours differ to females and sneaker males often display female colours (Gross 1982; Sinervo \& Lively 1996). Blue cod display colour polymorphisms (Francis 2001), which are largely sex-specific but have some overlap between sexes (Mutch 1983; Carbines 2004b). The sneaker male strategy has not yet been identified in blue cod, but the sex ratios in some populations and the expression of colour polymorphisms suggest that they could employ this tactic.

The effect of density on sex ratio was weak in the GLM analysis and not significant in the density correlation analyses. A density effect might be obscured by the inability of cod pots to catch small blue cod, or behavioural interactions between fish. It may be that the offer of an easy meal from cod pots enticed subordinate males to enter home ranges of dominant males, disrupting the normal social structure. On the other hand, the differences in density may have been too little to influence sex ratio or sex change frequency, or as blue cod populations have been so heavily fished, the populations may have been out of equilibrium. Primary sex may have been environmentally determined (Ospina-Alvarez \& Piferrer 2008), in which case the conditions that influenced the sex ratios recorded in this study may have changed over time, and therefore, density and environmental conditions at the time of this study may not have influenced the observed sex ratios. Research on smaller, younger blue cod sex ratios, or longterm studies may shed some light on the density, social group composition, and environmental influences on primary sex determination.

The GLM predictors explained $16.4 \%$ of sex ratio variability, indicating that there may be more influential factors that were not measured in this study, or a sizeable random component. Temperature-dependent sex determination is common among teleosts, where higher temperatures have been shown to increase the proportion of males (Ospina-Alvarez \& Piferrer 2008). Temperature was not recorded in this study, but could be recorded in future surveys. Additionally, water currents may influence feeding patterns, abundance, and thus sex ratio of blue cod caught in cod pots. If the environmental preferences between male and female blue cod differ, the conditions in which pots were set may have an influence on the observed sex ratio.

Social factors are thought to be the most influential environmental determinant regulating sex change in hermaphroditic fish (Baroiller et al. 1999). A common explanation for the maleskewed sex ratios in the Marlborough Sounds blue cod is that by disproportionate removal of large males, which suppress sex change in smaller females, populations respond by overcompensation of sex change (Carbines 2004b; Beentjes \& Carbines 2005; MPI 2014). In 
this study, areas where very large blue cod $(>45 \mathrm{~cm})$ were present did indeed have a higher proportion of females. This effect was not apparent where the largest male blue cod was less than $45 \mathrm{~cm}$, suggesting that males might need to be very large for the suppression effect to be felt. However, it was not possible to confidently attribute the difference in sex ratios to sex change, as it is equally plausible that smaller male blue cod emigrated from areas where large male blue cod were present.

Tagging studies indicate that, by and large, blue cod in the Marlborough Sounds tended to stay within $1 \mathrm{~km}$ of the capture site (Carbines 2004b) and within the same headland or reef (Mace \& Johnston 1983). Moreover, smaller blue cod moved further than larger ones. The movement patterns observed by Carbines (2004) and Mace \& Johnson (1983) supported the theory of socially structured populations in blue cod, as was observed in the North Island blue cod populations by Mutch (1983), where large male blue cod controlled loose territories comprised of a number of females. Furthermore, comparison of SCUBA diver counts, spear fishing to determine sex ratio, and cod pot sampling by Cole et al. (2001) showed that sampling by cod pots gave an unbiased estimate of density and sex ratio, however, blue cod that were $<20 \mathrm{~cm}$ were underrepresented when cod pots were used. This study did not catch any blue cod below 16 cm TL. Conversely, Mace \& Jonston (1983) reported cod pots as being an undesirable survey technique for blue cod in the Marlborough sounds. This was because they were difficult to handle on small boats, and were frequently invaded by hagfish Eptatretus cirrhatus, which deposited fish-repelling mucus in the pots. It is not clear why cod pots continue to be used for blue cod surveys given this observation. Conger eels also deter blue cod from entering pots, and consume blue cod within the pots (Mace \& Johnston 1983). Information of conger eel and hagfish presence was not available to this study, so it is not know if this effect was substantial. A believed low movement rate, and acceptable (although not perfect) accuracy of the sampling method, suggests that the group and pot level analyses here were adequate representations of local populations. Therefore my evaluation of hypotheses was valid.

Blue cod sex ratios were spatially variable. In areas where fishing pressure can be assumed to be highest (because of proximity to townships and batches), namely the inner Pelorus and Marlborough Sounds, sex ratios tended to be less male dominated than in other areas. The low movement rates of blue cod observed in other studies (Mace \& Johnston 1983; Beentjes \& Carbines 2005) implies that blue cod may have multiple populations within the survey region. It might be assumed that in areas where fishing pressure was high, removal of large males was similarly high, and therefore, the populations were expected to have responded by increased rate of sex change, and have male-dominated sex ratios. However, the opposite was observed in this study. Assuming that the size-structure of populations were attributed to fishing pressure, and 
that the removal of large males promoted sex change, the male-biased sex ratios of local populations may be attributed to fishing pressure. However, the distribution of recreational fishing pressure within the Marlborough Sounds area is not documented, only anecdotally inferred. Interestingly, the inner Marlborough Sounds were closed to fishing from 2008 to 2011. The removal of fishing pressure with its disproportionate removal of large males may have allowed the population to return, or move towards, an even sex ratio. It is also noted, and mentioned by Henderson (2009), that while the blue cod fishery was closed in the Marlborough Sounds, fishing for other species continued and accidental capture of blue cod is likely to have occurred. Blue cod are prone to post-release mortality (Carbines 1999a), and therefore some fishing mortality on the stock was likely to be experienced during the fishery closure.

This thesis indicates that vary large males might have an effect on sex ratio, whether they inhibit sex change, or otherwise (e.g. exclude small males from areas). However, the analyses were correlation based, so the actual drivers of sex ratio cannot be determined from this study. The current recreational fishing rules in the Marlborough Sounds are a minimum landing size (MLS) of $33 \mathrm{~cm}$ TL and a daily bag limit of 2 fish per person. These may promote the removal of large males, which may cause even more male-biased sex ratios in the future. Furthermore, a small daily bag limit of 2 fish means that fishers might be more likely to target very large fish to make for a fruitful fishing trip. The MLS of $33 \mathrm{~cm}$ may increase the frequency of undersized catches, as the average fish in this survey was $31 \mathrm{~cm}$. The previous rules in the Marlborough Sounds included a slot-size rule, which meant only fish between 30 and $35 \mathrm{~cm}$ TL could be landed. It seems that the replacement of the slot-size rule with a MLS of $33 \mathrm{~cm}$ TL is unlikely to reduce post-release mortality markedly because the return rate of fish below the MLS is likely to remain high. In light of the results of this thesis, the fishery should consider employing a maximum landing size limit of $45 \mathrm{~cm}$, encourage fishers to target mid-range fish, and increase the daily bag limit. This could remove the targeting of large, male fish that may suppress sex change. It may also decrease the return rate of undersized fish, which are susceptible to post-release mortality (Carbines 1999a).

In conclusion, population density, the presence of large males, sampling conditions, and area were all estimated to have some effect on blue cod sex ratio. Sex ratios were spatially variable and there was some evidence to suggest that large males had an influence on sex ratios at the small spatial scale. However, only the presence of very large males $(>45 \mathrm{~cm})$ might influence sex ratios. The male biased sex ratios may be the result of density and increased frequency of sneaker male tactics. Future research should target younger fish and compare density, sex ratio, population structure, and environmental variables over time to get a more accurate indication of 
the factors influencing sex ratios. Furthermore, observational studies would be useful to identify sneaker male behaviour, territorial defence by large males, and spawning behaviour.

\section{Analysis of Otolith Imaging Software With Blue Cod Otoliths}

Image-Pro Premier OtolithM was not consistent in counting growth zones on blue cod otoliths. The software largely overestimated age compared to expert age estimates, with some estimates up to three times that of the expert estimated age. The age estimates of different transect lines on the same otolith were highly variable, and overall age estimates were therefore imprecise; this was found even when the software was calibrated to accurately estimate age on the first transect for that particular otolith. The age estimated by the software was highly dependent upon the transect line chosen, the quality of the otolith image, and the quality of the otolith cross-section. The software was very sensitive to microstructure and was not efficient in resolving or smoothing overall patterns in light intensity, therefore, lines and marks on the otolith that the expert didn't identify as yearly growth zones were identified as growth zones by the software.

When the transect line was drawn across the entire otolith through the nucleus, the software was able to find the first growth zone. However, this was possible only by adjusting the software's threshold settings. The software could not independently identify the nucleus of first growth zone with the default settings.

The benefits of the software were its ability to quickly produce growth increment and age measurements, and that digital copies of the otolith images could be stored in a database system, eliminating the requirement for physical storage of otoliths, and making for quick and easy otolith growth and age analyses.

It seems the human eye is very good at making sense of the overall patterns of translucent and opaque zones of otoliths, despite much variability, and can identify growth patterns quickly and easily. The software is very sensitive to micro scale changes in light intensity. It is therefore necessary to carefully calibrate the software and adjust settings to ensure only "true" growth zones are counted. Therefore, using the software does not yet remove the subjectivity in otolith analyses, because user adjustment is necessary for each otolith.

Main Pessimistic Conclusions

- Poor agreement between expert and software increment counts.

- Highly variable counts between transects of the same otolith. 
\begin{tabular}{l|l} 
Chapter $V$ & Analysis of Otolith Reading Software with Blue Cod Otoliths
\end{tabular}

- Does not identify the nucleus.

- Settings need to be adjusted for each otolith and transect in order to read increments accurately.

- Otoliths sections need to be clear and well cut thought the nucleus to obtain reasonable age measurements.

- Otolith images must be focused and clear.

Main Optimistic Conclusions

- Quick and easy increment width measurements.

- Some growth marks are detected well by the software, accurate age estimates may be possible with software development, but needs to be much more sophisticated.

- Would give reproducible results (in principle), with no reader drift or bias.

\section{Overall Conclusions and Relevance}

This thesis presents a number of key findings, which might influence the management of blue cod in the Marlborough Sounds. Firstly, it was demonstrated that the macroscopic classifications used on the blue cod survey did not accurately measure maturity and led to biased $\mathrm{L}_{50}$ estimates. Biased $\mathrm{L}_{50}$ estimates would lead to biased SSB estimates. The macroscopic maturity key should be reviewed. Secondly, histological methods also identified that females did not reach $100 \%$ maturity in the larger length bins and therefore indicated that female maturity could be better estimated using a three-parameter capped logistic ogive. Thirdly, density and large male presence were shown to influence blue cod sex ratios, and therefore larger male blue cod should be protected in order to help balance blue cod sex ratios. Finally, imaging software did not perform well in ageing of blue cod otoliths. The software had the ability to accurately identify growth zones on some otoliths, but in order for the measurements to be accurate and repeatable, the software needs to be much more sophisticated.

On $20^{\text {th }}$ of December 2015 the Marlborough Sounds area fishery regulations were changed. The slot-rule was replaced by a minimum landing size of $33 \mathrm{~cm}$ and the daily bag limit remained at 2 per person. In a letter to stakeholders, the Honourable Nathan Guy, the Minister for Primary Industries, said:

"I understand that in some areas of the MSA it may be difficult to catch a fish that is larger than $33 \mathrm{~cm}$. In areas where large fish are scarce it is likely that the fishery is in need of rebuild. I 
encourage fishers to avoid these areas until blue cod numbers have recovered, and in the meantime, move to locations where larger fish are more abundant."

In light of research presented here, where in areas or populations where large males are present, the sex ratios are more female dominated than other areas; the targeting of these areas and removal of the large males is likely to further promote male-biased sex ratios in the Marlborough Sounds. Male-biased sex ratios lower overall productivity as eggs become limited, and reduce genetic diversity, which further lowers population viability. Moreover, raising the MLS to $33 \mathrm{~cm}$ TL is likely to promote the occurrence of undersized catch, which are prone to post-release mortality. These regulations may put greater pressure on blue cod stocks, target populations with higher proportions of females, and lower the overall SSB of Marlborough Sounds blue cod. 


\section{BIBLIOGRAPHY}

1.

Alday, A., Uriarte, A., Santos, M., Martín, I., Martinez de Murguia, A. \& Motos, L. (2008). Degeneration of postovulatory follicles of the Bay of Biscay anchovy (Engraulis encrasicolus L.). Scientia Marina, 72, 565-575.

2.

Alonzo, S.H., Ish, T., Key, M., MacCall, A.D. \& Mangel, M. (2008). The importance of incorporating protogynous sex change into stock assessments. Bulletin of Marine Science, 83, 163-179.

3.

Amos, W. \& Harwood, J. (1998). Factors affecting levels of genetic diversity in natural populations. Philosophical Transactions-Royal Society of London Series B Biological Sciences, 353, 177-186.

4.

Andrew, N. \& Francis, M. (2003). The living reef: the ecology of New Zealand's rocky reefs. Craig Potton Publishing.

5.

Baroiller, J.-F., Guiguen, Y. \& Fostier, A. (1999). Endocrine and environmental aspects of sex differentiation in fish. Cellular and Molecular Life Sciences CMLS, 55, 910-931.

6.

Beentjes, M. \& Carbines, G. (2011). Relative abundance, size and age structure, and stock status of blue cod off South Otago in 2010. New Zealand Fisheries Assessment Report, 42, 60.

7.

Beentjes, M.P. \& Carbines, G.D. (2005). Population structure and relative abundance of blue cod (Parapercis colias) off Banks Peninsula and in Dusky Sound, New Zealand. New Zealand Journal of Marine and Freshwater Research, 39, 77-90.

8.

Beentjes, M.P. \& Carbines, G.D. (2012). Relative abundance, size and age structure, and stock status of blue cod from the 2010 survey in Marlborough Sounds, and review of historical surveys. New Zealand Fisheries Assessment Report, 43. 
9.

Beer, N. \& Wing, S. (2013). Trophic ecology drives spatial variability in growth among subpopulations of an exploited temperate reef fish. New Zealand Journal of Marine and Freshwater Research, 47, 73-89.

10.

Beer, N., Wing, S. \& Carbines, G. (2013). First estimates of batch fecundity for Parapercis colias, a commercially important temperate reef fish. New Zealand Journal of Marine and Freshwater Research, 47, 587-594.

11.

Berkeley, S.A., Hixon, M.A., Larson, R.J. \& Love, M.S. (2004). Fisheries sustainability via protection of age structure and spatial distribution of fish populations. Fisheries, 29, 2332.

12.

Billard, R. (1986). Spermatogenesis and spermatology of some teleost fish species. Reproduction Nutrition Développement, 26, 877-920.

13.

Birkeland, C. \& Dayton, P.K. (2005). The importance in fishery management of leaving the big ones. Trends in Ecology \& Evolution, 20, 356-358.

14.

Bobko, S.J. \& Berkeley, S.A. (2002). Maturity schedule, ovarian cycle, fecundity, and agespecific parturition of black rockfish, Sebastes melanops, off the Oregon coast. Redacted for Privacy, 13.

15.

Brouwer, S.L. \& Griffiths, M. (2005). Reproductive biology of carpenter seabream (Argyrozona argyrozona)(Pisces: Sparidae) in a marine protected area. Fishery Bulletin, 103, 258269.

16.

Campana, S. (2001). Accuracy, precision and quality control in age determination, including a review of the use and abuse of age validation methods. Journal of fish biology, 59, 197242.

17.

Carbines, G. (1999a). Large hooks reduce catch-and-release mortality of blue cod Parapercis colias in the Marlborough Sounds of New Zealand. North American Journal of Fisheries Management, 19, 992-998. 
18.

Carbines, G., Jiang, W. \& Beentjes, M.P. (2004). The impact of oyster dredging on the growth of blue cod, Parapercis colias, in Foveaux Strait, New Zealand. Aquatic Conservation: Marine and Freshwater Ecosystems, 14, 491-504.

19.

Carbines, G. \& McKenzie, J. (2001). Movement patterns and stock mixing of blue cod in Southland (BCO 5). Final Research Report for Ministry of Fisheries Project BC09702. 16 p.(Unpublished report held by Ministry of Fisheries, Wellington.).

20.

Carbines, G.D. (1999b). Large hooks reduce catch-and-release mortality of blue cod Parapercis colias in the Marlborough Sounds of New Zealand. North American Journal of Fisheries Management, 19, 992-998.

21.

Carbines, G.D. (2004a). Age determination, validation, and growth of blue cod Parapercis colias, in Foveaux Strait, New Zealand. New Zealand journal of marine and freshwater research, 38, 201-214.

22.

Carbines, G.D. (2004b). Age, growth, movement and reproductive biology of blue cod (Parapercis colias-Pinguipedidae): Implications for fisheries management in the South Island of New Zealand. University of Otago.

23.

Carbines, G.D. \& Beentjes, M.P. (2003). Relative abundance of blue cod in Dusky Sound in 2002. Ministry of Fisheries.

24.

Chilton, D.E. \& Beamish, R.J. (1982). Age determination methods for fishes studied by the groundfish program at the Pacific Biological Station. Department of Fisheries and Oceans.

25 .

Claramunt, G., Serra, R., Castro, L. \& Cubillos, L. (2007). Is the spawning frequency dependent on female size? Empirical evidence in Sardinops sagax and Engraulis ringens off northern Chile. Fisheries Research, 85, 248-257.

26.

Cleveland, W.S. (1979). Robust locally weighted regression and smoothing scatterplots. Journal of the American statistical association, 74, 829-836. 
27.

Cole, K.S. \& Shapiro, D.Y. (1995). Social faciliation and sensory mediation of adult sex change in a cryptic, benthic marine goby. Journal of experimental marine biology and ecology, $186,65-75$.

28.

Cole, R., Tindale, D. \& Blackwell, R. (2001). A comparison of diver and pot sampling for blue cod (Parapercis colias: Pinguipedidae). Fisheries research, 52, 191-201.

29.

Cole, R.G., Davey, N.K., Carbines, G.D. \& Stewart, R. (2012). Fish-habitat associations in New Zealand: geographical contrasts. Marine Ecology Progress Series, 450, 131-145.

30.

Cole, R.G., Villouta, E. \& Davidson, R.J. (2000). Direct evidence of limited dispersal of the reef fish Parapercis colias (Pinguipedidae) within a marine reserve and adjacent fished areas. Aquatic Conservation: Marine and Freshwater Ecosystems, 10, 421-436.

31.

Davey, N., Cole, R. \& Cairney, D. (2006). Survey of marine recreational fishing along the West Coast, South Island. Final Research Report for Ministry of Fisheries Research Project REC2005-04 Objectives 1 \&2. National Institute of Water and Atmospheric Research.

32.

Devlin, R.H. \& Nagahama, Y. (2002). Sex determination and sex differentiation in fish: an overview of genetic, physiological, and environmental influences. Aquaculture, 208, 191-364.

33.

Donelson, J., Munday, P., McCormick, M., Pankhurst, N. \& Pankhurst, P. (2010). Effects of elevated water temperature and food availability on the reproductive performance of a coral reef fish. Marine Ecology Progress Series, 401, 233-243.

34.

Dunn, O.J. (1964). Multiple comparisons using rank sums. Technometrics, 6, 241-252.

35.

Erisman, B.E., Petersen, C.W., Hastings, P.A. \& Warner, R.R. (2013). Phylogenetic perspectives on the evolution of functional hermaphroditism in teleost fishes. Integrative and comparative biology, 53, 736-754.

36.

Fitzhugh, G.R. \& Hettler, W. (1995). Temperature influence on postovulatory follicle degeneration in Atlantic menhaden, Brevoortia tyrannus. Fishery Bulletin-National Oceanic and Atmospheric Administration, 93, 568-568. 
37.

Forrest, R.E., Martell, S.J., Melnychuk, M.C. \& Walters, C.J. (2008). An age-structured model with leading management parameters, incorporating age-specific selectivity and maturity. Canadian Journal of Fisheries and Aquatic Sciences, 65, 286-296.

38.

Francis, M. (2001). Coastal fishes of New Zealand: an identification guide. Raupo.

39.

Francis, R. \& Horn, P. (1997). Transition zone in otoliths of orange roughy (Hoplostethus atlanticus) and its relationship to the onset of maturity. Marine biology, 129, 681-687.

40.

Ghiselin, M.T. (1969). The evolution of hermaphroditism among animals. Quarterly Review of Biology, 189-208.

41.

Green, B.S., Mapstone, B.D., Carlos, G. \& Begg, G.A. (2009). Introduction to otoliths and fisheries in the tropics. Springer.

42.

Grier, H.J. (1981). Cellular organization of the testis and spermatogenesis in fishes. American Zoologist, 21, 345-357.

43.

Gross, M.R. (1982). Sneakers, satellites and parentals: polymorphic mating strategies in North American sunfishes. Zeitschrift für Tierpsychologie, 60, 1-26.

44.

Hawkins, J.P. \& Roberts, C.M. (2004). Effects of fishing on sex-changing Caribbean parrotfishes. Biological Conservation, 115, 213-226.

45.

Henderson, I. (2009). Optimising recreational harvests of blue cod: The effects of catch-andrelease mortality and size selectivity. Fisheries Research, 99, 184-195.

46.

Hourigan, T.F. (1989). Environmental determinants of butterflyfish social systems. Environmental Biology of Fishes, 25, 61-78.

47.

Hunter, J. \& Macewicz, B.J. (1980). Sexual maturity, batch fecundity, spawning frequency, and temporal pattern of spawning for the northern anchovy, Engraulis mordax, during the 1979 spawning season. Calif. Coop. Oceanic Fish. Invest. Rep, 21, 139-149. 
48.

Hunter, J.R. \& Macewicz, B.J. (1985). Measurement of spawning frequency in multiple spawning fishes. NOAA Technical Report NMFS, 36, 79-94.

49.

Jiang, W. \& Carbines, G. (2002). Diet of blue cod, Parapercis colias, living on undisturbed biogenic reefs and on seabed modified by oyster dredging in Foveaux Strait, New Zealand. Aquatic Conservation: Marine and Freshwater Ecosystems, 12, 257-272.

50.

Källqvist, E.M., Pirker, J.G. \& Marsden, I.D. (2015). Assessment of Recreational Fishing within the Akaroa Harbour Taiāpure Management Area, South Island Te Waipounamu, New Zealand. New Zealand Natural Sciences, 40, 1-15.

51.

Kamler, E. (2005). Parent-egg-progeny relationships in teleost fishes: an energetics perspective. Reviews in Fish Biology and Fisheries, 15, 399-421.

52.

Karlou - Riga, C. \& Economidis, P. (1997). Spawning frequency and batch fecundity of horse mackerel, Trachurus trachurus (L.), in the Saronikos Gulf (Greece). Journal of Applied Ichthyology, 13, 97-104.

53.

Kimura, D.K. \& Lyons, J.J. (1991). Between-reader bias and variability in the age-determination process. Fishery Bulletin, 89, 53-60.

54.

Klibansky, N. \& Scharf, F. (2015). Success and failure assessing gonad maturity in sequentially hermaphroditic fishes: comparisons between macroscopic and microscopic methods. Journal of Fish Biology, 87, 930-957.

55.

Leach, F., Davidson, J. \& Fraser, K. (1999). Pre-European catches of blue cod (Parapercis colias) in the Chatham Islands and Cook Strait, New Zealand. New Zealand Journal of Archaeology, 21, 119-138.

56.

Liu, M. \& Sadovy, Y. (2004). The influence of social factors on adult sex change and juvenile sexual differentiation in a diandric, protogynous epinepheline, Cephalopholis boenak (Pisces, Serranidae). Journal of Zoology, 264, 239-248. 
57.

Lloret, J., de Sola, L.G., Souplet, A. \& Galzin, R. (2002). Effects of large-scale habitat variability on condition of demersal exploited fish in the north-western Mediterranean. ICES Journal of Marine Science: Journal du Conseil, 59, 1215-1227.

58.

Lutnesky, M.M. (1994). Density-dependent protogynous sex change in territorial-haremic fishes: models and evidence. Behavioral Ecology, 5, 375-383.

59.

Mace, J. \& Johnston, A. (1983). Tagging experiments on blue cod (Parapercis colias) in the Marlborough Sounds, New Zealand. New Zealand Journal of Marine and Freshwater Research, 17, 207-211.

60.

Martell, S.J., Pine, W.E. \& Walters, C.J. (2008). Parameterizing age-structured models from a fisheries management perspective. Canadian Journal of Fisheries and Aquatic Sciences, $65,1586-1600$.

61.

McKight, P.E. \& Najab, J. (2010). Kruskal - Wallis Test. Corsini Encyclopedia of Psychology.

62.

McMillan, D.B. (2007). Fish histology: female reproductive systems. Springer Science \& Business Media.

63.

Mercier, L., Panfili, J., Paillon, C., N'diaye, A., Mouillot, D. \& Darnaude, A.M. (2011). Otolith reading and multi-model inference for improved estimation of age and growth in the gilthead seabream Sparus aurata (L.). Estuarine, Coastal and Shelf Science, 92, 534-545.

64.

Mills, S.C. \& Reynolds, J.D. (2003). Operational sex ratio and alternative reproductive behaviours in the European bitterling, Rhodeus sericeus. Behavioral Ecology and Sociobiology, 54, 98-104.

65.

Morales-Nin, B. (1992). Determination of growth in bony fishes from otolith microstructure. Food \& Agriculture Org.

66.

Morgan, M.J. (2008). Integrating reproductive biology into scientific advice for fisheries management. J. Northwest Atl. Fish. Sci, 41, 37-51. 
67.

MPI (2014). Fisheries Assessment Plennary November 2014: Stock Assessments and Stock Status.

68.

MPI (2015a). Blue cod regulatory review for the Marlborough Sounds and Challenger East areas

69.

MPI (2015b). Stock assessments and stock status volume 1: Introductory sections to hoki. Fisheries Assessment Planary, 1, 114.

70.

Munday, P.L., Buston, P.M. \& Warner, R.R. (2006a). Diversity and flexibility of sex-change strategies in animals. Trends in Ecology \& Evolution, 21, 89-95.

71.

Munday, P.L., White, J.W. \& Warner, R.R. (2006). A social basis for the development of primary males in a sex-changing fish. Proceedings of the Royal Society of London B: Biological Sciences, 273, 2845-2851.

72.

Murua, H., Kraus, G., Saborido-Rey, F., Witthames, P.R., Thorsen, A. \& Junquera, S. (2003). Procedures to estimate fecundity of marine fish species in relation to their reproductive strategy. Journal of Northwest Atlantic fishery science, 33, 33-54.

73.

Mutch, P.G. (1983). Factors influencing the density and distribution of the blue cod (Parapercis colias)(Pisces: Mugiloididae). University of Auckland.

74.

Nakamura, M., Kobayashi, Y., Miura, S., Alam, M.A. \& Bhandari, R.K. (2005). Sex change in coral reef fish. Fish physiology and biochemistry, 31, 117-122.

75.

Nelson, J.S. (2006). Fishes of the World. John Wiley \& Sons, New York.

76.

Ospina-Alvarez, N. \& Piferrer, F. (2008). Temperature-dependent sex determination in fish revisited: prevalence, a single sex ratio response pattern, and possible effects of climate change. PLoS One, 3, e2837-e2837.

77.

Pankhurst, N. \& Conroy, A. (1987). Seasonal changes in reproductive condition and plasma levels of sex steroids in the blue cod, Parapercis colias (Bloch and Schneider)(Mugiloididae). Fish Physiology and Biochemistry, 4, 15-26. 
78.

Pankhurst, N. \& Kime, D. (1991). Plasma sex steroid concentrations in male blue cod, Parapercis colias (Bloch \& Schneider)(Pinguipedidae), sampled underwater during the spawning season. Marine and Freshwater Research, 42, 129-137.

79.

Parker, K. (1980). A direct method for estimating Northern Anchovy, Engraulis mordax, spawning biomass. NATL MARINE FISHERIES SERVICE SCIENTIFIC PUBL OFFICE 7600 SAND POINT WAY NE BIN C15700, SEATTLE, WA 98115, pp. 541544.

80.

Rapson, A. (1956). Biology of the blue cod (Parapercis colias Forster) of New Zealand. Victoria University College.

81.

Reinboth, R. (1983). The peculiarities of gonad transformation in teleosts. Differentiation, 23, S82-S86.

82.

Robertson, D.A. (1973). Planktonic eggs and larvae of some New Zealand marine teleosts. University of Otago.

83.

Ross, R.M., Losey, G.S. \& Diamond, M. (1983). Sex change in a coral-reef fish: dependence of stimulation and inhibition on relative size. Science(Washington), 217, 574-576.

84.

Russell, B. (1975). The development and dynamics of a small artificial reef community. Helgoländer wissenschaftliche Meeresuntersuchungen, 27, 298-312.

85.

Sadovy, Y. \& Shapiro, D.Y. (1987). Criteria for the diagnosis of hermaphroditism in fishes. Copeia, 136-156.

86.

Sardenne, F., Dortel, E., Le Croizier, G., Million, J., Labonne, M., Leroy, B. et al. (2015). Determining the age of tropical tunas in the Indian Ocean from otolith microstructures. Fisheries Research, 163, 44-57.

87.

Shapiro, D. \& Rasotto, M.B. (1993). Sex differentiation and gonadal development in the diandric, protogynous wrasse, Thalassoma bifasciatum (Pisces, Labridae). Journal of Zoology, 230, 231-245. 
88.

Shapiro, D.Y. (1983). Distinguishing behavioral interactions from visual cues as causes of adult sex change in a coral reef fish. Hormones and behavior, 17, 424-432.

89.

Siau, Y. (1994). Population structure, reproduction and sex - change in a tropical East Atlantic grouper. Journal of fish biology, 44, 205-211.

90.

Sinervo, B. \& Lively, C.M. (1996). The rock-paper-scissors game and the evolution of alternative male strategies. Nature, 380, 240-243.

91.

Smith, H.M. (2012). Characterisation of the Mitochondrial Genome and the Phylogeographic Structure of Blue Cod (Parapercis colias).

92.

Trip, E., Clements, K., Raubenheimer, D. \& Choat, J. (2011). Reproductive biology of an odacine labrid, Odax pullus. Journal of fish biology, 78, 741-761.

93.

Trivers, R.L. \& Willard, D.E. (1973). Natural selection of parental ability to vary the sex ratio of offspring. Science, 179, 90-92.

94.

Venerus, L., Parma, A. \& Galván, D. (2008). Annual occupation pattern of temperate rocky reefs by the Argentine sandperch Pseudopercis semifasciata in San José Gulf Marine Park, Argentina. Fisheries Management and Ecology, 15, 217-229.

95.

Venerus, L.A., Irigoyen, A.J., Galván, D.E. \& Parma, A.M. (2014). Spatial dynamics of the Argentine sandperch, Pseudopercis semifasciata (Pinguipedidae), in temperate rocky reefs from northern Patagonia, Argentina. Marine and Freshwater Research, 65, 39-49.

96.

Vignaux, M. (1993). Catch per unit of effort (CPUE) analysis of the hoki fishery, 1987-92. MAF Fisheries.

97.

Vitale, F., Svedäng, H. \& Cardinale, M. (2006). Histological analysis invalidates macroscopically determined maturity ogives of the Kattegat cod (Gadus morhua) and suggests new proxies for estimating maturity status of individual fish. ICES Journal of Marine Science: Journal du Conseil, 63, 485-492.

98. 
Walker, S.P. \& McCormick, M.I. (2009). Fish ears are sensitive to sex change. Biology letters, 5, 73-76.

99.

Walker, S.P., Thibaut, L. \& McCormick, M.I. (2010). Density - Dependent Sex Ratio Adjustment and the Allee Effect: A Model and a Test Using a Sex - Changing Fish. The American Naturalist, 176, 312-321.

100.

Wallace, R.A. \& Selman, K. (1981). Cellular and dynamic aspects of oocyte growth in teleosts. American Zoologist, 21, 325-343.

101.

Warner, R.R. (1984). Deferred reproduction as a response to sexual selection in a coral reef fish: a test of the life historical consequences. Evolution, 148-162.

102.

Warner, R.R. \& Hoffman, S.G. (1980). Local population size as a determinant of mating system and sexual composition in two tropical marine fishes (Thalassoma spp.). Evolution, 508518.

103.

West, G. (1990). Methods of assessing ovarian development in fishes: a review. Marine and Freshwater Research, 41, 199-222.

104.

Wilson, C.A. \& Nieland, D.L. (1994). Reproductive biology of red drum, Sciaenops ocellatus, from the neritic waters of the northern Gulf of Mexico. Fishery Bulletin, 92, 841-850.

105.

Wilson, D. \& McCormick, M. (1997). Spatial and temporal validation of settlement-marks in the otoliths of tropical reef fishes. Marine Ecology Progress Series, 153, 259-271.

106.

Ye, Z., Zhang, C., Panhwar, S., Li, Z. \& Wan, R. (2015). Ageing Belanger's croaker, Johnius belangerii (Cuvier, 1830), based on otolith shape analysis. Journal of Applied Ichthyology, 31, 27-31. 


\section{APPENDIX I}

In this appendix, model fits are illustrated for each maturity ogive calculated in Chapter 2. Each model is illustrated in two panels, the upper panel showing the observed data (points) and the model fit (solid line), with $\mathrm{L}_{50}$ estimate (broken line). The lower panel shows the residuals for the model fit. The headings "larger sample" refer to the total $(n=3247)$, and "subsample" to the sample used for histology $(\mathrm{n}=252)$.

\section{Females Macroscopic GLM (larger sample)}
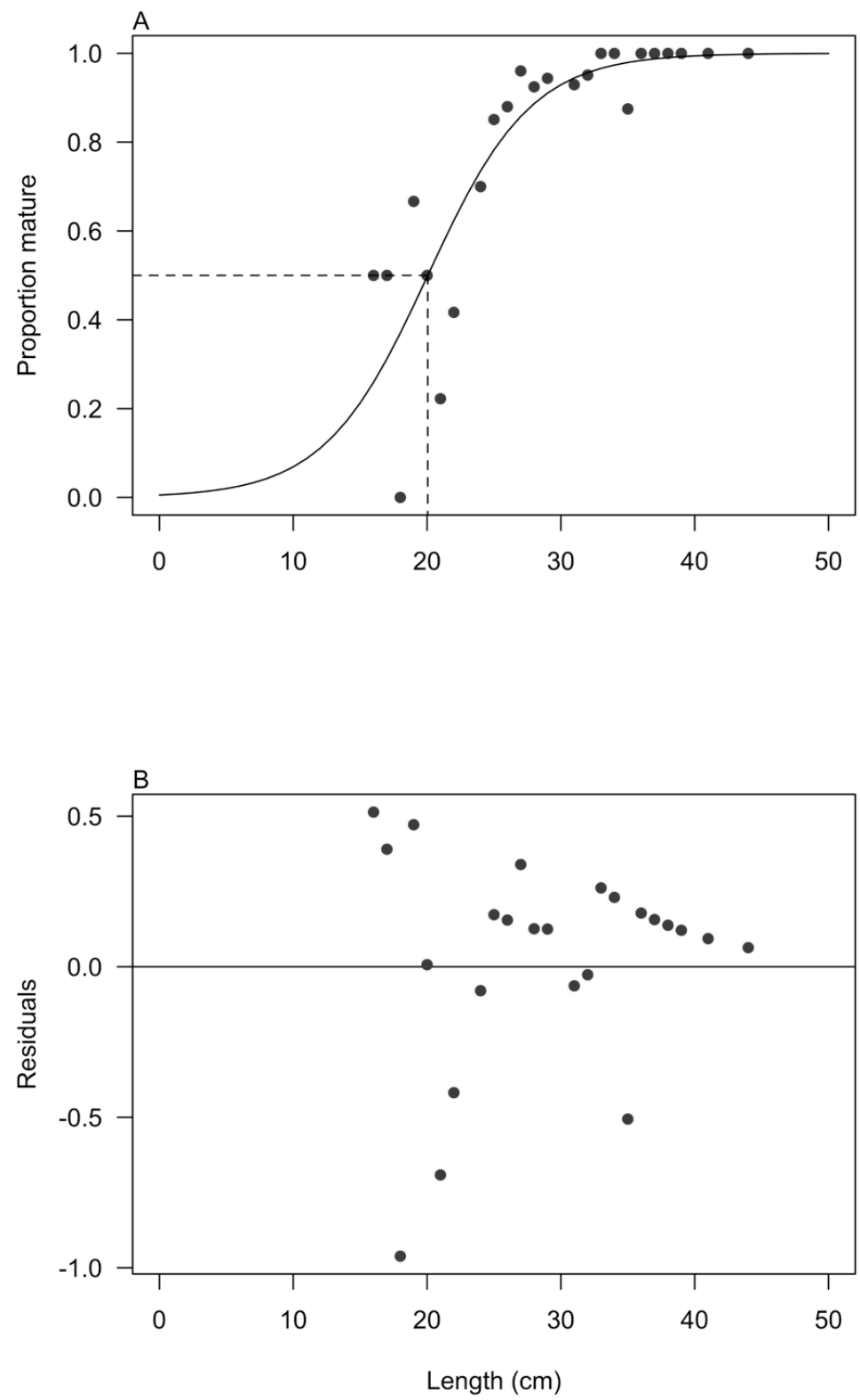
Males Macroscopic GLM (larger sample)
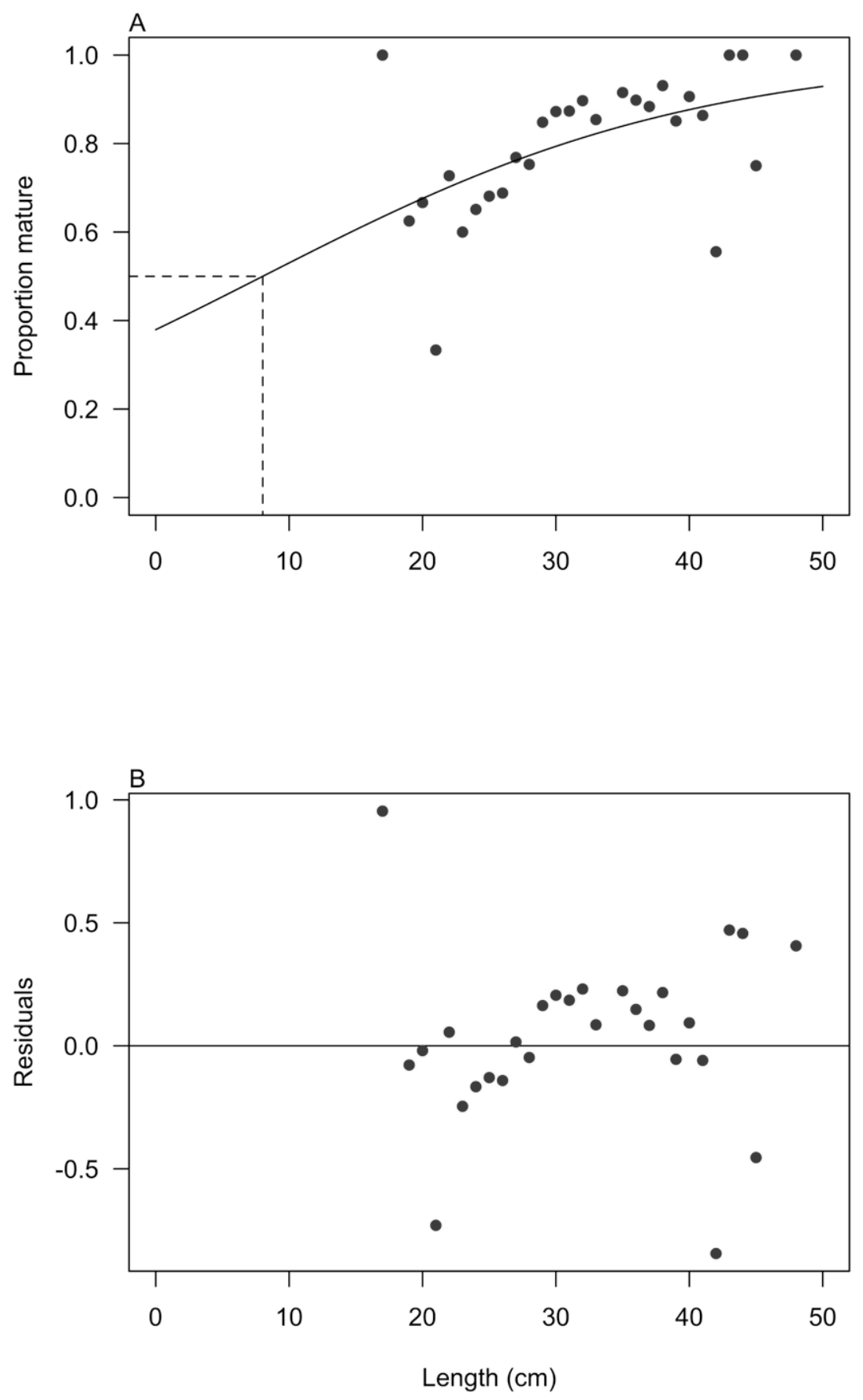
Females Histology GLM
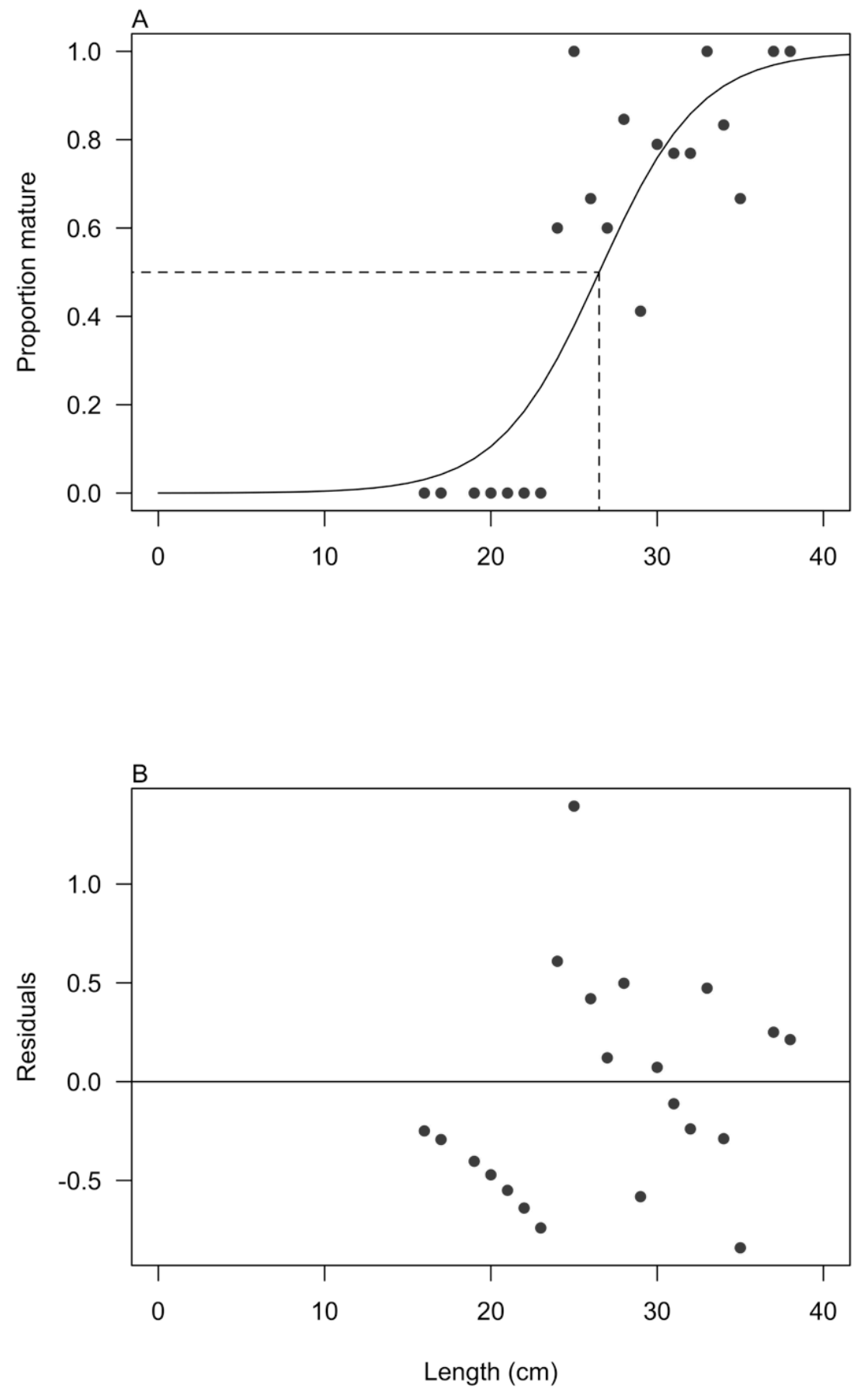
Males Histology GLM
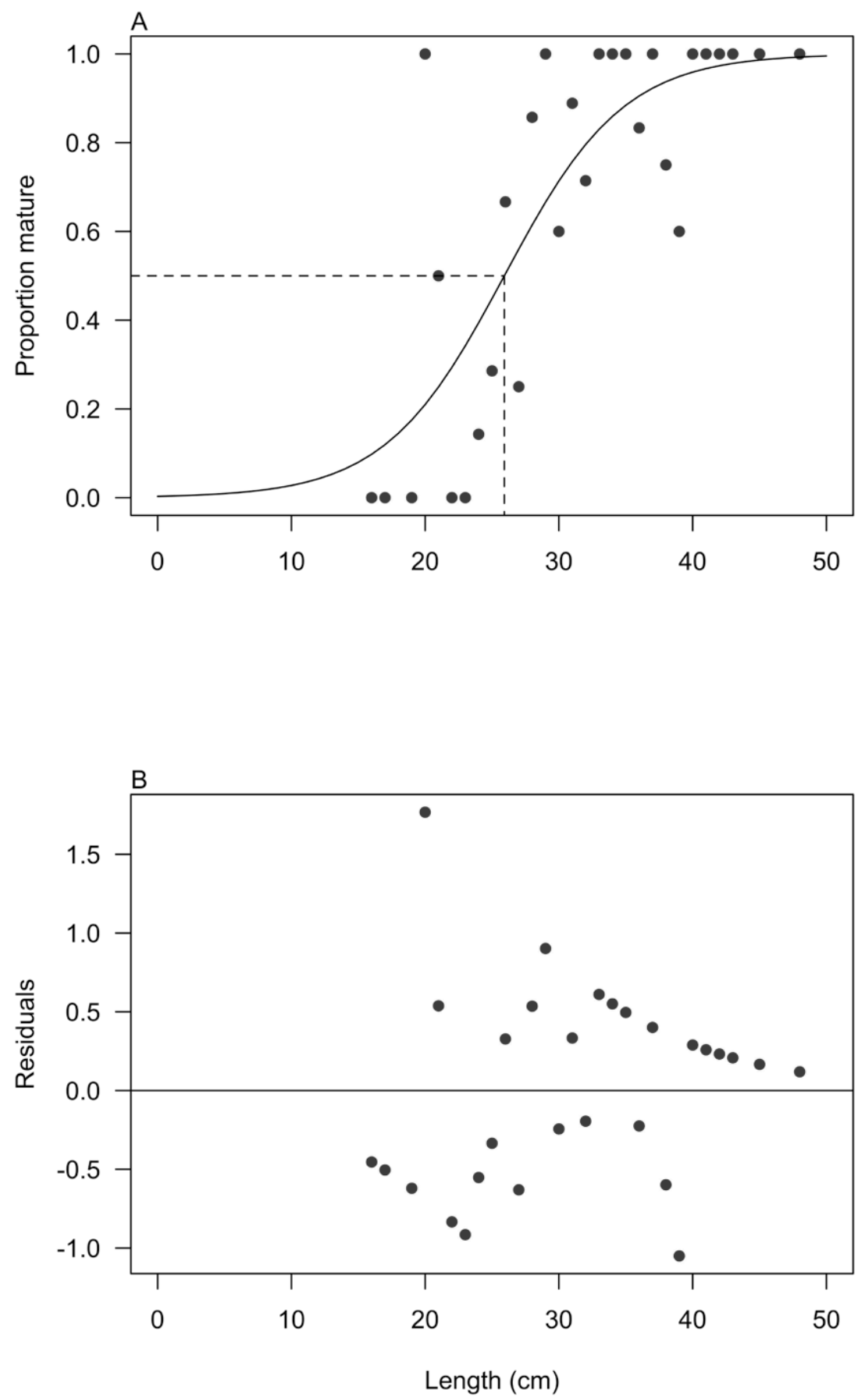
Male Histological Least Squares
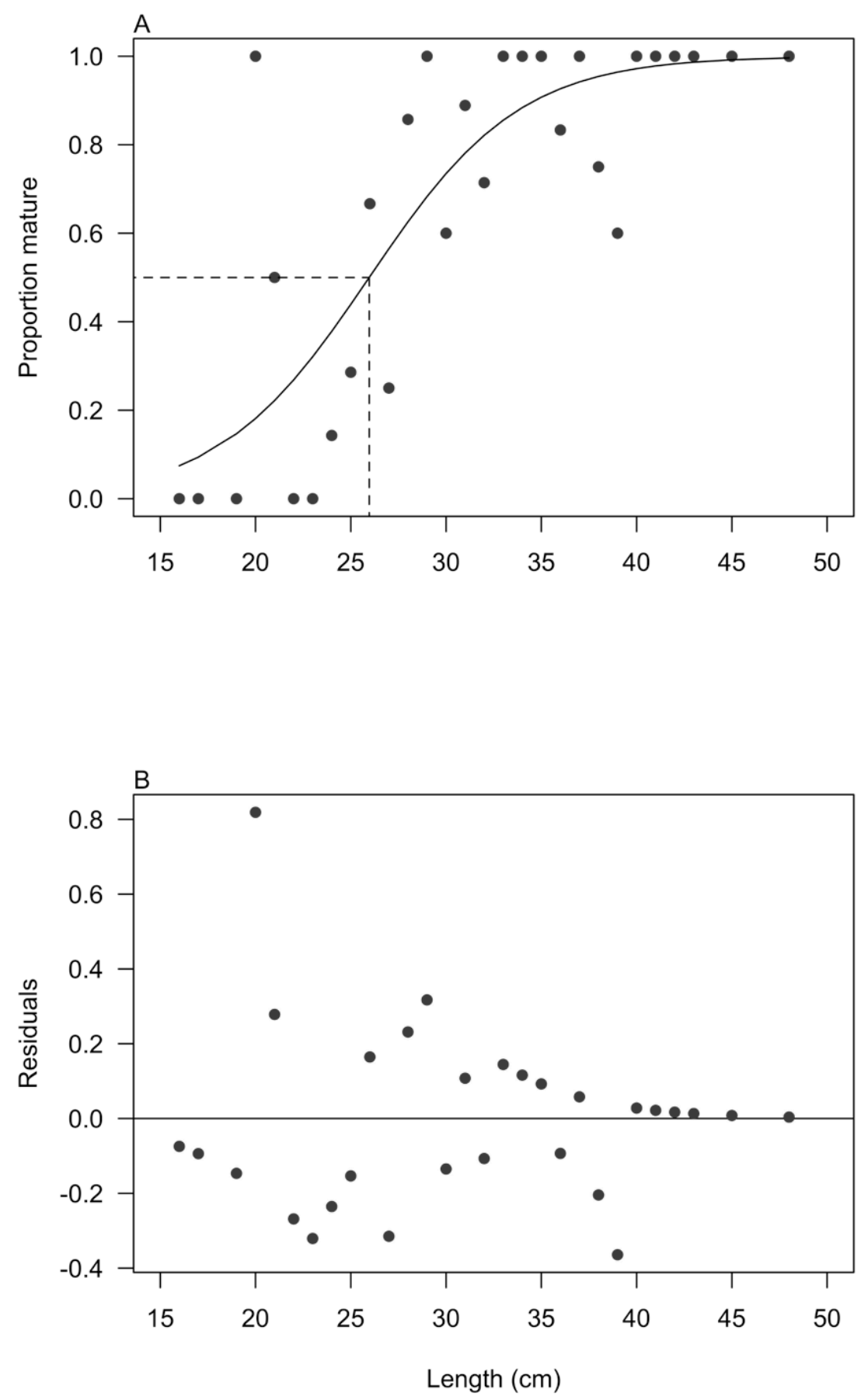
Male Macroscopic Least Squares (larger sample)
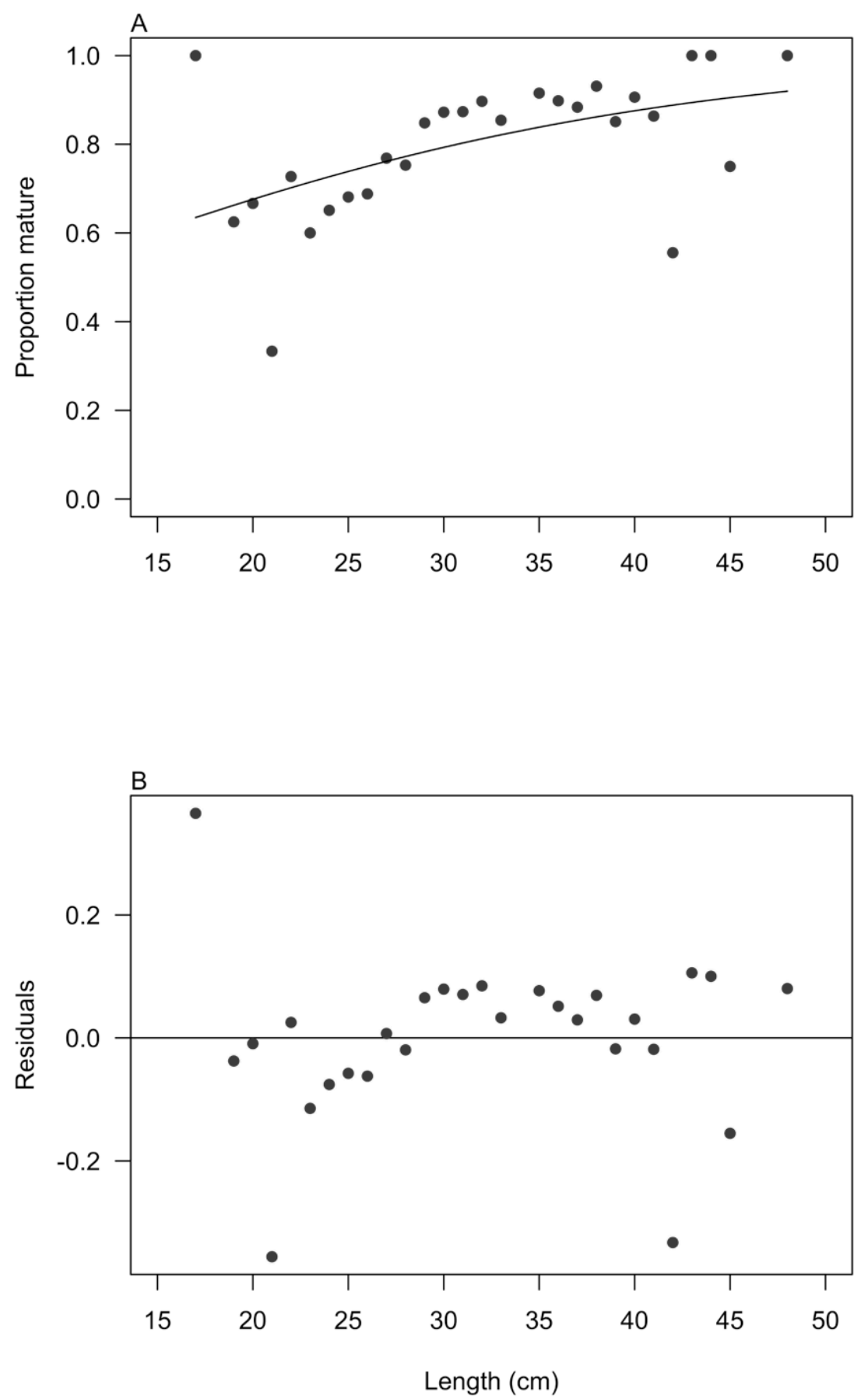
Female Histological Least Squares
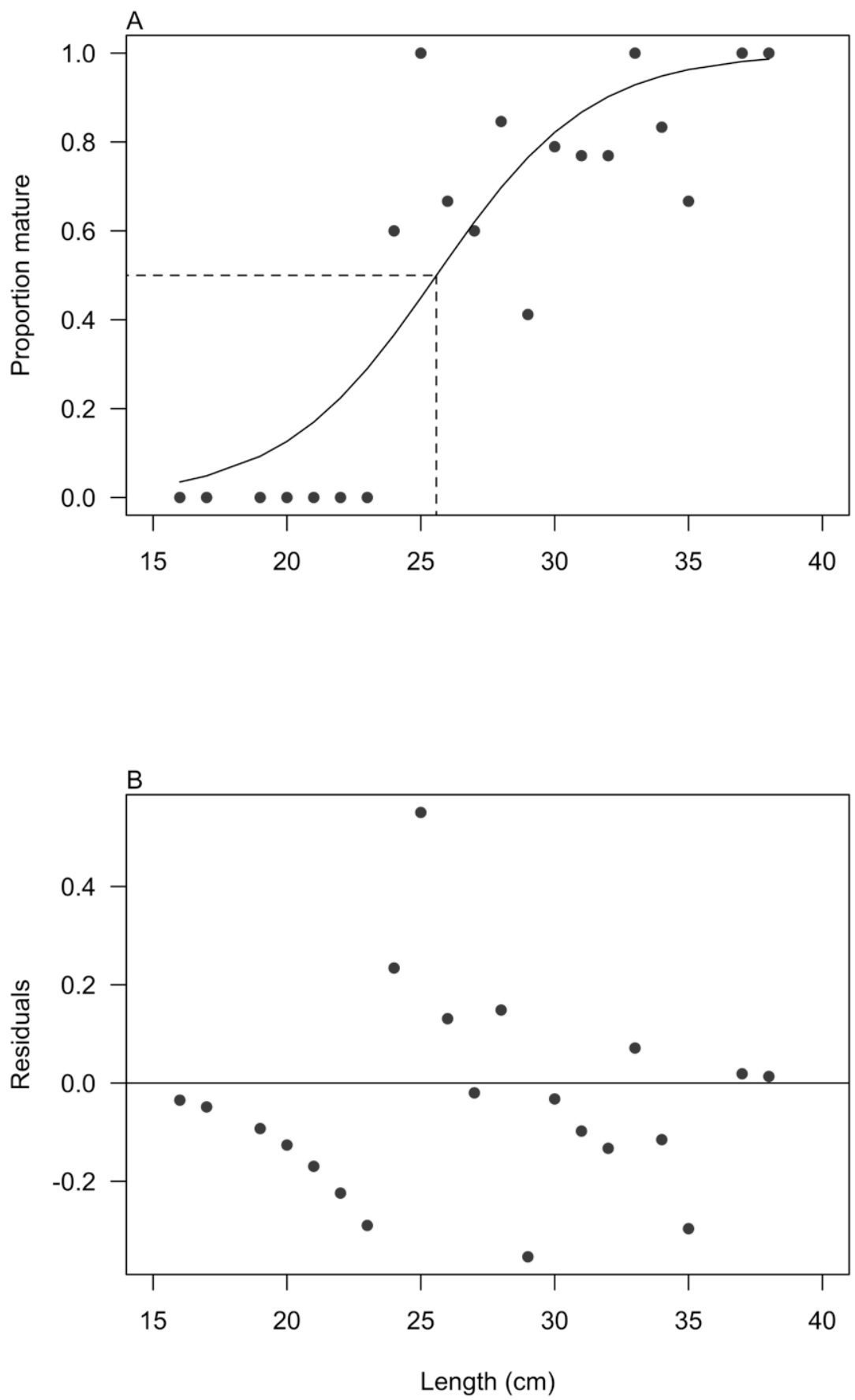
Female Macroscopic Least Squares (larger sample)
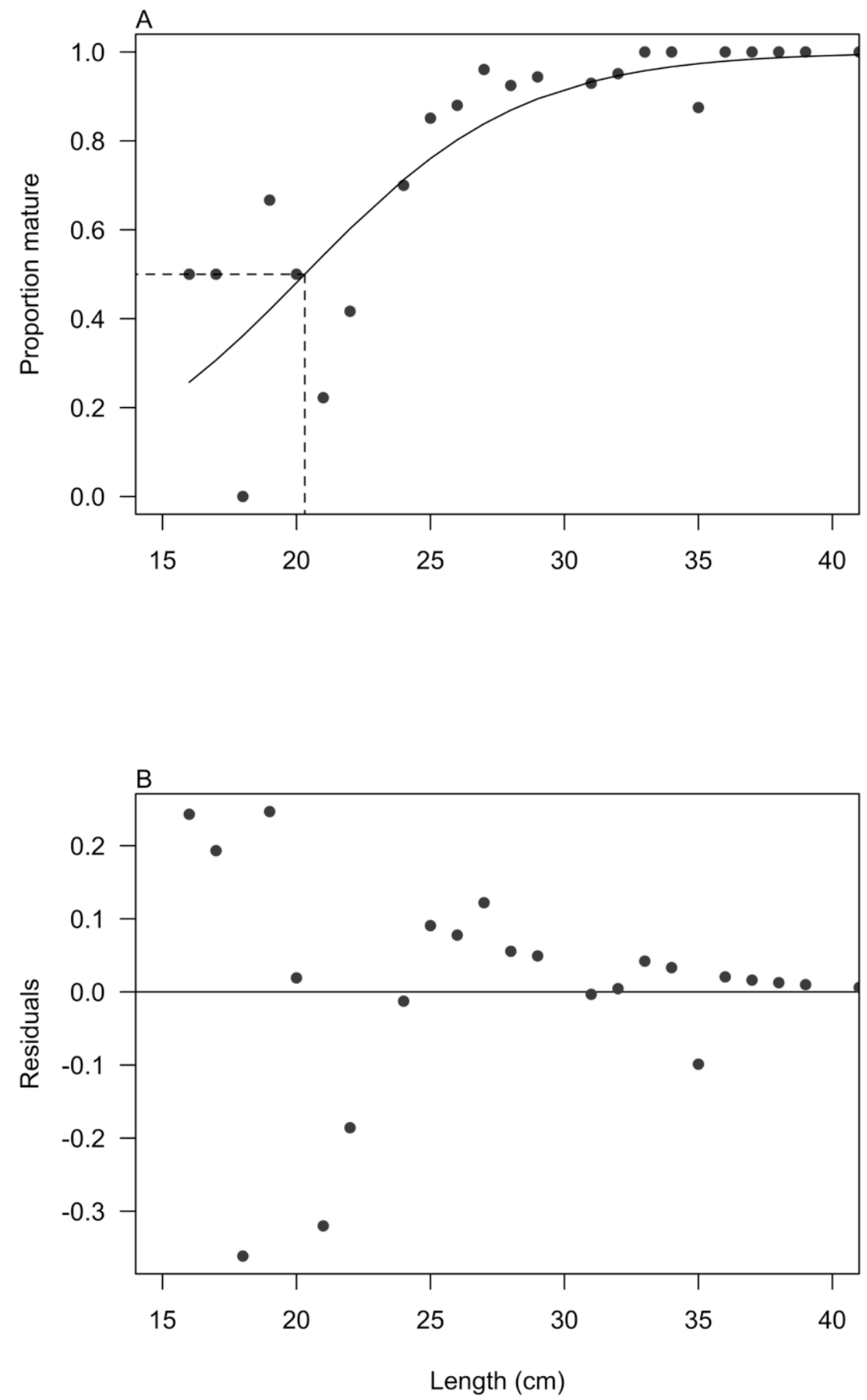
Female Histological Least Squares with Cap
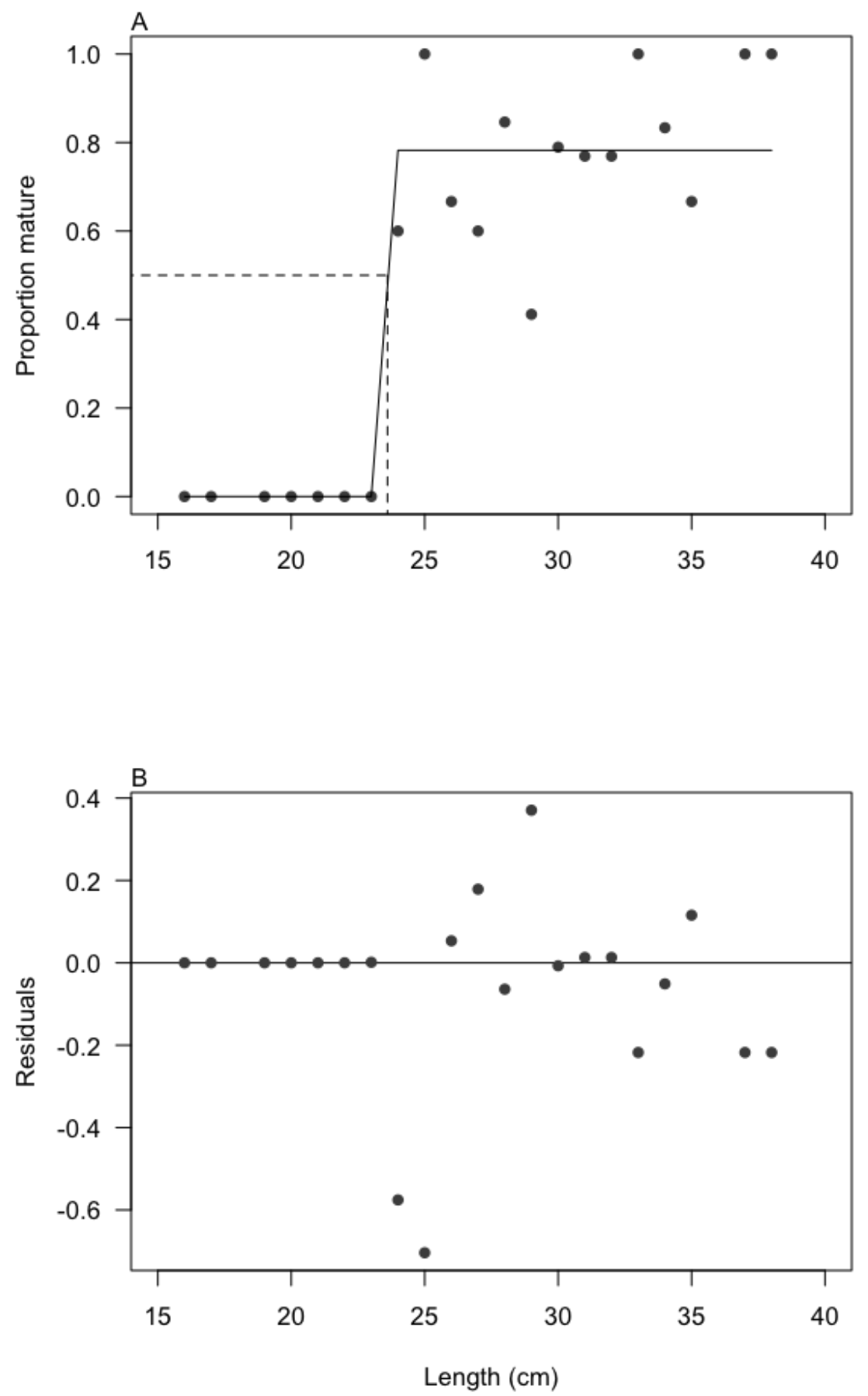
Male Macroscopic Least Squares (subsample)
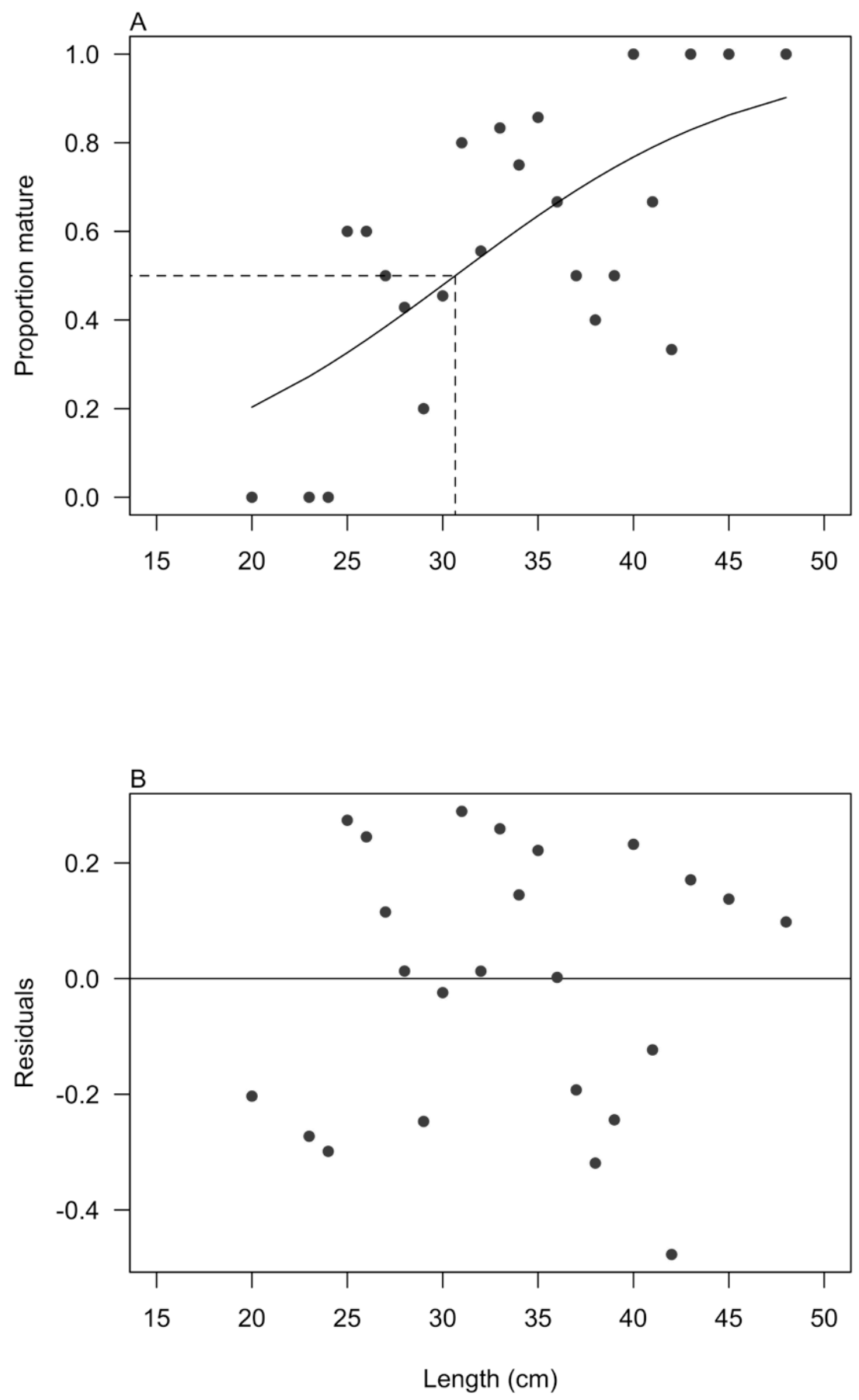
Female Macroscopic Least Squares (subsample)
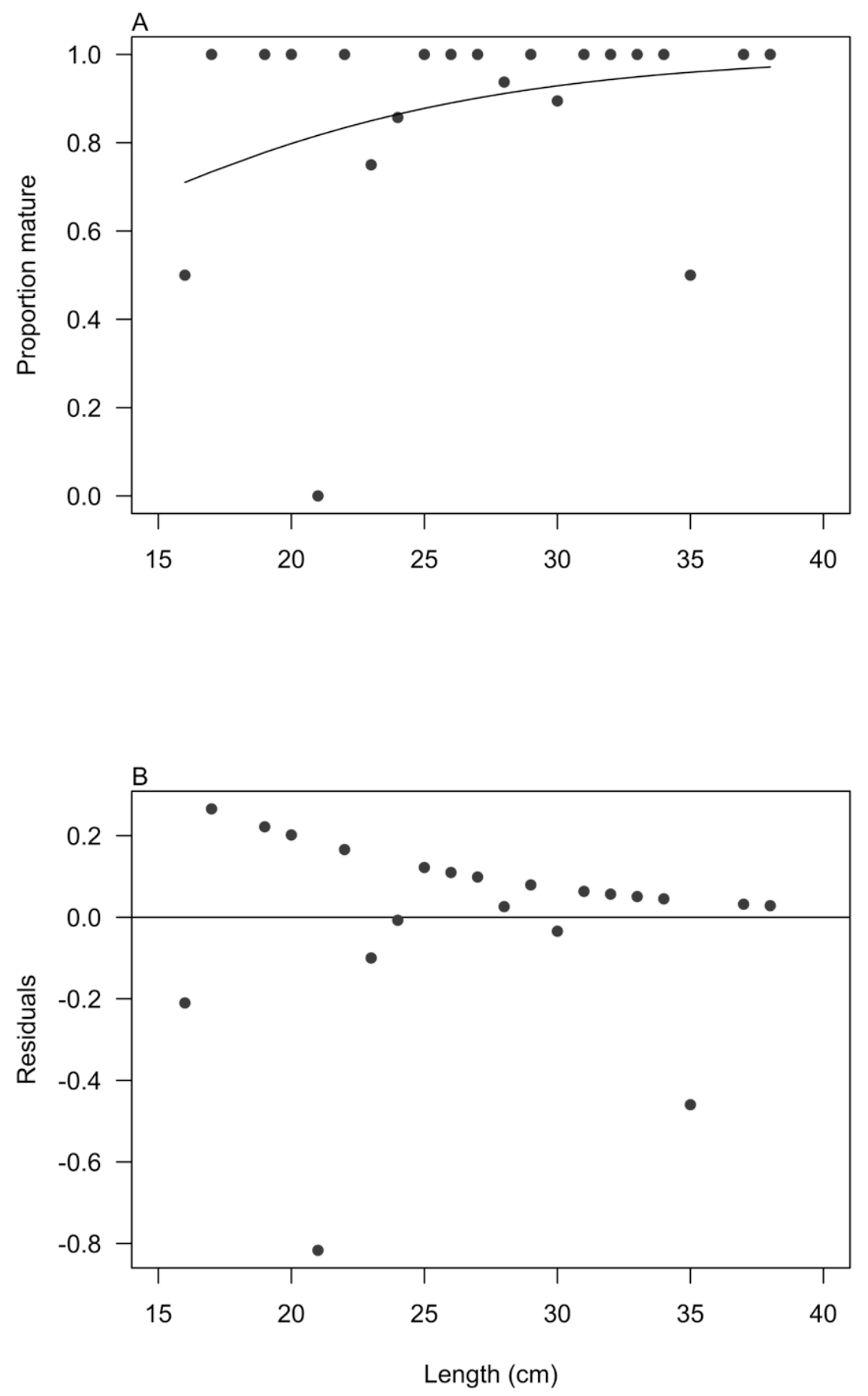
Female Macroscopic GLM (subsample)
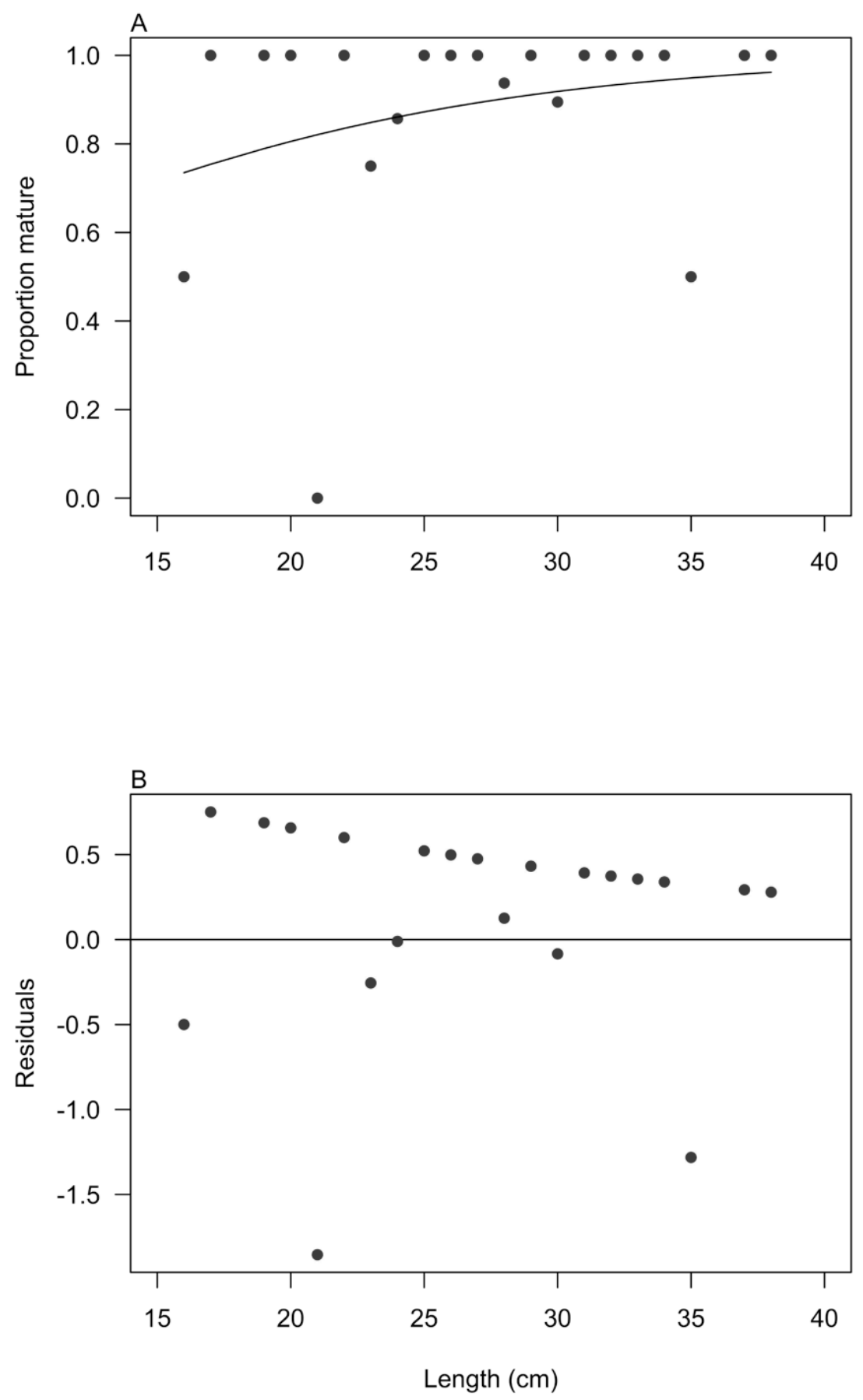
Male Macroscopic GLM (subsample)
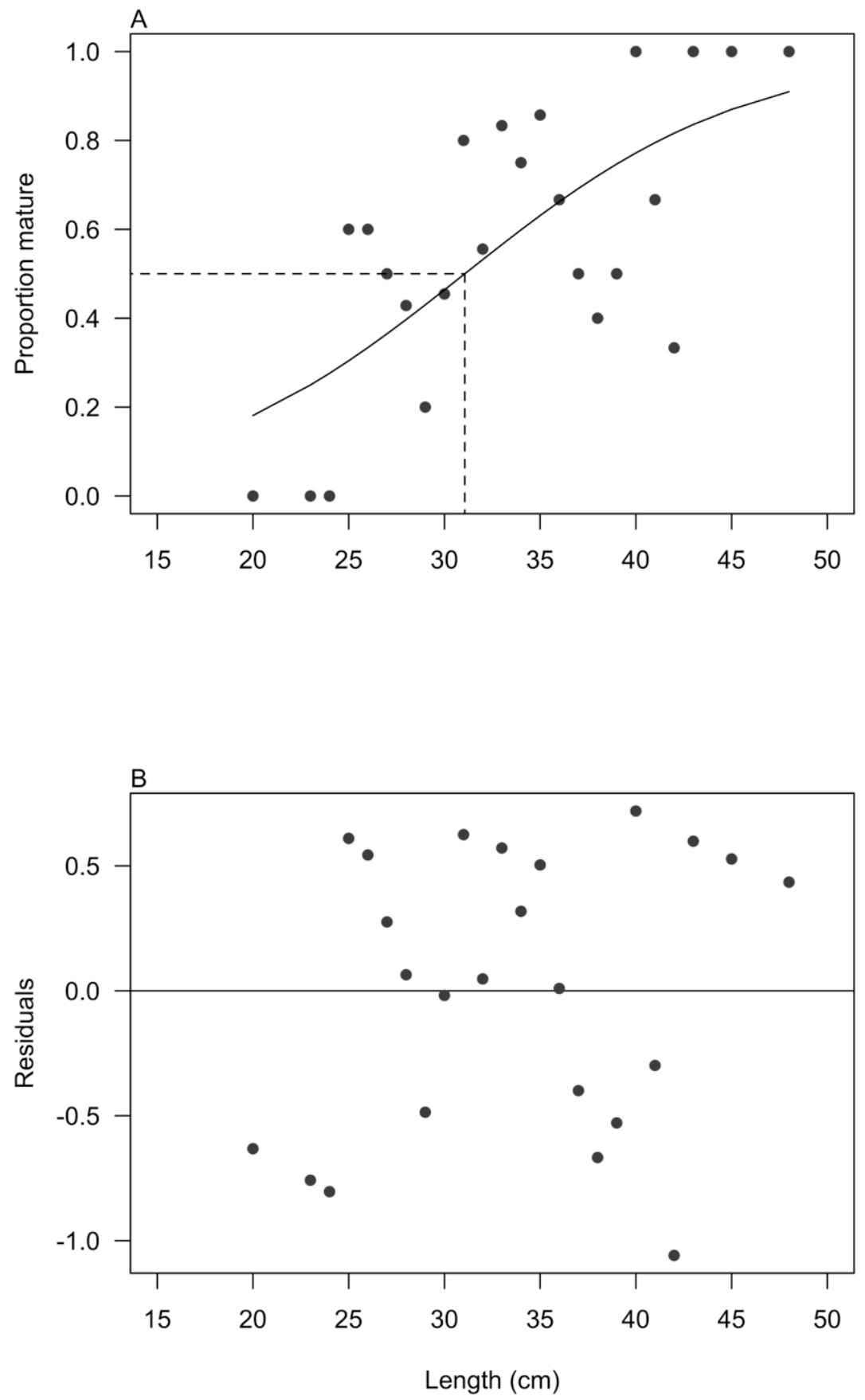
